\title{
Click off: How digital has disrupted New Zealand sports journalism
}

\author{
By: Greg Michael Stutchbury
}

A thesis submitted to Victoria University of Wellington in fulfilment of the requirements for the degree of:

Master of Arts in Media Studies

Victoria University of Wellington

December 2019 


\section{ABSTRACT}

This thesis examined through a political economy framework how New Zealand's two largest newspaper chains, Fairfax and NZME, have been impacted by the advent of digital technologies and the effects these have had on the practice of sports journalism. Digital technology, falling revenue and increasing pressure from financial owners have all played a part in the restructuring of both Fairfax and NZME's editorial news operations, especially in the last five years as both companies transitioned to a 'digital-first' environment.

Semi-structured, in-depth interviews were conducted with 16 senior journalists who had knowledge of the transition from a print to a digital focus. These interviews highlighted the strategies adopted by both companies as they faced a challenging and evolving marketplace. They also underlined the internal tensions within newsrooms between not only journalists and editorial news managers but also the digital and print operations.

Despite the belief that digital technologies would make the print news media more collaborative and provide greater diversity and plurality, the opposite has occurred. Sports reporting remains highly routinised, coverage diversity is shrinking, and greater control is now exerted by editorial managers over the production of journalistic content. Digital technologies have also impacted the forms of content, with decision making on editorial content and resourcing now strongly influenced by data analytics, although there was still strong resistance to greater interactivity with readers. The relationship between sports organisations and print news media organisations, while considered in theory to be a symbiotic one but in reality, is an area of conflict, has also further deteriorated as sports organisations introduce significantly greater control over the media agenda. An element of this control has also heightened tensions with sports organisations moving into the digital space and competing directly with print news media organisations. 


\section{ACKNOWLEDGEMENTS}

Like institutional political economy, this thesis was not produced in isolation. It needed a lot of input, support, cajoling, negotiation, adaptation and moulding of behaviours and some plain-spoken truth to be imparted to ensure its completion. Some thanks are in order.

My family. Without you, I would not have made it this far. You have no idea how much you all mean to me.

My supervisor Peter Thompson needed the patience of a saint at times. His insight, guidance and knowing when a light touch or a more disciplined directive were needed was a perfect balance to ensuring I completed the project. He continually challenged me academically and I think I finally 'got it' in the end. And while both of us were unhappy that Liverpool somehow did not win the 2018-19 EPL, we accepted the Champions League was consolation enough.

Adam Crisp and Alan Samson were valuable sounding boards and provided words of reassurance when Voldemort (that which shall not be named) got to the final stages and was in danger of imploding into sleep-deprived, caffeine-induced, non-sensical gibberish. Carl Holland and Justine Wealleans were generous hosts in Auckland. Their only request was providing help with their eldest daughter's media studies homework. She got an 'A'.

And finally, thanks to all the journalists who gave me their time to discuss how digital has affected sports journalism within New Zealand. The future of the print news media environment in New Zealand is tenuous, with little long-term job security. They are under pressure from sports organisations and management and face increasingly hectic work and time pressures. Yet, they turn up to work determined to adhere to the foundational principles of journalism. To hold those in power to account. To ask the questions the public need to know answers to. And to act as their voice when those in power would rather not listen. To them, I can only offer my sincere gratitude and the words that have sustained me in the 25 -years of my journalism career:

\section{"Illegitimi non carborundum"}




\section{TABLE OF CONTENTS}

Abstract 1

Acknowledgements 2

Table of contents 3

Preamble 4

Introduction 6

$\begin{array}{ll}\text { Literature review } & 11\end{array}$

$\begin{array}{ll}\text { Institutional political economy } & 11\end{array}$

$\begin{array}{ll}\text { From mastheads to digital first } & 15\end{array}$

News values, news production \& news content 20

The conflicts facing sports journalism 25

Research methodology 32

$\begin{array}{ll}\text { Discussion } & 40\end{array}$

News is free. Journalism costs $\quad 41$

The top two inches - dealing with structural pressure 45

The Rumble in the Jungle - tension in the newsroom 60

News gathering, news production \& news values 68

$\begin{array}{ll}\text { The contested space } & 83\end{array}$

$\begin{array}{ll}\text { Conclusion } & 97\end{array}$

$\begin{array}{ll}\text { References } & 105\end{array}$

$\begin{array}{lr}\text { Appendices } & 120\end{array}$ 


\section{PREAMBLE}

The idea for this study was sparked more than a decade ago when the company I work for, international news agency Thomson Reuters, as a sports journalist embarked on a protracted coverage boycott of Australian cricket over their accreditation terms and conditions (T\&Cs). Under the revised T\&Cs Cricket Australia (CA) had introduced a fee of up to $A \$ 10,000$ for accreditation to attend matches, claimed ownership of the intellectual property (text, photographs and video) produced by journalists, imposed a limit on the number of digital photographs that could be taken and restricted how text and photos were distributed to, and used by, traditional and digital media outlets (Allen, 2007).

From my perspective, CA had appeared to have decided unilaterally their sport was no longer a 'news' event but licenced intellectual property that they controlled and expected compensation for, from all sectors of the media. The question that then loomed was, what's next? Would sports organisations move to impose terms that restricted criticism? Or refuse to allow their athletes, coaches and administrators to be held to account for their behaviours, decisions and results? Or ban journalists who were deemed to be 'trouble' for asking those questions? And then, if they managed to succeed, what's next? Would that spread to general news? Political reporting? Business and economic reporting? Or local government? Was the 'Fourth Estate' as we knew it within western industrialised-democracies imperilled? Reuters, AP, AFP and print media companies saw it the same way:

"This is a very direct attempt to limit freedom of the press and the freedom to cover news, because sport is news and not entertainment."

Monique Villa - Reuters Media managing director (Allen, 2007)

In the intervening decade since this confrontation, print news media organisations have been at loggerheads with sports organisations over restrictive terms of accreditation and access that would limit their editorial coverage. The right to cover the English Premier League has been a constant battle (Sweney, 2011). Soccer clubs in the UK have in recent years also refused to accredit news organisations that do not have a commercial relationship with the club, reasoning they can communicate with fans directly through their own website or social media channels (Rawlinson, 2015a), 
and have banned journalists for what they consider to be negative coverage (Rawlinson, 2015b).

International news agencies, local print media companies and television broadcasters, however, have fought back. They refused for years to cover the Indian Premier League Twenty20 competition over restrictions on the use of match footage and the supply of photographs to clients (Spits, 2010). Reuters, AP and AFP also imposed a total ban on coverage of the Indian national cricket team within India (personal recollection). Closer to home, Australian and New Zealand print news media organisations have also refused to accredit their reporters for the 2011 and 2015 Rugby World Cups (Plumb 2015), the 2016 Rio de Janeiro Olympics (Peacock, 2016a) and the 2018 Gold Coast Commonwealth Games (Meade, 2017, 2018a). It was these conflicts and the 'contested space' that was emerging that opened the door for a far more in-depth analysis of New Zealand's print news media sports journalism in the digital age. 


\section{INTRODUCTION}

The print news media has faced tectonic shifts in their industry since the turn of the $21^{\text {st }}$ century. Advertising and circulation, the lifeblood of print news media companies' revenue, have been trending down for the better part of 60 years (Curran, 2010) while digital advertising revenue has been gobbled up by intermediaries like Google and Facebook (Bell, 2016). Financialisation has also placed immense pressure on editorial news managers (Winseck, 2010). To provide increased return on investment, especially relative to other investment sectors, print media companies have been forced to look at different ways of generating new revenue streams and make significant cost savings because of the tightening financial situation, notably through wholesale job cuts, a trend that is mirrored across the Western industrialised democracies (Nel, 2010; Grieco, 2018).

The structural pressures of financialisation and digital technology have also contributed to news organisations restructuring their editorial news gathering and changing the distribution platforms of editorial content. Journalists' 'newswork', or how they produce the news, (Deuze, 2005) has changed. Reporters who previously worked in a print-focussed environment are now required to provide content across different distribution platforms, with an emphasis on being multi-skilled (Singer 2003, 2004; Dupagne \& Garrison, 2006; Anderson 2011). Digital technology has also contributed to changes in the rhythms of newsrooms and the workflow for journalists, so that increased time pressures are becoming manifest in print news media companies (Wallace 2013; Cohen, 2018). The introduction of data analytics has also affected news values, editorial news judgement and challenged the print news media's gatekeeping role (Anderson 2011; Lee, Lewis \& Powers, 2014; Cohen, 2018).

Sports journalism has historically been a valuable economic driver of newspapers' circulation, which attracted advertising revenue (Lowes, 1999; Rowe, 2007). Sports, however, has not been immune to the structural pressures of financialisation or digital technology. Cuts to budgets and staffing have drastically changed the nature of sports event coverage and seen a greater reliance on information subsidies such as audio and video clips from teams overseas or planned media conferences (Davis, 2000). Digital technology has also had an impact on the newswork by print media sports journalists (English, 2011, 2012, 2015). The rise of digital technology has also seen 
the new external tension arise with sports organisations, similar to the conflict with Cricket Australia. The pressures have also produced a new 'contested digital space' between sports and print news media organisations. These structural pressures may not amount to a crisis within the print news media industry as argued by Winseck (2010), but they do contribute to an uncertain future.

Sports journalism presents an interesting internal conflict for sports media academics who have been particularly critical of the practice of sports journalism - labelling it the "toy department of the newsroom" (Rowe, 2007:385). Sports journalists, however, reject this characterisation and instead state they believe their normative behaviours mirror those of the rest of the newsroom. They also hold to the belief that there are important 'Fourth Estate' principles that need to be upheld, which give journalism its institutional legitimacy (Salwen \& Garrison, 1998; Schudson, 2011; Nicholson, Zion \& Lowden, 2011). How these tensions are manifested under stress from financialisation and digital technology can help examine internal power dynamics within newsrooms.

While there has been a symbiotic relationship between print news media sports journalists and sports organisations (Lowes, 1999; Rowe, 2007), the relationship might be better viewed as an external conflict, with a struggle for power evident. Sport is a multi-billion dollar a year industry where professional live sports events have been turned into a commodity that can be sold to broadcasters. Sports organisations are highly protective of these live events and have sought to limit access through strict accreditation terms and conditions and attempted to control the content produced by print news media companies. They also have 'professionalised' their administration and adopted public relations practices that control and limit access to athletes, coaches and administrators. They also have trained athletes, coaches and administrators in how to set and control the news agenda by producing often bland quotes and observations or refusing to answer questions.

Sports organisations and print news media organisations are also now rivals within a 'contested digital space'. Sports organisations have moved into the media production business and established their own websites to provide news and information and 'exclusive' content to fans. They also utilise social media applications like Twitter, Facebook and Instagram to communicate directly with their followers, bypassing the media completely and negating their 'gatekeeper function'. 
Print news media companies within New Zealand are not immune to these structural pressures with the two biggest print news media companies in the country, Fairfax and NZME, certainly under stress in every department as they negotiate the digital age. Fairfax owns two metropolitan mastheads The Dominion Post and The Press and six provincial daily newspapers as well as two Sunday weeklies (Myllylahti, 2018). NZME's major masthead is the Auckland-based The New Zealand Herald. It also owns six provincial dailiesand owns the Radio Network, which has the highly popular Newstalk ZB and Radio Sport within its stable. Combined together, both companies reach almost 90 percent of the New Zealand print market (Myllylahti, 2017:15). Both Fairfax and NZME have been involved in digital publishing for about 20 years. The New Zealand Herald launched its website in 1998, while Fairfax (at the time owned by INL) launched the Stuff website in 2000. The two companies now also dominate the online market in New Zealand. Fairfax's Stuff website receives about 2.1 million unique visits a month (Hufferdine, 2018), while NZME receives more than 1.7 million unique visits a month to its online news websites (Molineux, Matheson, Myllylahti, Phelan \& Thompson, 2016; Myllylahti, 2018).

The structural pressures of financialisation and digital technology, however have affected the way Fairfax and NZME have interacted with the media environment as they transition away from a print to a digitally-focussed environment. These pressures have also impacted the way sports journalism is practiced and how sports news is now produced within New Zealand. Integrated editorial systems that allow both companies to centralise their editorial production processes across their chains have been introduced across both Fairfax and NZME, while both companies have also restructured their editorial operations to provide multi-media digital journalism. Fairfax has transitioned away from single mastheads, with their reporters now working in an agency/bureau model providing content across the newspaper chain. NZME has integrated all their Auckland-based mastheads, digital platforms and radio stations into a single editorial operation in one centralised location.

Examining New Zealand's print news media sports journalism through institutional political economy allows us to look at how these structural pressures have influenced the way each organisation has responded. As Winseck (2016:95) points out both Fairfax and NZME are likely to have reacted differently to these structural pressures because "none of these processes comes in a one-size fits all form". Contextual issues 
such as ownership structure, where each company's revenue is generated, its organisational structure and newsroom culture and how they respond to changing technologies will also play a part in shaping the different responses of both Fairfax and NZME in the digital environment. While Fairfax and NZME are different companies, face different economic challenges and have adapted their own strategies to deal with the changing environment, it is possible that common themes can be identified and applied to New Zealand sports journalism. It is also possible that that this can be widened into other areas of the print news media companies.

These structural pressures may have also played a factor in re-categorising what is news and whether news values have changed in the digital age. Schudson (2011:4) reminds us that news is a social construction and "the product of journalistic activity". How journalists determine what is newsworthy, however, is a complex process reinforced by workplace norms and practices and newsroom culture (Harcup \& O'Neil, 2001; McGregor 2002; Allan, 2004; Deuze, 2005). There have been several attempts to categorise how journalists decide what is 'newsworthy'. Galtung \& Ruge (1973) produced a seminal work in categorising factors that make events newsworthy withthe more that an event matches the list of factors, the more likely that it will be considered news. This list of factors has been critiqued and modified by McGregor (2002) and Harcup \& O'Neil $(2001,2017)$ to take account of the increasingly different media landscape of the late 1960 s and early 1970 s to that of the $21^{\text {st }}$ century.

There has also been little research conducted into the work practices of New Zealand's print media sports journalists and even little discussion about what is happening, especially in the digital environment. In short, there is a gap in the literature that this study will address. It will build on the pioneering work done by Lowes (1999), who detailed the institutional practices of sports journalism newswork at a Canadian newspaper, Anderson (2013), who studied a Philadelphia newsroom transitioning into a multimedia digital-first entity, and Moritz (2014), who focussed on the newswork of American sports journalists in the digital age.

This study aims to showcase some of the broader themes that are affecting the print news media industry within New Zealand. Sports departments appear to have been early adopters of the evolving digital technology with its events lending itself to the development for rolling blogs, live streaming of media conferences or the introduction 
of multi-media packaging of sports stories. An examination of these production processes can also allow us to examine whether news content, and news values, have changed and whether these changes can be witnessed in other areas of the newsroom.

The following research questions will therefore be asked:

RQ1: How did Fairfax and NZME's response to financial pressures within New Zealand's print news media environment affect sports journalism within those organisations?

RQ2: What tensions were evident within Fairfax and NZME as they transitioned from print to digital first?

RQ3: How has the digital environment affected sports news production and sports news content at Fairfax \& NZME?

RQ4: In what ways has the digital environment created a contested space between print media journalism organisations and sports bodies?

The following chapters will include a review of the relevant literature on sports journalism and how technology has affected news production and content. A section on the methodology of the research project will then follow, before a discussion and analysis of the results are placed into the context of the dominant themes that have emerged. The final chapter will summarise the study. 


\section{LITERATURE REVIEW}

This thesis draws on three areas of previous academic research to place it into context: institutional political economy, the sociology of journalism and the sociology of sports media. This chapter will now outline the relevant theories and literature that helped frame the research questions outlined in the previous chapter that need to be answered.

\section{Institutional political economy}

Political economy study has its roots in the work from "the Scottish Enlightenment thinking in the $18^{\text {th }}$ Century and its critique in the $19^{\text {th }}$ century" (Wasko, 2009:3). Typically, it relied on the application of what we would term classical economic theory to everyday life and looked at how society dealt with the production and distribution of scarce resources. Political economy then evolved in the $19^{\text {th }}$ Century when Karl Marx and Frederick Engels introduced the concept of class analysis (Boyd-Barrett, 2009).

Institutional political economy emerged in the early part of the $20^{\text {th }}$ Century through the works of Thorstein Veblen, John Commons, Wesley Mitchell and Joseph Schumpeter (Wasko, 2009; Winseck, 2016). The work of Dallas Smythe and his conception of the audience commodity (1977) also played a significant role in examining media that relied on the advertising model for their revenue (like newspapers).

As Mosco (2009), Wasko (2009) and Winseck (2016) remind us different political economy models have emerged in the last 60 years. In a general sense, political economy of communication is the study of the wider societal factors influencing the power and social relations "that mutually constitute the production, distribution and consumption of resources" (Mosco, 2009:24). There has, as with most theoretical models, been disagreement by academia as to which is most applicable and there is no 'one size fits all'.

The work of monopolist-capitalists like Robert McChesney $(1989,2008)$, for example, played a significant role in the development of critical political economy, one of the driving forces for the study of institutions in the news media. The monopolist-capitalist school, however, can take too broad of an approach, because of its view that the 
super-structures of media conglomerates ultimately determine the editorial output of journalists. The monopolist-capitalist model also places too much emphasis on the supposed power of media moguls seeking to manipulate the political and economic system through the media. As Winseck $(2010,2011,2016)$ argues the ownership of large media conglomerates are now mostly held by financial shareholders and the pressures of financialisation are more likely to play a far more significant role in influencing how news media organisations react to changes in their environment.

Graham Murdock and Peter Golding (2005) argue that critical political economy allows researchers to:

- examine media institutions holistically

- place them in their historical context and examine long term changes in their environment

- examine how the structural forces of capitalism and state intervention affect them

- question whether they are fulfilling their roles and responsibilities for the "public good" (ibid:61).

Critical political economy is also concerned with the "interplay between economic organisation and political and social and cultural life" and "goes beyond situated action to show how particular micro contexts are shaped by general economic dynamics and the wider formations they sustain" (ibid:62). The theory also argues that the public have the right to access to information that will support their participation in society. The access to information, news events, news makers and sourcesis a key tension between the print news media and sports organisations, who have exerted increasing control over access to live sports events and newsmakers and is a key area of analysis in this thesis.

As Winseck (2011) reminds us, it is imperative to remember that institutions do not act in isolation; they must be mindful of the market conditions they face, the environment in which they operate, and the forces that can affect those conditions. These companies are also rarely politically neutral. They have an agenda that attempts to shape that environment, often in consultation/collusion with other media companies and government agencies. It is by understanding the historical and social composition 
of an institution that we can analyse its responses to changes and challenges in its environment and how it seeks to gain, maintain and control, power within that environment (Murdock \& Golding, 2005; Mosco, 2009).

Power is also seen as an important aspect of study in critical political economy. Where power lies, how it is exercised and how people use it to control the allocation of scarce resources is crucial to understanding how institutions work (Hardy, 2014). This is true in terms of internal examinations between departments and how the institutions, in this case, the print news media companies Fairfax and NZME, have reacted to change in the locations of power in their external environment.

Winseck (2016) also points out in the work done by Murdock and Golding, who argue that the experiences of the media in, or indeed within, one country is not the same as they are in another. Indeed, institutions respond to contextual pressures such as who owns it, where does its revenue come from, its organisational culture and increasingly how they respond to changing technologies differently, because "none of these processes comes in a one-size fits all form" (ibid:95). English's comparative studies $(2011,2012,2015)$ of the digital-first debate in sports departments of print news media organisations in Australia, England and India, are therefore particularly helpful in recognising that "the media systems in which the individual news organisations were operating had a significant impact on their strategies" (English, 2015:86). In Britain, for example, media companies initially gave away their digital content for free, while in Australia, the two major newspaper chains were early adopters of paywalls. India's massive population, however, allowed for the media companies to remain focussed on their print products because daily circulation was so high.

A key theme of this thesis is how the introduction of digital technology, like the Internet and the development of webpages, has affected or disrupted sports journalism at Fairfax and NZME. There is no question that new technological innovations have had an impact upon the print news media, and since the late $19^{\text {th }}$ century newsrooms have adapted new media technologies, industrial printing presses, typewriters and the telegraph, in producing their news. The advent of radio and television changed the nature of print news reporting, while in the $21^{\text {st }}$ century the Internet has introduced new tensions in terms of the distribution of news and created more competition. Indeed, Pavlik (2006) has suggested that technological change can affect the way journalists 
do their job, news content, the structure and organisation of the newsroom and news industry. Technological change also can affect the "nature of the relationships between and among news organisations, journalists and their many publics, including audiences, competitors, news sources, sponsors and those who seek to regulate or control the press" (ibid: 229).

However, as Wasko, Murdock and Sousa (2014:4) and Anderson (2011:554) argue "technological determinism" does not address how power is distributed and where there are inequalities, where there is conflict and ....in whose interests will be best served by these new (technological) potentialities..." (Wasko et al, 2014:5). While digital intermediaries like Facebook and Google have appropriated most of the digital advertising revenue (Bell, 2016), they are not the sole cause for the financial pressures print news media companies find themselves under. In short, institutional political economy forces examination of wider influences at work within the digitally-focussed environment that the print news media companies face.

A key template for this thesis is Thompson's (2017) analysis of the failed VodafoneSky merger in New Zealand. It provides valuable guidance in assessing the way in which New Zealand's print news media have adapted to their challenges within the digital environment. The analysis of the merger emphasised New Zealand's light regulatory framework and demonstrated how the macro-level forces influenced the shape of the New Zealand media market structure. It also examined "the way these structural pressures are articulated through the respective media sectors" (Thompson, 2017:31) and how institutions reacted to the pressures of financialisation and convergence.

This thesis adopted the following guidelines to be mindful of during the study of how New Zealand's print news media sports journalism had been disrupted in the digital age:

- it is important to focus on power and conflict over scarce resources.

- Control over the allocation of resources is an exercise of power.

- Institutions evolve with changes in their political and economic environment over time. 
- These structural conditions are also shaped by the political economic and social institutions within the media sector

- How the institutions respond is important.

- Institutionalism is also intra-organisational. The sports department is an institution within the newsroom. Newsrooms are institutions within the wider company and tensions within these internal organisations need to be examined.

- How individuals behave creates internal tensions, but the behaviour is governed by a wide mixture of influences. There is economic rationality behaviour like rent seeking, rational choice and utility maximisation. But, individuals have also been socialised into the cultures and norms of institutions, how we do things around here, particularly within a newsroom and in the practice of their profession. These cultural norms, however, have also been moulded/affected by the institutional organisational structures.

\section{From mastheads to digital first - tensions in the evolving newsroom}

News organisations adapting to the changing market conditions and political and economic structures is not a new phenomenon. It is an ongoing process. The history of the newspaper in the 20th century was one of evolution, producing changes in the way news is gathered and produced. Nerone \& Barnhurst (2003) argue that the American newspaper company had three distinct phases as print news media companies industrialised (1890s-1920s), professionalised (1920s-1950s) and then corporatised from the 1960s onwards. Each of these phases was associated with changing work and labour practices. The industrial paper took advantage of new machines to achieve efficiencies in production (ibid: 438), while the professional paper developed newsroom norms, behaviours and standards of ethics that journalists adopted to legitimise the profession. This period also witnessed the wall of separation between advertising and news, the so-called church-state divide, becoming institutionalised (ibid:441), with journalists being supposedly unaffected by direct commercial pressure by advertisers. The corporate newspaper, where the newspaper was becoming simply holdings of financial institutions and there was a drive to increase profitability, changed this. Neo-Marxist political economists like McChesney 
(2003, 2008) argue that the implications for this has been a move towards a less aggressive media, and one that fails to uphold its watchdog role.

The experience of the New Zealand's print news media industry in many respects does not sit in isolation from its counterparts in the other Westernised liberal democracies. Newspapers were established in New Zealand by prominent local families with the focus on covering local news, business and politics (Hope, 2012; Hope \& Myllylahti, 2013; Hirst, Hope \& Thompson, 2017). By the turn of the $20^{\text {th }}$ century, however, the local newspaper became more commercially focussed as "urbanised economic growth reshaped the ownership and management structures of provincial dailies" (Hirst et al, 2016:354-355).

By the 1920s, New Zealand's newspapers were being reshaped as "politically involved proprietors gave way to staid newspaper companies with new divisions of labour" (Hope, 2012:30). Arguably the biggest change in New Zealand's economic direction in the late $20^{\text {th }}$ century came with the election of the Fourth Labour government in 1984 when the country underwent a massive economic liberalisation programme. This resulted in a move away from the 'broadly social democratic Keynesianism' model to more market-oriented policy outcomes, with the focus on commercial goals and 'less' government regulation of those markets (Goldfinch, 2000; Hope 2012). Within New Zealand' print news media industry, there was a flurry of takeover activity and "further concentrations of press ownership" (Hope, 2012:36).

Myllylahti's annual review of the ownership of New Zealand's news media environment since 2011 has demonstrated an increasing shift of ownership models so that by 2018 , the country's major media companies were "largely owned by financial institutions such as banks, investment banks, investment management firms and private equity corporations" (Myllylahti, 2018:53). This financialisation of media ownership has "destabilised" New Zealand's print media industry (Myllylahti, 2012) since the turn of the 21st century. Indeed, as Hope \& Myllylahti (2013:203) remind us, "the financialisation of New Zealand media corporations has occurred at the same time as the media industry is going through an historical transformation from print to digital ... thus, the intensification of financial ownership has taken place at the same time as the media corporates' business models are faltering and their profitability is under serious pressure." Both 1Fairfax and NZME have been the subject to the vagaries of 
institutional investors whose primary focus, in the short term, is to "maximise investment returns before moving on" (ibid).

The economic and financial challenges facing the corporate newspaper in the $21^{\text {st }}$ century, including Fairfax and NZME, has witnessed what has been labelled as 'convergence' of newsrooms. The definition of convergence however varies to the point that "...it would be safe to say that convergence has almost as many interpretations as it has advocates" (Quinn, 2005:30). Early studies argued that it ranged from multiskilling of existing journalists to provide content for multiple distribution platforms (Deuze, 2004) to a fully integrated regulatory convergence that shifts the "previously separate industry-based laws and regulations into a single legal and regulatory framework" (Dupagne \& Garrison, 2006:239). Definitions of convergence, adapted from Northeastern University's Rich Hall and explained by Quinn (2005), however, have proved to be the most useful in discussing the New Zealand print news media experience for this thesis:

"Ownership convergence: a partnership between large media companies that permit synergy, cross-promotion and content sharing between print and television owned by the same company

Tactical convergence: a partnership between a TV station and newspaper usually under separate ownership.

Structural -convergence: when media companies reorganise the newsroom and introduce new positions. It is more related to news gathering than management.

Information gathering convergence: where media companies require reporters to be multi-skilled.

Storytelling convergence: new forms of storytelling, using and exploiting technology to tell the story across platforms." (Quinn, 2005: 30-31)

The New Zealand experience has highlighted the adoption of forms of structural convergence and information gathering convergence. Both Fairfax and NZME restructured their newsrooms and editorial news gathering and both trained their 
journalists to become multi-skilled. Story-telling convergence has also developed. Fairfax for example hired a specialist team of former television journalists to provide in-depth video documentary stories, while both companies have hired technicians and data journalists. There have also been elements of tactical convergence, with Fairfax entering agreements with the state-owned Television New Zealand and Radio New Zealand to share audio and video content.

Early studies of media companies that 'converged' their editorial news operations to deal with these pressures and adapt to the new digital environment, however, also highlighted significant internal and external tensions because: "new demands in longestablished cultures inevitably create tensions" (Robinson, 2011: 1126). Management saw the restructuring as a way in which resources could be more efficiently organised for their journalists to provide content across their numerous distribution platforms, like print, digital, radio and television (Singer, 2004; Quinn, 2005; Dupagne \& Garrison, 2006; Saltzis \& Dickinson, 2007). Journalists, however, argued the reorganisation of newsrooms was simply an opportunity for management to cut costs (Singer, 2004; Deuze 2004). It also, created internal conflict within the newsroom for economic, labour and intellectual resources and there were arguments that editorial independence would be compromised (Dupagne \& Garrison, 2006). Deuze (2007:147) also argued that history had taught journalists that any time there was a change in their work it tended "...to go hand in hand with downsizing, layoffs and having to do more with less staff, budget and resources."

Deuze (2004) recognises that this organisational restructuring was an ongoing contest within each institution. Instead of the different news-gathering organisations coming together and working in an environment that increased co-operation between departments, he argued that these previously distinct areas of the company had been forced to work together and it was questionable whether they would be able to achieve the types of co-operation expected by management. He also recognises that, because of the volatile nature of the digitally-focussed environment then strategies are likely to be conflicted and then superseded, which creates more institutional tension. This was particularly evident in the New Zealand print news media industry, with both Fairfax and NZME respondents expressing frustration at some of the strategies pursued by editorial news management. 
Ryfe (2012) found in his study of American newspapers that there was increased scepticism towards the restructuring of editorial news gathering as it was considered further corporate management intrusion into the newsroom. These internal tensions have been significant stumbling blocks for media organisations to overcome as they reorganised their editorial news gathering. Newsroom cultures are deep rooted and difficult to break down and journalists developed a "fortress mindset" (Wallace, 2013: 103) during the process of reorganisation. This resistance to change was despite the recognition they needed to accept "they no longer worked for a newspaper or television station but for an information company" (Singer, 2004:3) or "in news" (Quinn, 2005:36). Journalists, however, were not the only staff members who needed to accept the reorganisation of the editorial news operations, with Quinn (2005) recognising that management also had to be committed to the strategies that were needed to ensure the organisation was able to adapt to its changing, and challenging, environment. Freedman (2009:40), however, argues that "for most news organisations, 'future-proofing' strategies are ... tentative, experimental, defensive and evolutionary rather than revolutionary."

A further area of institutional tension was between digital and print editorial operations, something Robinson (2011), discovered following her year-long ethnographic study of a newsroom in the American Midwest She discovered however that by the end of the first decade of the 21st century, the balance of power had tipped in favour towards the digital side of the editorial operation. The digital teams had also been elevated in status.

There has also been some evidence of underlying tension within sports departments of British newspapers, where an "us and them culture" (McEnnis, 2018:5) developed between print journalists and their online colleagues. Tensions between the work practices of print and online journalists were evident, with print journalists arguing their online colleagues were increasingly desk bound and not getting out of the office to meet sources. The use of social media as an official news source was also increasingly on the rise for British, Indian and Australian journalists (English, 2016), calling into the question the news gathering process.

Despite these deeply entrenched tensions the ability to take pictures and shoot and edit video and provide content for radio and television within their 'converged' 
organisation was considered as being beneficial to journalists' careers (Dupagne \& Garrison, 2006) or "an insurance policy" (Singer, 2004:7) against some of the effects of financial belt tightening (like redundancy). Ketter, McGuire \& Murray (2014) also found in their survey of sports editors that being able to work across platforms and provide video and photos as well as appear on camera or produce radio content was now an essential part of a sports journalist's skillset.

\section{News values, news production \& news content}

The move to a digitally-focussed environment has highlighted the evolving nature of news values in the $21^{\text {st }}$ century. Journalism, as Broersma (2010:22) reminds us, "is not a science" and has been described as a social construction of reality (Gans, 1979; Schudson, 2011). News as defined by Hall, Critcher, Jefferson, Clarke \& Roberts $(1978: 249)$ is "the end product of a complex process which begins with a systematic sorting and selecting of events and topics according to a socially constructed set of categories," while Louw (2005:73) states: "news making involves a process of selection, emphasis, and de-emphasis. Journalists refer to this process as knowing what is 'newsworthy'." How journalists determine what is newsworthy is a complex process reinforced by workplace norms and practices and newsroom culture (Harcup \& O’Neil, 2001; McGregor, 2002; Allan, 2004; Deuze, 2005 Schudson, 2011).

There have been several attempts to determine how journalists decide what is 'newsworthy', with Galtung \& Ruge (1973) providing a seminal work in categorising factors that make events newsworthy. The more that an event matches the list of factors, the more likely that it will be considered news. McGregor (2002) updated the list to include the values of visualness, which acknowledges the special power of presenting news through pictures" (ibid:3); emotion, which placed an emphasis on "tragedy, human interest dilemmas, survivors, victims, children and animals" (ibid:3); conflict, where the notion of fairness requires a story to present conflicting views of a story and finally the celebrification of the journalist, where reporters take on the "mythical role" of acting on behalf of the public to ask questions of those in power (ibid:4).

Harcup and ONeil also revisited Galtung and Ruge's work in 2001 and then updated their typology of news values in 2017. They agreed with Bell (2016) that digital 
intermediaries were now having an increasingly important effect on setting the news agenda to the point that "the quest for shareable stories is perhaps likely to become an increasingly important consideration within newsrooms" (Harcup \& O'Neill, 2017:1480). This is arguably one of the reasons for why data analytics were becoming increasingly important in the newsrooms (to be discussed later). While they recognised that the impact of digital technologies was not the sole determinant, they found that five new news values (marked with an *) had emerged in the digital environment in the first 20 years of the $21^{\text {st }}$ Century:

Harcup \& O’Neill's "new" news values in the digital age (2017:1472)

2001

The power elite

Celebrity

Entertainment

Surprise

Bad news

Good news

Magnitude

Relevance

Follow-ups

Newspaper agenda
2017

Exclusivity *

Bad news

Conflict *

Surprise

Audio-visuals *

Shareability *

Entertainment

Drama *

Follow-ups

The power elite

Relevance

Magnitude

Celebrity

Good news

Media organisation's agenda 
Journalists inherently knew whether something is newsworthy having been subject to institutional "initiation and socialisation" within their newsrooms (McGregor, 2002:2). It has also been drummed into them through formal training at journalism schools. Ross's (2017) study of an American journalism school however, acknowledged the changing nature of news values in the digital environment. She argues that much of the news media's institutional power comes from its ability to act as gatekeepers and to "dictate the rules regarding what is and is not newsworthy" (Ross: 2017:85). She also argued that journalism training was now recognising that newsrooms were using data analytics and moving away from teaching their students into developing a "nose for news" and encouraging them instead to develop an "attunement to audience interests" (Ross, 2017:94). This approach would undoubtedly create inter-generational tensions within current-day newsrooms but could also signal a significant shift in newsroom cultures.

The digital-focussed environment has challenged the news production process for print news media companies. Sparrow (2006) argues that print news media companies have turned newsgathering and the news production process into routinised practices because they face three economic, professional and informational uncertainties. in their environment. This is also true of sports departments with Lowes' (1999) analysis of a Canadian newspaper's sports department proving to be instrumental in analysing the production of sports news at the end of the $20^{\text {th }}$ century. In the print environment, sports, like other departments in the newspaper have had their work practices standardised.

Typically, a newsroom was divided into 'rounds' or 'beats' and reporters are assigned to these rounds based on their interest or expertise. Like their political, general and business news counterparts, sports journalists are "drawn into a symbiotic relationship with powerful sources of information by economic necessity and reciprocity of interest" (Herman \& Chomsky, 1994:18) and in some respects, engage in pack journalism where they routinely turn up to the same media events and report the same thing as everyone else (Frank, 2003). This can lead to a homogeneity of practice across the industry (Lowes, 1999) and "normative isomorphism", where newsroom cultures and normative behaviours create pressures for journalists to follow (Lowrey, 2011:74). 
The financial pressures that print news media companies have faced in the past 20 years, however, has created tensions in the production of news. As print news media companies restructured, newsrooms suffered major reductions in staff. In the decade from 2008 until 2017, journalism employment in the United States had shrunk by almost one-quarter (Grieco, 2018). Newspaper publishers, however, suffered the most, losing 45 percent of their newsroom staff. Prior to the global financial crisis in 2008 , newspapers accounted for almost two-thirds (62 percent) of all journalists within the United States. They now account for less than half (45 percent), prompting predictions of "the vanishing newspaper" and "no newspaper towns" (Neilsen, 2012:17). There have been similar trends in Britain ( $\mathrm{Nel}, 2010$ ), Australia (MEAA, 2011) and New Zealand (Barton, 2016). This resulted in what Robinson (2011) called job enlargement for the remaining staff. Journalists were expected to not only provide more content for no additional pay but also do tasks that were previously done by other journalists (like subeditors) who had been made redundant (Saltzis \& Dickinson, 2007; Buchanan, 2013).

The move to a digitally-focussed environment has also drastically altered the rhythms of news production at companies like Fairfax and NZME, which used to be governed by the print deadlines. This was something recognised by sports journalists who must "arrange their workday around the newspaper's deadlines" (Lowes, 1999:47). While television introduced a 24/7 news cycle, the introduction of digital technology has now enabled print news media companies to follow suit. The 24/7 news cycle requires immediate and constant production of news content (Cohen, 2018). This has resulted in the adoption of a news value into print news media that had traditionally been considered important only by news agencies and broadcast media - urgency or immediacy (Deuze, 2007). Journalists and editors are constantly monitoring their competitors and pushing reporters to either match or advance a story that has appeared in rival newspapers or on television stations (Sanders, 2003). This has helped create a homogeneity of news - through a new form of what Frank (2003) described as pack journalism.

Cohen (2018) also argues that this adherence to a 24/7 news cycle and availability of digital technologies like smartphones or portable computers have restricted the agency of journalists to control when and where they work and what they create. The constant news cycle also imposed a different labour dynamic that stretches journalists' 
working day and creates tension with editorial news managers. These technologies allow journalists to monitor news, social media and their emails outside of their 'normal' working hours, with an expectation from editorial news management that they "be available to work if and when news breaks" (Cohen, 2018:11).

The speed at which journalists are expected to work in the digital-first environment has also raised areas of tension between journalists and editorial print management. The need to fill an ever-demanding news hole raised issues of a reduction in the quality of journalistic output and led to "lowering of the bar" both journalistically and technically (Wallace, 2013:112). The immediacy of digital news has also meant that journalists have less time to adequately fact check, corroborate claims or seek conflicting opinions and different voices before the story is published. The drive for constant updates has also resulted in what has been labelled "churnalism" by Davies (2008:59), who likened the digital-focussed newsroom to working on a factory floor. Cohen (2018) also argued the digital environment has led to a new form of Fordism or Taylorism where "strategies of efficiency and rationalisation in the labor process" (ibid: 100) turns newsrooms into "a model of mass content production" (ibid:104) and, journalists become merely inputs on a conveyer belt, the outputs of which can be scientifically measured and analysed.

One of the long-standing key arguments about the increasing commercial pressures placed upon news management has been a suggestion that the line between the newsroom and the business office has blurred (Schudson, 2010:215). This has led to a move towards a 'sensationalist' news agenda and a reduction in the coverage of communities that do not meet these 'sensationalist' news values. Others have argued that this agenda has led to 'dumbing down' (Ursell, 2001), while there has been a shift in emphasis towards infotainment and the coverage of the trivial, sensational and celebrity (Thussu, 2008).

Digital technology, however, has likely further expanded this trend with the introduction of data analytics into newsrooms. The development of tracking and measurement software like Chartbeat, which has been adopted by both Fairfax and NZME, allows print news media organisations to ascertain with some certainty what content is being read (Cohen, 2018). Previously determining what was a news story that people should read involved journalists "preferring instead to trust their own professional instincts and 
the cues provided by peer institutions in making news judgements" (Usher, 2013:508) or "gut feeling typically associated with individual and collective decision making about newsworthiness" (Lee, Lewis \& Powers, 2014:509).

The data gathered by the Chartbeat software is routinely circulated to newsroom staff (Anderson, 2011; Lee et al, 2014), which "contributes to the culture of the click", where journalists now make the decision on a newsworthiness of a story dependent on whether it gets clicked by online readers (Lee et al, 2014 509, 510). It also holds increasing importance in the newsroom with editorial managers' desire to maximise readership and audience activity and turn it into financial return or the audience commodity articulated by Dallas Smythe in 1977 (Lee et al, 2014; Cohen, 2015). This drive to attract readers has led to an internal conflict with journalists, who object to the rise of 'clickbait' and a lowering of journalistic standards (Anderson, 2011). This clickbait approach creates a further internal tension over the workflow within newsrooms. As journalists are pressed for time to produce increasingly more content, they question whether it is worth spending time writing a story that might not 'get clicks'. News values are also challenged as editors instead make an opportunity cost consideration over resourcing as to whether it is worth allowing journalist to spend time on stories that have been proven to be less popular with readers.

Daum \& Scherer's (2017) analysis of a Canadian print news media company also illustrates the effects of the change in sports newswork in a media organisation under financial stress and is particularly relevant to the New Zealand experience given the similarities that have emerged within Fairfax and NZME and Canada's 'Postmedia'. Journalists are placed under greater pressure to provide more content, there is less time to gather and write news and feature stories, while the advent of analytics has ensured that professional men's sports has increased its dominance of the news agenda and the coverage of minority of sports has shrunk or been "further marginalised" (Daum \& Scherer, 2017:11).

\section{The conflicts facing sports journalism in the digital age}

Sports journalism, like other sections in the modern newspaper arguably owes much of its foundations to the $19^{\text {th }}$ century (Briggs \& Burke, 2009; Chapman 2005). Sports reporting has been prevalent since about the 1830s (Garrison \& Sabljak,1993; 
McChesney, 1989), but it was not until the 1880s that newspapers began to supplant magazines as the primary source of sports news. Technological (typewriters, industrial printing presses) and societal changes (increased urbanisation and literacy) and the development of organised sporting leagues all contributed to the advent of sports departments in newspapers (McChesney, 1989). Joseph Pulitzer established the first sports department in his New York World newspaper in 1883, but it was William Randolph Hearst who began producing what is considered the first sports section in the United States in the New York Journal in 1895 (McChesney, 1989).

Sports coverage provided "a highly concentrated and easily identifiable male demographic" that could then be sold to advertisers (Lowes, 1999:10). By the 1920s, sport had become an "indispensable" section (McChesney, 1989:55) of the newspapers and was important to their economic fortunes as it became a way to expand circulation (McChesney, 1989; Garrison \& Sabljak, 1993; Koppett,1994; Lowes, 1999, Boyle, 2017). Sports and newspapers consequently developed what has been considered an early symbiotic relationship. Sports was treated like news by newspaper proprietors and sports organisations gave free access to athletes and live sporting events to generate news content. This allowed professional sports teams and leagues particularly in the U.S. and U.K to boost their profile of sports teams amongst the public. Sports events being treated as news both 'legitimised' the nascent industry and acted as free advertising for the sports teams and leagues to attract spectators and build a fan base (McChesney, 1989; Garrison \& Sabljak, 1993; Koppett,1994; Lowes, 1999).

It is, however, this institutional relationship that been the subject of an ongoing internal conflict within the media industry. Journalism within westernised liberal democracies like New Zealand, adheres to a normative stance based on the liberal theories of a free marketplace of ideas and that it acts as a Fourth Estate. McQuail (2010) argues the term was coined in the late $18^{\text {th }}$ century by Edmund Burke to recognise that the press is the fourth pillar of the liberalised democracy, the other three being the monarchy, church and parliament, which kept check on the abuses of power by the other three estates. Schudson (2011) points out the industry also evolved throughout the $20^{\text {th }}$ century. Journalism became increasingly professionalised as reporters became more highly educated with courses being established at universities, codes of ethics were developed and a self-consciousness adhering to the norms of objectivity 
evolved to the point that "journalists began to articulate rules of the journalistic road" (ibid: 75$)$.

McChesney (1989:55), however argues that sports journalism developed as a distinct genre and was a "prime source of entertainment". Lowes (1999:12) describes most sports coverage as "publicity as news", while "expansive media coverage is the key to successful sports promotion: the objective is to get people excited about our entertainment product" (ibid). This has led to heavy criticism of sports journalism by media sports academics who argue it is the "toy department" of mainstream print news media companies (Rowe, 2007; Boyle 2006; Sugden \& Tomlinson, 2007) and does not adhere to "the serious function of the Fourth Estate" (Rowe, 2007: 385) because it concentrates too heavily on the reporting of sports contests. It also does not routinely confront issues like the treatment of women in sports, race relations, violence, mental health, labour exploitation, politics and public expenditure, drug use and the commercialisation of sports (Rowe, 2005, 2007).

Rowe (2007), Sugden \& Tomlinson (2007), Boyle et al (2002) and Carter (2007), have all also argued that there is an over reliance on a small number of mostly "official" sources by sports reporters, something also argued by Herman \& Chomsky (1994). If a "market is dominated by a small group of sources then journalists have no choice but to go to them and not to criticise" (Boyle et al, 2002:165), which has led to a "trivialisation" of sports news (Sugden and Tomlinson, 2007). Coupled with this belief of trivialisation has been the growing emphasis on 'celebrity' in sports journalism. Indeed Rowe (2007: 400) states it is exactly this celebrity culture that has allowed "sports journalism (to move) closer to an entertainment and celebrity journalism form that operates to sustain a sports star system".

In many respects, however, sports journalism is not at all dissimilar from other print news journalism. Sports journalists are held to the same ethical standards as their newsroom colleagues (Daum \& Scherer, 2017), while their adoption of the same work practices as their colleagues legitimate their newswork (Hutchins \& Rowe, 2017). Schudson (2011:7) also reminds us that while reporting on political affairs "makes the strongest claim to public importance", that the nature and form of journalism has changed over time. Studies of sports journalists perceptions of their behaviours in the newsroom also found that they believed they adhered to the same professional and 
ethical standards as their counterparts in other areas of the newsrooms (Salwen \& Garrison, 1998).'Boosterism in sports coverage compromised their integrity (Hardin, 2005), while "critical watchdog style reporting" (English, 2017:544) of sports organisations and sports people was expected and that "sports journalism should be about reporting, enquiring, explaining and at times holding to account sports on behalf of fans" (ibid:535). Weedon, Wilson, Yoon and Lawson (2016) also argued that perhaps academia judged sports journalism too harshly given objectivity and fairness are social constructions in themselves. Even Rowe (2007: 386) admits that "other journalistic rounds may be similarly accused of professional failure, and more prestigious journalistic 'beats' like politics and business contain their fair share of selfserving, innocuous, even vacuous discourse."

The relationship between sports and media organisations, however, has never been in balance. Professional sports are now a multi-billion-dollar business and their live sports events have been turned into a commodity, something that could be bought and sold "typically at a profit" (Dart, 2014:530). The biggest driver for the commercialisation of sport has been the advent of television, and in particular subscriber-based television, with broadcasters paying hundreds of millions of dollars to purchase the exclusive rights to televise live sports events. This revenue has "increasingly financially underwritten" sports organisations (Hutchins \& Rowe, 2012: 92) who have therefore exerted considerable control over the access to live sports events. The increased control of sports events by sports organisations has resulted in Boyle (2013:127) arguing that "sports contests are not news anymore. They are heavily policed and costly investments in exclusively controlled intellectual property."

New Zealand has also witnessed a similar state of affairs with Sky Television having "secured the most popular sporting properties (including rugby league, cricket, netball, the Commonwealth Games, and the Olympic Games) that now air on seven dedicated digital sports channels" (Scherer \& Sam, 2012:104). A light regulatory regime and a dedicated lobbying strategy has also allowed Sky TV to be "particularly successful in its efforts to keep inconvenient regulations off the policy agenda ... notably in respect to ... anti-siphoning regulations which would undermine its exclusive content rights deals for premium sports" (Thompson, 2017:35). This media environment, however, creates questions as to whether high performance sports teams, like the country's national rugby team the All Blacks, are a commodity that can be bought and sold or 
an expression of the country's national culture (Hope, 2002; Hutchins \& Rowe, 2009). If sports reflect the national culture, it therefore should not be able to be walled off behind subscription television or sold off to the highest commercial bidder. While Hope's (2002) argument that journalists have been complicit in helping to commercialise professional sports teams like the All Blacks, it is still evident that the print news media consider the reporting of sports and of live sporting events is, first and foremost, news.

Sports organisations have argued that they do not have an issue with journalistic enterprise at sports events, but the line that previously existed between print and broadcast journalism was now blurred in the digital age and that "the definition of what is news, where it starts and where it stops has been completely turned on its head" (Boyle, 2013:133). Hutchins \& Rowe (2010), however, have pointed out in their analysis of a government enquiry into the digital-focussed environment in Australia that media organisations argued they were simply responding to the changing environment. The advent of digital platforms required the need for " $24 / 7$ on-demand content (and) a failure to adjust to changing audience habits, such as accessing breaking sports news, regular score updates, image archives, and highlights packages online, would, they claim, be impractical and commercially counterproductive" (ibid:704).

There has been, however, an increase in hostility between the print news media in New Zealand, sports organisations and rights holders like Sky TV in recent years. Digital technology also allows sports organisations to bypass traditional linear broadcasters like Sky Television (Thompson, 2017) and are "no longer as beholden to any potential distribution logjam or failed negotiations with conventional broadcast, cable, or satellite television" (Dart, 2014: 49-50). This is most evident in North America, with all four major sporting leagues - the NFL, MLB, NHL and NBA - selling worldwide digital subscriptions to live sports events and bypassing television broadcasters in local markets internationally.

A further tension that has been evident between sports and media organisations has been the control of access to athletes, coaches and administrators in an effort to regulate the news media agenda (Lowes, 1999; Sugden \& Tomlinson: 2007; Sherwood \& Nicholson, 2017) and it is difficult"for sports journalists to penetrate the 
public relations blanket thrown around sports stars by their representative and employer organisations" (Rowe, 2005:129). The reason why sports organisations exert such control over their employees is because just like any other institution, sport can be subject to issues like sexism, race relations, violence, mental health, labour exploitation, politics and public expenditure, drug use and commercialisation that deserve to be investigated by the news media.

Sports organisations role as 'gatekeepers' manifests in several ways, all of which are evident within New Zealand sports journalism, and reflect the way in which both media and sports organisations have shaped each other's behaviour. Not only do media have to sign up to be accredited to attend not just live sports events, but also to attend what have been termed media information subsidies (Suggs, 2016) - organised media briefings where access is restricted to just accredited media. Media managers also control the length and time of 'all-in' press conferences. This limits the extent and opportunity for journalists to question athletes, coaches and administrators in depth, or in a one-on-one setting (Lowes, 1999; Sugden \& Tomlinson, 2007; Rowe, 2016). The level of control of access, which illustrated a strong area of conflict, was spelt out by Sherwood \& Nicholson (2017) in their study into how sports organisations' media managers are setting the news agenda in Australia with a quote from former Sydney Morning Herald soccer journalist Michael Cockerill:

"What do we get now? In the A-League, dressing rooms are forbidden territory, training sessions are often closed, players and coaches hardly ever hand out their phone numbers, and the media shuffle from press conference to press conference like zombies to be fed the party line by players or coaches who have been trained to say nothing, and look even more disinterested by the experience." (Sherwood \& Nicholson, 2017:147)

While sports organisations exhibit considerable control over the news agenda, the advent of the Internet has created a contested digital space between sports and media organisations. Sports organisations have entered the media production business and "the boundaries between professional news media and sports organisations, in particular, are being eroded" (Boyle, 2013:131). This has created a major institutional tension between sports and media organisations who are now in competition for the news (Grimmer, 2017), with sports organisations "now attempting to compete as 
media organisations in their own right, delivering their own news direct to their publics" (Sherwood, Nicholson \& Marjoribanks, 2017: 514).

Since the turn of the $21^{\text {st }}$ century, North American professional sports leagues all have reporters assigned to cover each of the clubs and provide content for their leagueowned websites (Mirer, Duncan and Wagner, 2018). This has also occurred in Australia, where reporters are attached to clubs for the domestic Australian Rules AFL competition and for rugby league's National Rugby League. Cricket Australia and Rugby Australia have also recently employed journalists to boost the editorial content on their websites.

Sports organisations can limit access to newsmakers (coaches, athletes, administrators) and monopolise journalistic content. Sherwood et al (2017)'s analysis of the tactics of sports organisations' media departments in Australia and Suggs' (2016) examination of similar organisations in the United States have also recognised that media managers have taken a more 'strategic' role to media relations and conducted what they termed an opportunity cost analysis of what information and content (like player interviews, breaking news) would be held back for their own digital platforms to communicate directly with fans. There was also a feeling amongst PR managers that "traditional media are not to be trusted with the ability to tell stories" (Sherwood et al, 2017:526), which again only serves to demonstrate the conflict evident between the sports media and sports organisations. 


\section{RESEARCH METHODOLOGY}

This thesis adopted a qualitative research approach through semi-structured interviews with16 journalists who had worked at NZME or Fairfax as each company transitioned from a print to a digitally-focussed environment. It is important to remember that social research is not carried out in isolation from the world in which the researcher is studying (Kuhn, 1970; Gratton \& Jones, 2004; McNamee, 2005; Bryman, 2008). Each researcher holds a different perspective on that social world, how best to obtain knowledge from that world, and how to interpret the data gathered because "there is usually more than one way to make sense of things" (Babbie, 2017, 33).

The qualitative method involves the use of "words rather than quantification in the collection and analysis of data." (Bryman, 2008:366) and is an inductive paradigm where the goal is to generate new theory out of the data (Babbie, 2017). Qualitative research allows researchers to try and understand experiences and to "create a sense of the larger realm of human relationships" (Brennan, 2017:4). Babbie (2017:13) also argues that social scientists do not attempt to study people, but rather "try instead to understand the systems in which people operate, which in turn explain why people do what they do". Qualitative research also "aims to find patterns in social life" (ibid:8).

Qualitative research also recognises that reality is a social construction (Brennan, 2017). Social constructionism argues that "social phenomena and their meanings are continually being accomplished by social actors" (Bryman, 2008:19) and that this allows "the researcher to consider the way in which social reality is an ongoing accomplishment of social actors rather than something external to them" (ibid: 20). Social constructionism also forms the basis for the theories of the sociology of journalism (Schudson, 2011).

Recorded, semi-structured interviews were conducted during the period of study because qualitative interviews are socially constructivist as "respondents are seen as important meaning makers" (Barrett, 2017:29). Semi-structured interviews also allowed the researcher to maintain some order and control over the interview process and helped articulate questions that would answer the research questions (Bryman, 2008; Barrett, 2017). Semi-structured interviewsalso allow for respondents to take the 
interviewer into areas of inquiry that had not been considered by the researcher (Babbie, 2017; Barrett, 2017). They also allow the researcher to gather more detailed information, to hear the respondents' own opinions, give more flexibility as respondents' answer questions and generate additional questions and allow the interviewer to focus on the topic (Frey et al, 2000; Bryman, 2008; Barrett, 2017).

An interview guide was constructed that followed the criteria suggested by Kvale (1996) (cited in Bryman 2008: 445-8). The interview guide is attached in the appendices. Icebreaker questions were initially used to garner some biographical detail from each respondent to "get the conversation going" (Barrett, 2017:34) before a series of open-ended questions followed in an effort to ensure that respondents gave as much information as possible without being influenced by the interviewer (Barrett, 2017:35). Often these answers can lead to follow-up questions, which rely on the respondent to provide more details (Bryman, 2008:445). These types of questions can be more probing and it is imperative that interviewers only ask these questions when they have built up trust with their respondent (Barrett, 2017). These topics, however, can also be broached through the use of indirect, open-ended questions (Bryman, 2008).

Semi-structured interviews over the telephone were essential for the data collection due to issues of time and cost (Sturges \& Hanrahan, 2004) and availability (Holt, 2008). Irvine, Drew and Sainsbury (2012:88) acknowledge research has indicated that "the lack of face to face contact is said to restrict the development of rapport and a natural encounter, elements that are considered to be important for generating rich qualitative data". Taking notice of verbal cues and making detailed notes were also important to remember in the interview process. (Sturges \& Hanrahan, 2004). Telephone interviews are also only considered to be appropriate for short interviews (Sturges \& Hanrahan, 2004). When conducting telephone interviews, it is also important that interviewers do not "direct the narrative" (Holt, 2010:118), nor allow silences to develop into a "strange situation" (ibid:119). They must also "build a rapport with a participant prior to an interview" (Trier-Bieniek, 2012: 631).

\section{Study sample}

The sample was drawn from a group of journalists who were employed by, or had worked for, either Fairfax or NZME in the last 20 years. A total of 24 individuals were 
identified as being potential interviewees. They were known to the researcher either through personal or professional contact. The potential interviewees formed a purposive sample and were selected based on their ability to provide relevant information to the research project; to answer the research questions generated by the literature; and to understand the social phenomenon being examined (Bryman, 2008; Barrett, 2017).

The majority were reporters, employed for either Fairfax or NZME's sports operations. Respondents were geographically spread across the country. The sample group was deliberately restricted to potential interviewees who were experienced journalists and would be classified as 'senior' within the industry. This restriction was imposed because the aim of the study was to investigate how the print news media companies were affected by the digital environment. All the potential interviewees, therefore, had worked extensively on newspapers for Fairfax or NZME before the transition into the 'digital first' environment and had experiences that are relevant to answering the questions as to how digital had disrupted sports journalism within New Zealand.

Each of the potential interviewees were initially contacted through email. Of the 24 identified, two did not reply to the email. Two others were ruled out due to time constraints. A total of 20 responded they would participate in the study. Two, however, withdrew the day before interviews were to take place and did not respond to followup emails to reschedule interviews. Two others did not respond to requests to set an interview time after initially agreeing, leaving a total of 16 respondents.

Most respondents held undergraduate degrees and had also completed post-graduate training in journalism. Almost all were aged in their 40s and averaged more than 19 years working within the industry as journalists, although not all that time was spent as sports reporters. All were male, as was expected given that sports journalism is a male-dominated occupation, not just in New Zealand, but in other Western liberal democracies (Salwen \& Garrison, 1998; Nicholson, Zion \& Lowden, 2011; Arnold, 2013; Greenslade, 2015; O’Neil \& Franks, 2016).

\section{Ethical concerns}

New Zealand sports journalism is a small pool, one that is shrinking year on year. The 16 respondents eventually interviewed for this study accounted for roughly one-third 
of the sports journalists working in the mainstream print news media in New Zealand in 2018. It was therefore imperative that confidentiality was observed by the researcher. The reason for this was twofold:

- Confidentiality leads to greater candour and the researcher's aim was to promote a frank and free exchange of opinions, ideas and answers to the semistructured interview questions.

- Confidentiality would ensure that sensitive material or critical assessments of the print news media organisations made by respondents could not be easily tied back to an individual and cause potential harm to their employment.

There were also concerns their privacy could be breached. The following steps were taken to try to minimise these concerns and were reviewed and approved by the Human Ethics Committee (HEC) at Victoria University of Wellington:

- Respondents were not asked to discuss the study with their colleagues as the process of elimination could make it easy to attribute comments within the research report and potentially leave to them being identified as having taken part.

- The only public identifiers in this study are a code $(\mathrm{Rx})$, based on the chronological order in which respondents were interviewed. R1 was the first respondent interviewed, on Aug. 26, 2018, while R16 was the final interviewee on Nov. 8, 2018. Respondents are identified just according to their (Rx) code. There are no indicators of their age, educational achievements, job title, lengthof-service, or experience.

- Respondents were not informed as to who else had taken part or whether anyone in particular had been approached.

An information sheet and consent form were also developed in consultation with the supervisor and approved by the HEC. The information sheet outlined the research goals, possible areas of discussion, the interview process and what the respondents' rights were in terms of their information, how their data would be stored and used and that they could withdraw from the study without prejudice. Each of the respondents were emailed the information sheet and consent form, along with the interview guide, prior to the interview and asked to read them beforehand. 
In consultation with HEC, the researcher also took steps to minimise the possibility of respondents feeling pressure to take part in the study. Preliminary contact was made with a small group of potential respondents to discuss whether they felt there was interest in this research. None expressed any doubts and said they expected there would not be any resistance from themselves or colleagues to participate. Journalists, by the nature of their work, deal with stressful situations daily and being asked to participate in academic research would not rank highly in terms of the pressures they encounter. They also have little compunction in speaking their mind. The fact that two potential interviewees did not respond to initial enquiries and four others withdrew at short notice or refused to re-engage with the researcher after originally agreeing, demonstrates there was not total compliance, nor pressure from the researcher in the process. Journalist are also aware how to conduct ethical interviews. They are taught what 'off the record' means and how to seek clarification to ensure they understand completely what this means to both parties. Practicing journalists also typically conduct hundreds of interviews a year and would be confident in the process.

\section{Data collection}

The semi-structured interviews took place between Aug. 26, 2018 and Nov. 8, 2018. Nine were conducted in person, with the remaining seven done by telephone, principally due to time and cost. Conducting telephone interviews also allowed for greater geographic coverage across New Zealand. The in-person interviews were conducted in venues away from the respondents' place of work, normally in a quiet café and generally away from public view so that any colleagues potentially walking past might not happen to see the interview taking place. Telephone interviews were conducted with respondents while they were away from their physical place of work.

Prior to each interview, respondents were asked if they had read the information sheet and consent form and understood and agreed to them. They were also given the opportunity to ask any questions about the process or what they would be asked. They were also asked again if they were comfortable participating in the study and reassured of the confidentiality of the process. Face-to-face respondents were asked to sign and date a copy of the consent form and give it to the researcher. Telephone interviewees were asked to acknowledge they had read and understood the information sheet and consent form. 
Interviews were recorded with a digital voice-recorder. Respondents were told of this prior to starting the interview and approval again sought. Respondents were also told the data generated would be transcribed only by the researcher and held in a secure computer for a period of three years before being destroyed. The information would only be shared with the thesis supervisor for the purpose of guidance before the thesis was completed and that it was not to be used for any other reason other than academic research. Respondents were also told that they had a right to stop the interview at any time and withdraw from the study without prejudice.

Halloran (2009:210) reminds researchers that "objectivity dies hard in journalism but dies even harder in the social sciences". Pragmatically, objectivity is an ideal and does not truly exist in journalism - or even academic research - but in an effort to try to be fair and present as accurate a picture as possible, respondents were told by the researcher that there was no set agenda in terms of the research. There was "no right or wrong, or blame" or a desire to determine which print news media company was "best". Respondents were also told they had been selected solely because of their experiences and their ability to answer the relevant questions for this study. Personal opinions of the researcher and whether respondents agreed or disagreed with them were not factors in the research.

The majority of interviews lasted between 60 and 90 minutes, although two went longer than two hours. As each respondent had been sent the interview guide beforehand the interviews initially began with discussions around those points. Interviews started with obtaining biographical information before they moved into the four main themes that had been identified: financialisation, technology, newswork and the contested space. Respondents were given time to answer the questions and to elaborate as they saw fit. At times, the elaboration had been prompted by follow-up questions. Questions for later participants also emerged from earlier interviews, allowing the topics of inquiry to evolve and widen over time. Transcription took place over several days from late-October 2018 until mid-November 2018. Detailed notes, however, were also taken during every interview and referred to during the transcription process to ensure that observed behaviours or nuance from in-person and telephone interviews could be inferred from the answers (Bryman, 2008; Barrett, 2017). 


\section{Data analysis}

Semi-structured interviews can produce a massive volume of data and be time consuming and difficult to analyse (Bryman, 2008). It was therefore important to consider that the analysis of the data was an ongoing process (Frey, Botan \& Kreps, 2000). The key in data analysis is to examine the data and find "explanatory patterns" (Babbie, 2017:392). Notes about the most obvious themes were made on a piece of paper after reading each transcript. The transcripts were then re-read to generate more thematic and theoretical notes (Babbie, 2017), in effect conducting a thematic analysis.

Once the major themes had been identified a simple coding system was implemented to try and draw out observations that were relevant to answer the questions generated by the literature. Institutional tensions, for example were a key component of the underlying theoretical analysis. How Fairfax and NZME negotiated the structural pressures of financialisation and digital convergence were split into several categories. Comments that identified internal institutional tensions were highlighted red. Replies that indicated a tension with external institutions were highlighted yellow. Comments that illustrated how organisations reacted to financial pressures were highlighted in green. Orange or bolding was used to emphasise changing news practices or news values. Once this analysis was completed, the observations/quotes were sorted according to their themes and news organisation, which indicated not only the institutional differences but similarities across the industry.

\section{Research limitations}

Sports departments within print news media companies have typically been made up of reporters, the content creators, production staff (sub-editors) who are tasked with the assembling the physical newspapers (Lowes, 1999; Buchanan, 2011) and editors, who are employed to make the ultimate decision on the sports department's editorial direction while holding financial control. Each have an important task to undertake in the social construction of news (Schudson, 2011). None of the respondents interviewed in this study, however, were production staff, mainly because both Fairfax and NZME have drastically reduced their print news production staff. The print news product, the newspaper, is now essentially a "by-product of the digital output" (R16, 2018). Online-only journalists were also not interviewed, and neither were senior 
'news content directors'. The principal reason for this is because they were essentially those who refused to take part.

To provide a wider picture, interviews with senior management of both print news media companies would have been beneficial. Four of the initial 24 identified potential respondents, were or had been employed at that level, but interviews were unable to be arranged or agreed with two, while time pressures were a factor in the researcher's ability to source interviews with the remaining two and prevented seeking potential interviews with alternative senior management figures. 


\section{DISCUSSION}

New Zealand's two major print news media companies, Fairfax and NZME, have faced a challenging environment in the last two decades. Financial pressure from corporate owners (Myllylahti, 2011; Winseck 2012; Hope \& Myllylahti 2013) and the continual decline in revenue from advertising and circulation have forced editorial news managers to find ways to manage shrinking budgets and reduce staff numbers (Buchanan 2013).

The advent of new digital technologies like high speed Internet and cellular networks, smartphones, laptop and tablet computers has also seen increasing number of news readers move online (Neilsen, 2012). Both Fairfax and NZME have invested in new technology to adapt to the changing digital environment. Journalists have been supplied with smartphones to take photos and video; individual laptops became more prevalent; communications and direct editorial input software programmes have been purchased or adapted for their needs. Significant capital expenditure was also made by NZME in bringing separate editorial news gathering operations together under one roof in Auckland (NZME, 2015), while both companies restructured their editorial news gathering operations by shifting their focus away from individual mastheads or distribution platforms.

Digital intermediaries like Facebook and Google have also disrupted the economic drivers for print news media companies. The two tech companies have come to dominate the revenue generated within the digital marketplace. They also "have become extremely powerful in terms of controlling who publishes what to whom, and how that publication is monetised" (Bell, 2016) because they can provide "cheap, targeted online advertising" (Neilsen \& Ganter, 2018:1601). Such is Google and Facebook's dominance of the online advertising market "it is now estimated that of every dollar spent on advertising in the western world, 90 cents end up in the pockets of Google and Facebook" (Simons, 2017). This has created a significant tension with print news media companies, who have variously labelled the technology giants as a "parasite", a "content kleptomaniac" a "digital vampire sucking newspaper blood" or just straight out "plagiarists" (Chyi, Lewis \& Zheng, 2016:790). 
The production of sports journalism and sports news content in the digital age has also changed as both NZME and Fairfax adapted their news gathering operations and moved towards a digitally-focussed environment. The digital disruption, however, has also witnessed a change in the relevance of sports journalism within the print news media, with conflict in the relationships between print news media and sports organisations within New Zealand. The battle for the 'contested space' between sports and media organisations also has wide-ranging ramifications for other sections of the newspaper and globally as the protection of intellectual property rights and control over access widens the gap between the two industries.

\section{News is free. Journalism costs - financial issues affecting the NZ print news media}

The print news media within westernised liberal democracies have experienced significant financial shocks in the last 40 years. The advertising-model that had sustained the mass-market newspaper for more than a century is in terminal decline (Cairncross, 2019). Readership and circulation have also been steadily dropping for more than 60 years because, as Curran (2010) points out, society changed. Work patterns, workplaces, transportation and changing leisure times, the advent of rolling news television channels and the rise of the Internet and digital technologies, have all also had an impact on the readership of newspapers (Winseck, 2010).

New Zealand's print news media companies have not been not immune to these global trends. According to the New Zealand Advertising Standards Authority (NZASA), advertising revenues for newspapers in 2003 amounted to about NZ\$689 million, or about 37.1 percent of the total advertising spend in the country that year. By 2011, newspaper advertising was $\mathrm{NZ} \$ 582$ million or 26.7 percent of the total ad spend in New Zealand, a marked decline in the industry's revenues. The 2017 report however, paints an increasingly stark picture as the NZASA survey showed that about NZ\$353 million was spent on newspaper advertising. Another NZ\$82 million was generated from online advertising on the print news media organisations' websites. The total spent on advertising in newspapers (both print and digital) was NZ $\$ 435$ million, about 17 percent of the total advertising spend of NZ\$2.561 billion in 2017, and while digital advertising spend in newspapers is tracking up, the overall spend is decreasing, not only as a total figure but as a percentage of the total advertising spend year on year. 
Circulation has also dropped substantially, with latest Audit Bureau of Circulation figures showing a decline in all newspaper sales in the previous 12 months, continuing a trend that has been occurring for more than 20 years. The circulation of the biggest selling newspaper in the country, NZME's New Zealand Herald, was about 108,000 in the last year until Sept. 30, 2018 (New Zealand Audit Bureau of Circulation, 2018). The drop, however, is precipitous when you consider that its circulation in 2012 was around 170,000 copies a day, while at its height it would sell more than 200,000 copies a day (Media Watch, 2012). Fairfax's two major metropolitan mastheads, Wellington's Dominion Post and Christchurch's The Press, have also suffered significant reductions in the 12 months until Sept. 30, 2018 with their circulations dropping off by 12.21 percent and 11.31 percent respectively. The Dominion Post now sells less than 43,000 copies daily, while The Press is only marginally better at just under 43,500. New Zealand's provincial daily newspapers have also experienced significant declines, with Fairfax's mastheads dropping at almost 15 percent across the board. Across the chain, Fairfax's six daily provincial titles were selling just over a combined 65,000 copies. While NZME's regional publications were also declining, they were doing so at a much slower rate, with typical percentage drops around five percent.

\section{Financialisation of the NZ print news media}

In the latter part of the $20^{\text {th }}$ Century there was also a great deal of media concentration within the westernised liberal democracies (Farhi, 2008; Franklin, 2008; Freedman, 2006; Mosco, 2009, McChesney, 2008, Winseck, 2010, 2012) as media conglomerates "completed highly leveraged takeover deals" of newspapers (Farhi, 2008:15). These leveraged takeovers in an increasingly deregulated financial sector have resulted in the financialisation of the media industry (Winseck 2012; Hope \& Myllylahti, 2013). This financialisation has turned print news media companies into a "business unit" (Hirst, Hope \& Thompson, 2017:362), whose goal is to maximise profit and match the return on investment provided by other financial assets. The outcome of financialisation of ownership is that it "prioritises short-term returns over long-term viability of media institutions (Hope \& Myllylahti, 2013:194). It also places a great deal of power in the hands of financial analysts who have "sought to align senior management interests with shareholders" (Fitzgerald \& Winseck, 2016:91-92). These factors can make print news media companies "more vulnerable to restructuring" (Myllylahti, 2014:15). 
The experience of the New Zealand's print news media industry in many respects does not sit in isolation from its counterparts in the other westernised liberal democracies. Newspapers were established in New Zealand by prominent local families with the focus on covering local news, business and politics (Hope \& Myllylahti, 2013; Hirst, Hope \& Thompson, 2017). By the turn of the $20^{\text {th }}$ Century, however, the local newspaper began to become more commercially focussed as "urbanised economic growth reshaped the ownership and management structures of provincial dailies" (Hirst et al, 2017:354-355).

As the $20^{\text {th }}$ century progressed there was a move within New Zealand's economy towards corporatisation and consolidation and the start of overseas ownership of print news media companies with Rupert Murdoch purchasing the two Wellington newspapers The Dominion \& The Evening Post in 1964 (Hope, 2012: Hirst et al, 2017). With the freeing up of capital markets in the 1980s (Goldfinch, 2000; Hope, 2012), there was a further flurry of takeover activity within the New Zealand print media industry, with the emergence of three major players -- New Zealand News (owned by Brierly Investments), Independent Newspapers Limited (INL) and Wilson \& Horton, which dominated the newspaper market. In 1987 Murdoch's NewsCorp assumed a 40 percent interest in INL. In 1989, it increased its holdings to 49 percent (Hirst et al, 2017:356). By the 1990s, "New Zealand's media system was being hollowed out by transnational corporations with cross-media holdings" (Hope \& Myllylahti, 2013:196) so that by the turn of the $21^{\text {st }}$ century, New Zealand's print news media industry was dominated by two companies, Murdoch's INL and the APN News \& Media, which was owned by Irish businessman Tony O'Reilly's Independent News and Media (INM).

The turn of the $21^{\text {st }}$ century, however, saw a major shakeup in New Zealand's print news media industry as it "assumed a trans-Tasman dimension" (Hope \& Myllylahti, 2013:197) when Murdoch sold the INL newspapers to Australia's John Fairfax Holdings, the owners of the Sydney Morning Herald and Melbourne Age, in 2003 for NZ\$1.88 billion (Hope, 2012: 41). The sale "was to have a major impact upon media ownership patterns, journalism and news content" (Hope et al, 2016: 356).

The numerous changes in ownership structures for both NZME and Fairfax has meant they became subject to the vagaries of institutional investors throughout the first two decades of the $21^{\text {st }}$ century (Rosenberg, 2008, Myllylahti, 2011-2018). APN had 
signalled by 2014 that it was keen to divest itself of its New Zealand holdings and attempted to spin it off, but "the market told it there was no real interest" (Murphy, 2016). It later managed to demerger the New Zealand operation, rebrand it NZME and listed it on the New Zealand Stock Exchange in 2016 (Myllylahti, 2016), although its provincial daily in Masterton The Wairarapa Times-Age was later sold to the newspaper's general manager (Shaw, 2016).

Fairfax's parent company in Australia has since been purchased by Australia's Nine Entertainment Holdings, which includes commercial television channel Nine, after agreeing to a A $\$ 2.16$ billion buyout in July 2018 (Meade, 2018b). The takeover had been made possible by Australia's relaxation of media ownership laws in 2017, which removed "the so-called two-out-of-three-rule prohibiting one organisation from owning all three media - television, newspaper and radio - in any given city" (Packham 2018). The takeover was approved on Nov. 2018 and completed on Dec. 7, 2018 (Davies, 2018) with the announcement that almost 150 jobs would be cut and regional titles prepared for sale (Meade, 2018c). The takeover has also had ramifications for New Zealand's media environment, with Nine stating in early 2019 that it would look to sell off their New Zealand operations (Pullar-Strecker, 2019). This demonstrated the priorities of shareholders wanting to exit a market where they did not see enough financial return. It has also created considerable uncertainty amongst journalists, with one respondent exclaiming in a follow-up interview:

"It's bad. The boss came through a couple of weeks back and said, 'if you don't already have a Plan B, get one'." (R14)

The changes of ownership, falling core revenues and structural pressure of financialisation has created uncertainty within New Zealand's print news media companies. These pressures have occurred while "the media industry is going through an historical transformation from print to digital" (Hope \& Myllylahti, 2013:203), which has affected their levels of profitability and forced editorial print managers to adapt and change their organisations in a fast-moving environment. 


\section{'The top two inches' - how Fairfax and NZME responded to pressure (of financialisation)}

Print news media companies, not only attempt to shape their environment through their relationships but are also shaped by these external pressures (Winseck, 2012). This was evident in the ways that both Fairfax and NZME reacted to the changing digital environment while they battled with increasing financial pressures from their owners. The following section will set out what strategies both companies have pursued in an effort to meet the expectations of their institutional shareholders in the last 20 years and how they have affected sports journalism in New Zealand.

\section{Diversifying revenue streams}

Economic pressures have led to both companies, like their counterparts overseas, seeking to diversify their revenue streams. Fairfax was the first to make a major play in the digital environment with the NZ\$700 million acquisition of online marketplace Trade Me in 2006 "in order to increase its online holdings, exploit electronic commerce and to capture the migration of classified advertising towards the Internet" (Hirst, Hope, \& Thompson; 2017:356-57). It was also part of the strategy by the company to transform itself "from a print organisation to a digital one" (ibid). Under pressure from institutional shareholders, however, the company periodically sold off its share in the company to pay down debt. The second and final sale of 51 percent of the company in 2012 reduced overall company debt from $A \$ 981$ million to just over $A \$ 100$ million. Ironically, Trade Me was immensely profitable with an annual return of almost 18 percent to shareholders after Fairfax sold it and its sale to British private equity company Apex Partners for NZ\$2.56 billion is now awaiting regulatory approval (McBeth, 2019).

Despite the sale of Trade Me, Fairfax's management has indicated an underlying belief in economic and technological determinism. Various managers have stated they believed the company's future was in the digital market place and with the decline in revenue from print journalism there was no other choice but to seek to change the way company generates its funding by entering that digital environment. In the past four years Fairfax has expanded its holdings outside their core business of journalism. It entered into a joint venture with former telecommunications executives to launch an 
Internet Service Provider (Stuff Fibre) in 2016 to capitalise the rollout of the fibre network across the country, because as then chief executive Simon Tong said: "tech was an opportunity that stood out" (Pullar-Strecker, 2016). It then expanded on this in establishing Stuff Pix, an online pay-per view movie streaming service (Croot, 2018) and bought 49 percent of the energy retailer energyclubnz (Winter, 2017). It also set up a health insurance joint venture with Australian company health care fund NIB in 2017 (Fairfax correspondent, Dec. 13, 2017).

Fairfax also bought social media network Neighbourly in late 2017 (Fairfax correspondent, Nov. 1, 2017) and incorporated it into the main digital infrastructure in a move that chief executive Sinead Boucher said would enable the company's journalists "to connect with communities across New Zealand, talk to them about what matters locally, and keep them informed" (Stuff, Nov. 1, 2017). This purchase highlighted management's strategy to drive everything into the digital environment with Boucher stating: "we need to continue to act decisively in transitioning our business model into an increasingly digital business" (Read, 2017b). It also exposed a conflict between journalists and their editorial news managers over the strategy to transition into a digital services company. As one respondent remarked:

"They talk about 'planets'. Stuff is one planet and Neighbourly is another. The two planets circle each other. They think that more people who use Stuff will use Neighbourly and they can then sell advertising. ... Of course, we think 'what are you on about'? They've slashed all the local reporters and news coverage. Someone is on a planet that I'm not on." (R9)

Boucher continued the theme of digital determinism when she said the need for diversification was imperative, so the company could continue to "fund journalism at scale (and) ... to find ways to replace the money that was with print and which has gone elsewhere" (Pullar-Strecker, Feb. 1, 2018). Fairfax's revenue, however, is still heavily dependent on the print editions of the newspaper, with respondents all stating that as late as October 2018 that management had regularly said that about "90 percent of the revenue was still coming from newspapers" (R11). It is interesting that while print is providing the majority of revenue for Fairfax, it is the area that has suffered the most in terms of job and budget cuts, indicating that financial investors 
appear not to be interested in where the money comes from as long as the company meets its goals to reduce costs and improve return on investment.

While NZME followed a similar tactic in terms of acquisition of digital services and rhetoric about their future, their approach has also been different, reflecting the ways in which each company has reacted and adapted to their environment. NZME also either created websites that incorporated digital classified advertising or acquired services such as online gaming (sports tipping site Jimungo) or e-commerce (shopping marketplace GrabOne). Former NZME chief executive Brett Chenoweth said the diversification into new areas was because it was "becoming an increasingly important contribution to earnings" (NZ Herald, Aug. 18, 2011), while the 2012 purchase of ecommerce service brandExclusive, showed the company was "serious about digital". (NZ Herald, June 22, /2013). It also ventured into an online dating service, a jobseeking website (Yudu), a head-hunting operation (Talent 17) and property website (Oneroof).

NZME respondents ( $R 2, R 3, R 6, R 8)$, however, also pointed to a relatively strong subscriber base for the New Zealand Herald as being a significant contributor to overall revenue from the print media side of the business, while the Saturday edition The Weekend Herald was estimated to provide about 40 percent of the revenue. One respondent also said that a recent meeting with management had said that print was contributing more than 60 percent of the overall revenue and it was one of the reasons why NZME had chosen to not "set fire" to their print products in the same manner that Fairfax had (R3):

"The Herald today still has a really-strong subscriber base. It's a monetized base too. We're not dishing out freebies. We still make money off our subscriber base. That may work against us in the end because we have held on to it. But it's guaranteed income and we are conscious that we can't treat them poorly. You could argue that we possibly have, in the terms we have shaped the papers in our news imperative, but what I'm saying is that the Herald have been quite different in the way they have approached it to Fairfax, who have basically set fire to their print products and throw all their resources behind Stuff. It may pay off for them, but we still haven't found a way to monetise it." (R3) 
Until May 2019, neither company had implemented a paywall for access to their digital editorial news content in an effort to recoup some of their lost revenue. Their experience is not isolated. Williams (2016) found that in 1997 there was only one newspaper in the U.S. with a paywall, The Wall Street Journal. By 2010, six massmarket U.S. newspapers had some sort of digital pay model (Williams, 2016). By 2015, it was 77 of the 98 newspapers with circulations greater than 50,000. All of Rupert Murdoch's News Corp publications in Britain, the United States and Australia are now behind 'hard' paywalls.

Both Fairfax and NZME were reluctant to go behind a wall themselves. NZME had prepared the infrastructure in 2014 but shelved their plans as they attempted to win the traffic war with Fairfax (R3, R4, R6; Manhire, 2019). The company, however, implemented a freemium model paywall in May 2019, deciding that the digital market had matured enough in New Zealand to attempt the risk. Breaking news, or what respondents labelled as 'commodity news' was typically free, while analysis and commentary and sections like business and politics behind the wall. The company, however, was not abandoning its print editions, with newspaper subscribers receiving free digital access (Murphy, 2019). This indicated their strategy was to keep their newspapers going for as long as possible and to protect the income from their print products, which meant they "couldn't abandon print too quickly" (R3).

"Print still makes a lot of money and online is struggling to break even. So that has been the whole issue, trying to keep print alive. It's a constant fight between doing as much as we can online and trying to keep print alive and not forgetting print to the point where you're hastening its decline ... you want to keep a quality product so you can retain that audience for as long as you can. If there are print readers for another 15 years, then that's better than five years." (R4)

As Myllylahti (2019) pointed out, the decision showcases the different responses by both institutions to the revenue issues they are facing. Fairfax has recognised that its future lay as a digital services company, wanting to try and capture as wide a market as possible to sell its other products and services off the back of its journalism. NZME was, in contrast, focussed more on extracting higher returns from the readers of its journalism products. 


\section{Building a championship-winning organisation}

The pressure on print news media companies to cut costs has also led to major structural changes at both companies. Following international examples (Dupagne \& Garrison, 2006; Robinson, 2011; Wallace, 2013), NZME amalgamated, or 'co-located' its Auckland-based news media operations into one building in late 2015 with the desire to have news teams from radio, print and online working together in "one integrated, multi-platform, 24/7 operation" (NZME correspondent, Sept. 15, 2015).

NZME managing editor Shayne Currie later said it had cost the company "millions" to construct its newsroom, which includes a television studio to shoot video for the websites (Ralston, 2016:24). Staff, however were less than enamoured with the newsroom because: "it looked akin to a call centre. Others described it as a language school, a battery chook barn, sow crates in a piggery and a Dickensian sweatshop" (Barton, 2016:152)

Currie described the revamped newsroom as having three heartbeats, the breaking news, the developing story, and the exclusive content, which involves substantial cross-platform planning (Ralston, 2016:24-25). The primary focus of the amalgamated newsroom in Auckland, however, was undoubtedly to provide a technical and economic convergence of resources (Dupange \& Garrison, 2006). Reporters are expected to provide content across three platforms, print, digital and radio, and there was greater co-ordination between all three departments. This was evident from the NZME respondents, who said that bringing all of their editorial resources under one roof and making journalists work across platforms had provided greater interaction (R2) and 'broken down silos' (R4). It also allowed sports journalists to become multiskilled (R3) and get used to sharing more of their content (R4):

"It's about the expectation that our journalists can perform a range of tasks across the platforms and can perform them jointly. Anyone can audio tape an interview and send the audio to RadioSport, but now I think there is an expectation that they can edit that as well and have it usable for radio." (R3)

Fairfax, as part of its 2014 News Rewired project, restructured its editorial operations, including its management, appointing 'national editors' while several masthead editors were made redundant. Younger (and likely cheaper) editors were then appointed into 
restructured 'regional editor' jobs (Tucker, 2014). This reorganisation also created an integrated 'virtual' newsroom with journalists from individual mastheads organised into 'national verticals' (R14), with the focus on providing news stories that would resonate outside of the newspaper's circulation area. The reorganisation also has ramifications for news values and newsgathering (to be discussed later).

The sports departments were also nationalised into one operation and masthead sports desks essentially disappeared, with reporters working in a bureau model favoured by news agencies (R10). All of the sports journalists now reported to a national sports editor, who had two assistants who are described as 'sports news directors' and who control the flow of copy to the sports section on the Stuff website and liaise with the sports production staff on what stories would appear in the newspaper sports' pages (R7, R10, R12, R14). All the content was then distributed to the website rather than the individual mastheads ( $R 5, R 7, R 9, R 10)$ :

"The mastheads have been thrown out the window. In the case of Fairfax, you are based in XYZ place and that's where your office is and that's all it is. It does not define what masthead you work for. Your content could turn up in any given paper at any particular day." (R8)

These structural changes have highlighted some of the micro decisions made by editorial news managers as they adapted their institutions to the pressures of financialisation to cut costs and improve return to shareholders in the digital environment. While there has been capital outlay by NZME to consolidate their Auckland-based newsrooms into one building, it would be able to recoup the costs saved from having multiple tenancies in the central city. Fairfax's decision to cut staff and adopt a bureau model also saved the company money in the long term with salaries and travel costs likely to be reduced in the future. The decision also allowed them to focus on their digital-first environment.

\section{Consolidation of the print product}

Both companies have also undertaken several other steps of consolidation of their print publications. On Sept. 10, 2012, NZME's flagship masthead, Auckland's New Zealand Herald newspaper was printed for the first time in a tabloid format, abandoning the larger broadsheet format that it had been printed since its inception in 
1863. The move to a tabloid had been widely expected for several months and media commentator John Drinnan (2012) suggested the move to a compact format was because of head office pressure to turn around low share prices and to improve their value to shareholders, a sure sign of financialisation of the print news media industry.

Fairfax's Australian newspapers followed suit in March 2013, with its metropolitan mastheads in Australia downsizing to a 'compact' size (Business Day 2013). While commercial director Ed Harrison said the change might provide a short-term boost in circulation he did not expect it would result in a "long-term turnaround in circulation fortunes" (ibid). Boucher was a bit more optimistic in her appraisal when Fairfax said in October 2017 it would begin downsizing their New Zealand print publications by mid-2018, stating that she believed the move to the compact size would "show readers and advertisers that the company was committed to print" (Read, 2017a).Respondents, however, doubted that was the case, pointing to the closure of the regional weeklies and reduction of publication days at The Marlborough Express and Evening Mail as signifiers of the future:

"The day will come when there won't be a print edition of (local newspapers). They're not interested in local or community news. It's all geared towards stories that will get the highest number of clicks on the website." (R7)

Both companies have also consolidated the printing of their newspapers, with NZME moving some of the printing of its regional titles to an upgraded facility in Auckland in 2013 to save NZ\$40 million in publishing costs (Business Desk, 2014). Fairfax also consolidated the print runs of their regional papers in Wellington by 2015 after a NZ $\$ 21$ million upgrade of their press in Petone. In 2014, both companies also reached an agreement to print some of Fairfax's upper North Island newspapers on NZME's press in Auckland. Fairfax chief executive Greg Hywood described it as common practice in other parts of the world, while it ensured his company would not need to make "significant capital investment" (ibid). The companies also agreed in 2015 to consolidate distribution within provincial areas like Hawke's Bay and Waikato with NZME delivering the Fairfax newspapers (Myllylahti, 2015).

The effects of consolidation of the printing of newspapers created issues for sports journalists, who now cover more events in the evenings. Night games have always created issues for print deadlines. Reporters needed to write as they go, or even pre- 
write large sections of a story, then massage it depending on how a match played out. Often stories for the first edition of newspapers were game copy, second editions were reaction and follow ups. But this practice has now disappeared (R11, R15). To meet their printing and distribution obligations, as well as the timings of various print runs for different newspapers, deadlines had to be brought forward, particularly if the regional daily newspapers were being printed in Wellington or Dunedin. Print deadlines that used to extend up until $2200(10 \mathrm{pm})$, or in the case of breaking news for page one as late as 0100 (1am), were now brought forward to early evening. This meant that 'live games' are not making morning editions, creating tensions between reporters and editorial news managers. NZME respondents said that coverage of sports matches held in Auckland at night did not routinely make the next day's newspaper (R2, R4, R6). Fairfax respondents also acknowledged that the importance of 'live' sports to a newspaper had become increasingly apparent when the deadlines were brought forward with feedback from readers suggesting there were ramifications for circulation:

"The move to night sport meant that things that happened post 6pm never made the next day's edition which was seriously noted by readers and subscribers. That's when they started rapidly falling off. That acceleration has been constant." (R11)

This consolidation has also led to a homogenisation of news content, particularly for Fairfax, a reduction in local news coverage and diminution in the plurality of voices. Respondents said daily newspapers were typically given between three and five pages to fill with local content. Most of the rest of the pages had been set as a national "template" (R9) to the point that respondents described a similarity of the print news products across the entire country. One respondent suggested that, on any given weekday, a person could fly the length of New Zealand and stop at every city with a Fairfax-owned newspaper and there would be little difference from what they picked up in Auckland to what they bought in Invercargill (R15).

Sports pages were even more affected, with job cuts reducing the number of production staff company-wide (see section below on job cuts), so that just two specialist sub-editors based in Wellington are responsible for all the newspaper sports copy in the country (R13). The smaller tabloid-sized newspapers also meant individual 
mastheads were typically given three sports pages, two of which were already given over to stories of 'national' significance with just one page set aside for stories of local interest (R10, R15). These template pages have created conflict with the sports production staff, who are also required to sub-edit other sections of the newspaper and often pressed for time:

"We go to a production staff member in Wellington and tell them we don't want that story in our paper tomorrow and we get told 'tough shit, it's going in'. We might get one page in a tabloid-sized newspaper and if we're lucky we can get one local news story in there." (R9)

Fairfax and NZME's consolidation of their print products was no doubt a reaction to financialisation with an aim to reduce printing costs and to extract as much value and longevity out of their presses before they need to be replaced. Capital outlays of that magnitude would force both companies to question whether they continue to produce their newspapers at all. This has normative ramifications for the profession being a watchdog for their local readers and for providing a local public sphere from which the community can see its identity reflected.

\section{Taking one for the team - job cuts in the NZ print news media industry}

Job cuts have also affected the print news media industry within New Zealand. Both NZME and Fairfax outsourced and then centralised their subbing operations so that "for the first time, newspapers were sliced apart into content-makers ... and production staff" (Buchanan, 2013:29). It has resulted in the loss of more than 100 sub-editing jobs across the country (Peacock, 2016b). The largest single shakeup of jobs for New Zealand, however, occurred when Fairfax adopted their 'digital-first' strategy in 2015, with 159 editorial jobs 'disestablished' as it moved to further increasing content sharing across the group (Read, 2015b). The company, however, said they would create 174 new jobs, which the journalists would need to re-apply for(ibid) ). Most of the jobs lost were sub-editing production jobs and one of the consequences was that reporters were then encouraged under the 'Right First Time' programme to publish directly to the website. This meant that there was no sub-editing or fact checking and copy was posted live to the website. Reporters were also undertaking the tasks previously done by sub-editors such as selecting and cropping photos, writing captions, embedding social media, linking metadata and writing the headline to accompany their story. 
Sports has not been immune, with job losses at NZME and Fairfax both affecting the sports departments. Journalists covering the horse racing industry have virtually disappeared (R3, R7, R9), while senior staff who retired, left voluntarily or made redundant were not replaced $(R 7, R 11, R 15)$. Fairfax also made all 11 of its sports reporters at its daily regional newspapers, like The Taranaki Daily News and The Southland Times, redundant in 2017. In late 2018, they said they would also make 11 of their 14-senior sports staff reapply for nine jobs. This move, however, was stymied by the journalists' union E tu, who said it was illegal and the plan was tabled "for now" (R14). NZME has also reduced the headcount of their regional sports reporting staff by not filling vacant positions (Peacock, 2018). It then said in late-September 2018 that it would dis-establish all the sports positions at the New Zealand Herald, with the reporters forced to re-apply for fewer jobs (Ellis, 2018). Five positions were ultimately disestablished (R3).

\section{Gut check time - cuts to sports budgets}

One of the consequences of financialisation has been cuts in operating budgets for editorial departments year on year. One Fairfax respondent said that it was a constant battle with their head office in Sydney over budgets.

"Every year ... we did get messages to cut travel or cut staff because we had overspent. They were saying 'there's not as much money coming in, let's find a way to do it.' But it has basically been about cost stripping or redirecting of spending somewhere else, which is digital." (R1)

One of the significant effects on sports journalism through these budgets cuts has been the reduced amount of travel by sports reporters in the $21^{\text {st }}$ century. Nearly all respondents from both print media news organisations spoke about previously travelling regularly to attend events outside their newspapers' geographical coverage area because that sport was part of their regular round/beat. One Fairfax respondent said that as late as 2015 he had covered a New Zealand cricket test in the South Island, and every other major Fairfax masthead, even those from the North Island, had sent reporters to cover the match. All of the reporters were "operating independently" of each other (R15). 
Reporters also routinely travelled to follow regional sporting teams, like provincial rugby sides, basketball or soccer teams, playing in national sporting competitions, with the presence of a journalist at away fixtures seen as imperative to add commercial value for their local mastheads and readership and to reflect the local community in their newspapers:

“Our editor always saw the value in that. It didn't matter if it was Invercargill or Whangarei, we were there. l'd turn up to games and even the local (home town) journos were sitting in the office and covering it off TV!" (R11)

A similar practice has developed at NZME with one respondent describing situations where Auckland-based reporters would not attend matches being played by the region's three national provincial rugby teams, North Harbour, Auckland and Counties Manukau.

"They would have a guy sitting in Auckland writing a game off the telly, even if it was in Auckland! They wouldn't go to the game. That didn't happen all the time, but you would think the New Zealand Herald would send someone to games in Auckland." (R8)

It is just not the local sports events that have been affected, with coverage of global sporting events like the Summer Olympics subject to tighter budgets. This was no more evident in the last decade when Fairfax sent a team of 10 reporters and photographers to the 2012 London Olympics. By the 2014 Glasgow Commonwealth Games there was seven in the team. Although Fairfax 'boycotted' the 2016 Rio de Janeiro Olympics (to be discussed later) they had originally planned to send six staff. This trend has only accelerated since then:

"At the 2018 Commonwealth Games on the Gold Coast we sent two. And a lot of our coverage was done back here. At London all the coverage would have been done by the guys on the ground. Compare that to the Commonwealth Games this year, about 20 percent of the coverage was done by the guys on the ground with the rest done back here." (R14)

The danger of not having journalists at sports events is that controversies, poor performances and issues like doping scandals would not get covered by a 'local' reporter. The reduction in travel budgets has important ramifications for sports 
journalism, especially in its relevancy in the digital environment. There is the real possibility that sports journalists would be unable to argue they fulfil the normative Fourth Estate principles of their colleagues of being able to ask questions of newsmakers, particularly those who receive government funding (like most Olympic sports organisations and athletes) to create public good journalism.

These budget cuts are not restricted to overseas events. NZME respondents mentioned one example as the 2017 Rugby League World Cup in New Zealand where Fiji beat the hosts 4-2 in the quarter-final in Wellington, to record the biggest upset in the tournament's history. NZME covered the match from Auckland by watching television and frustration at not being able to ask questions of the Kiwis' management and players about the loss was evident, particularly when halfback Shaun Johnson's "yous got your way" retort at the media resonated for months afterwards (Bidwell, Nov. 18, 2017).

"History was made. We couldn't do the story. Couldn't do the stories afterwards. That was a relatively small expense. That may have been just a misjudged decision. But it was more symptomatic of the approach 'oh you can do that from your desk and watching TV'." (R4)

An outcome of the reduction in travel and in journalists' numbers, has been the increased use of what Davis (2000) has called information subsidies. Often a media manager travelling with a team will provide audio or video from the routinely scheduled media conferences and either email the file, or a link to an online 'Dropbox', for journalists in New Zealand to access. Sometimes, it might even be the media manager acting as a 'journalist' and asking questions of players or coaches. This can lead to a heavily mediated (or even edited) version of events being substituted and regurgitated as 'news', while creating a false impression the news organisation has sent a reporter to cover the team.

An interesting outlier to this practice amongst (most) national sporting bodies is New Zealand Rugby (NZR), who steadfastly refuse to give any support to print news media companies. Fairfax respondents said that due to their budgetary constraints they had been unable to send a rugby reporter to five offshore All Blacks tests in 2018 - the first time they had not sent someone to cover the team overseas. The company then 
approached NZR about the possibility of providing audio clips from press conferences and two respondents recounted that "we were basically told to $f^{* *} k$ off" (R13, R14).

The traditional 'church-state divide' - the supposed demarcation line between the commercial and editorial departments (Amazeen \& Muddiman, 2017) has also now become increasingly fuzzy as sports departments try to find ways to fund event coverage. This divide was once sacrosanct in newspapers, particularly in the sports sections. Sponsors' names of events and teams were deliberately excluded in editorial copy, despite the pleas and protestations of sports organisations. The divide, however, has now been blurred, if not disappeared altogether. This is particularly evident with commercial agreements helping fund international travel to cover sporting events. These agreements always include a disclaimer at the bottom of editorial copy where 'A Reporter travelled to the World Tiddlywinks Championships courtesy of (insert appropriate commercial sponsor name)', to indicate an arms-length relationship between reporter, the newspaper and the commercial sponsor. They are, however, almost essential now to fund travel to most international sports events:

"There are tours that we once considered essential as part of the news agenda, we wouldn't even consider now. It's been a while since we sent someone on an overseas cricket tour that they haven't been able to fund themselves." (R3)

"The amount of money invested by the company has been minimal, especially for international events. They have invested money domestically and for big events. But you're always fighting to justify the reasons why we should go to (events) apart from an Olympics and Commonwealth Games." (R2)

The most evident blurring of the church-state divide in recent years has been the coverage of the career of Auckland-based professional boxer Joseph Parker. Both NZME and Fairfax have taken advantage of free travel and accommodation offered by Parker's managers Duco Events to cover his fights in Europe or training camps in the United States. Most respondents said their coverage and journalistic objectivity had not been compromised and argued they were not there to "write pro-Joseph Parker stories" (R5). Ethically, the respondents argued, the "lines were blurred", although one felt that lines had been crossed:

"Anything we do with Duco is advertorial" (R13). 
Both companies have also entered into content agreements with sports organisations, with NZME working closely with the New Zealand Olympic Committee (NZOC) and other NSOs to generate content of sports that might not otherwise get regular coverage. One respondent, however, described such an agreement as "ethically ambiguous" and in the end "counter-productive" for both:

"Partnering with NSOs has had no benefit to us at all. It doesn't attract people to the websites and keep them there. I doubt the NSOs would have got new members." (R3)

It is apparent that sports organisations like Duco, the NSOs and even the media managers of travelling sports teams are keen to subsidise the media in various ways because it is within their institutional interests to generate publicity of their sports within a crowded marketplace. Duco's desire, for example, is to generate interest in Parker to drive pay-per-view sales on subscription television. Most New Zealand sports organisations also recognise that readers are interested in how their teams are performing overseas. It is apparent, however, that print news media do not have the financial resources to travel to events, nor even the staff to cover them remotely. If sports organisations do not provide regular, timely and interesting information subsidies, they run the risk of being ignored by New Zealand print media organisations.

News coverage also legitimises the event in the eyes of the readers, with a semblance of "perceived credibility ... by audiences" (Amazeen \& Merriman, 2017:5). While print news media companies might be willing to take advantage of the news subsidies, the blurring of the church-state divide is bound to provide issues over credibility. In an increasingly fragmented sports-media market, where readers have "exposure to a much wider variety of news sources" (Fletcher \& Park, 2017: 1281) through fan blogs, sports organisations official websites, athletes' social media platforms and quasi-news digital platforms like The Bleacher Report and The Players' Tribune (McCullough, 2018), trust in the mainstream media organisations remains high. A greater reliance on news subsidies could therefore have economic effects as well because "newspapers trade on their credibility and brand at least as much as they trade on the information they provide" (Lowrey, 2011: 66). In short, if news coverage is perceived to have been paid for, trust in the integrity of the news disappears. 


\section{Stuff/Me}

A further response to the challenges of the digital environment was the potential proposed merger of Fairfax and NZME. ZBoth companies announced in May 2016 they had applied to New Zealand's Commerce Commission to merge, creating a single publishing company that would work across print, radio and digital platforms. The companies said the nature of the Internet meant that they were not only competing with local bloggers, digital-only media organisations which were starting up (like The Spinoff and the 2017-launched Newsroom), but the websites of TVNZ and Newshub and global media organisations in the domestic news market - in short they believed there was a substitutability of news providers and competition for news, which ensured a plurality and diversity of voices that fulfilled their normative Fourth Estate obligations. Both companies also argued that it would also allow the merged entity to capture more of the digital advertising dollar and provide a far more comprehensive platform to deliver advertising to readers. A merger would, according to NZME chief executive Michael Boggs, allow them to "invest more in journalism and actually have better content in the marketplace" (Espiner, 2016:24). The merger was rejected in May 2017, with NZCC head Mark Berry acknowledging that a merger "could extend the lifespan of some newspapers and lead to significant cost savings anywhere between $\$ 40$ million to around $\$ 200$ million over five years" (NZCC, 2017) but that it would exert too much control over the media market and eventually abandoned in late 2018 after subsequent appeals to New Zealand's High Court and Court of Appeal failed.

The sports departments at Fairfax and NZME were also the subject of another potential merger after meetings were held in May 2018 to discuss the establishment of a separate standalone entity that would provide sports coverage to both organisations (Murphy, 2018a). The standalone company would have created efficiency gains, eliminated duplication of coverage and saved "hundreds of thousands of dollars a year" on travel costs and journalist salaries (ibid). While providing sports content for both companies, it also could have also sold their content to third-party providers, generating revenue for both. Respondents, however, indicated the proposal was never really followed through:

"There was a meeting. But I think that was because NZME don't get as much clicks as we do so they wanted us to do all the breaking news stuff and then 
put all their heavy hitters behind a paywall. It never got any further than the initial meeting." (R9)

These proposals highlighted that both institutions were attempting to influence the structure of their environment because they felt New Zealand's media regulation was "weak" (Thompson, May 3, 2017). It also highlighted how they continued to explore ways to respond to the pressures of financialisation and falling revenues for their print products.

\section{The Rumble in the Jungle - institutional tension in the newsroom}

In his early studies of newsrooms transitioning into the digital environment, Deuze (2004:148) described it as "an ongoing contest" as the print and digital operations coexisted in competition for resources and relevancy. The early days of the digital editorial environment at both NZME and Fairfax were typical of many of their international counterparts (Dupagne \& Garrison, 2006; Singer, 2004, Garrison, 2011). The shift from a print focus to digital first newsrooms in New Zealand was characterised by institutional tension and conflicted newsroom cultures and as Ryfe (2012) found in his study of American newspapers, scepticism towards further corporate management intrusion (the outcome of financialisation) into the newsroom. The move to a digital-first environment therefore did not start until after the financial pressures started to bite from about 2010 and gathered greater momentum from 2015 when both NZME and Fairfax announced major overhauls of their news operations (Read, 2015a; NZME 2015).

\section{‘They dropped the ball' - tensions between journalists and management}

Like many of their counterparts in the westernised liberal democracies, both Fairfax and NZME entered the digital space at the turn of the $21^{\text {st }}$ century. There was widespread consensus amongst respondents that the reason why both companies moved into putting their content on digital platforms was a simple belief in it being a chance to widen their traditional audience because circulation was falling, and younger people were not reading the newspapers (Singer, 2004). It was also a "nice supplement to have with the print product" (R3). Another respondent described the move as a reaction to newspapers "staying relevant" because they were a "sunset 
industry" (R7), while another said it was more to do with a recognition that people were accessing their news on digital devices:

"More and more people were going to phones, desktop, the internet and they felt that this is where people were moving to. Less people were looking at print and the move in market meant they had to adapt and try to be ahead of the game. Unfortunately, with the way that's gone, the horse has bolted." (R2)

The economic tensions created by financialisation, however, have led to several changes of leadership in both companies, which influenced the editorial strategic direction of each institution. One example that highlights how institutional reactions to structural pressures can be shaped by a single person's decision was NZME's decision to implement a paywall in 2014. NZME had built the technical infrastructure to introduce the paywall $(R 3, R 6)$. The the new chief executive, who held an extensive marketing background but no journalism experience, however, killed it because they felt the battle was for market share with Fairfax to "become number one" and until they achieved that they would continue to make their digital platforms free to access (R6).

"There is that feeling there have been a lot of strategy changes, so you never know if the strategy is working because it changes again. ... it could be the classic NZME way that they don't know what the $f^{\star *} k$ they are doing. That's the impression the staff get. They don't know what they're doing. A friend of mine said it reminded him of the South Park episode where the gnomes steal all the underpants. 


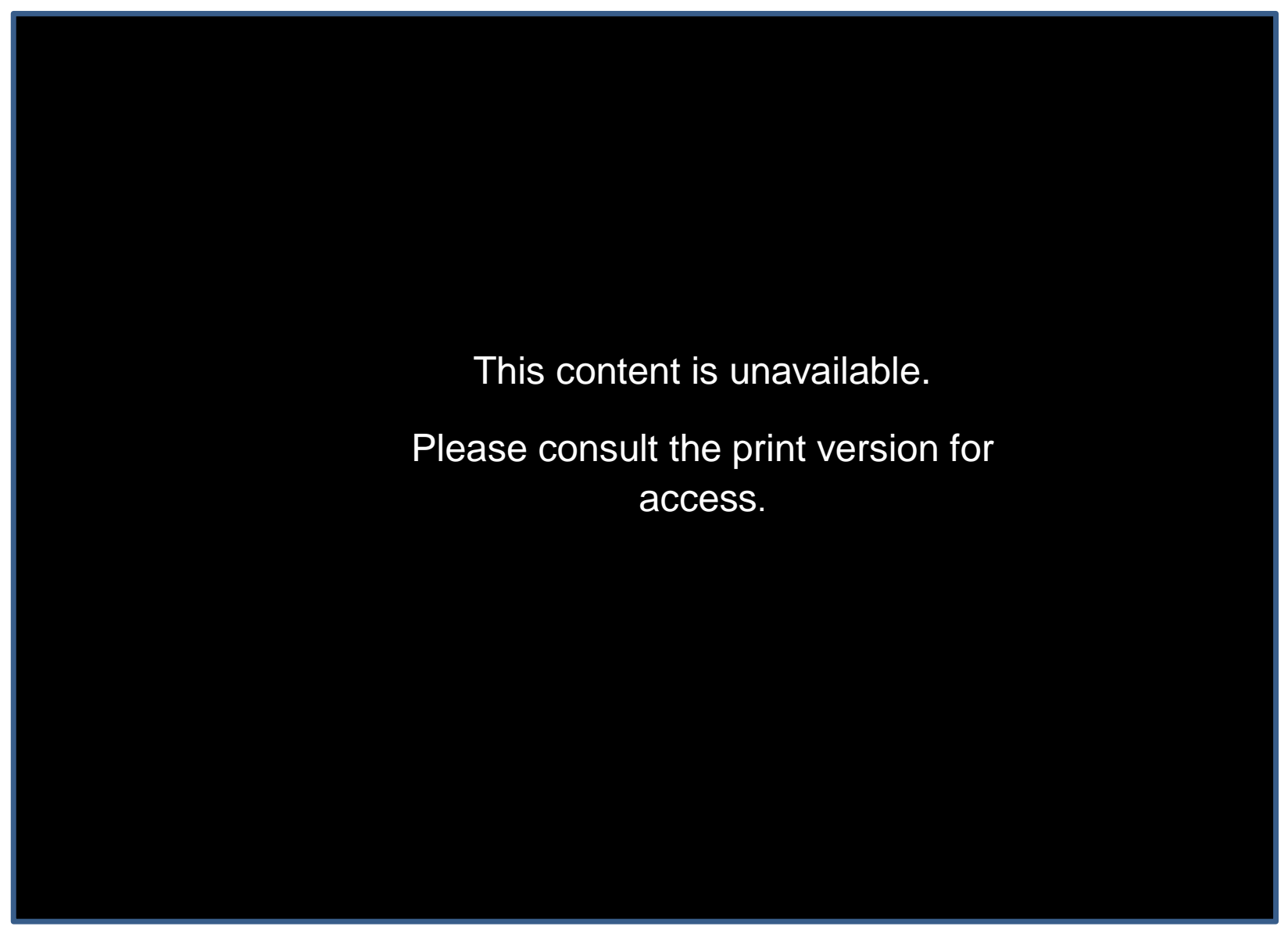

"News is like that. It's digital first and win the traffic war, then what? It's a strategy where they don't know what the crucial part is, how to monetise it." (R6)

Another source of tension amongst respondents has been a seemingly constant trial and error approach, and the abandonment of digital editorial practices before giving them an opportunity to 'bed down' properly. In an attempt to either build an audience to attract advertisers or to generate revenue, both NZME and Fairfax have attempted podcasts or asked reporters to shoot short video pieces to camera discussing or analysing sports events. These approaches have since been abandoned:

"Both NZME and Fairfax have tried podcasts. Now they haven't really taken off, but podcasts are a really easy way to promote with a commercial partner. Because it's just two people talking, how many plugs can you get in for a product in an hour? That's a workable revenue model. Of course, that takes time to produce the content, but I just don't know if they ever got given the chance. They were dropped. To me that is something if you take time into building an audience you might be able to generate some revenue. Some days 
it looked like they were just sitting at their desk and throwing stuff at the wall and seeing what stuck. You just don't know what was going to work and what wasn't." (R8)

While there was some sympathy for the challenges faced by editorial leaders with one respondent acknowledging "it's not an easy environment" (R6), there was also frustration as to management's "lack of curiosity" (R3) as to where digital might be headed or to anticipate the impact of the digital intermediaries like Google and Facebook:

"I would confidently say that up until 2010 management in Fairfax and NZME would not have anticipated the rise of Facebook and Google and how it would impact them. They had no strategy to combat that. They're now paying the price. Well management isn't. They're still going to be there. The guys who are, are the journos and subs. They're the ones paying the price. Management survives and it's the grunts that get killed." (R7)

Respondents at both organisations said one of the most concerning factors discussed in the newsrooms was the economic risk associated with adopting a digital-first focus was that they were essentially giving their news away for free. Many were concerned putting the news online for free undercut the economic foundations of the newspaper and changed the focus of the value chain ( $R 2, R 3, R 4, R 5, R 7, R 12, R 15, R 16)$.

"The (masthead) reporters would often mutter away 'what the $f^{\star *} k$ are we doing with online? We get 98 percent of the revenue from newspapers, so why are we doing online and giving it away for free?' I guess they were sharp enough at that point to realise their jobs would come under pressure." (R12)

"The biggest gripe with a lot of people was when we started publishing things digitally first. We'd have a cracking story and it would go up at 3pm and then would be the back page lead the next morning. That was the big one that scared a lot of the older ones in the newsroom. They were thinking 'why would people buy the newspaper if it was going online at 3pm?' I think that's when the reality dawned on people as to where it was heading." (R15)

Despite the fact respondents said these concerns were made plain to editorial management in numerous staff meetings ( $R 4, R 13, R 15)$ they acknowledged the 
financial pressures put on their organisations by their owners were the major drivers in both Fairfax and NZME accelerating their push towards a digitally-focussed environment. Editorial management rhetoric was therefore firmly focussed on stating that if they did not change then the company would collapse. One Fairfax respondent said their editorial managers had drawn an analogy with American photographic company Kodak to illustrate why there was a need to move ahead with the digitalfocussed strategy:

"Kodak ... never embraced the digital age ... and as a result 'where are they now?'. The used that in a seminar they gave us where they said: 'if we don't get ahead of the game now, if we're not at the forefront of digital media then Fairfax won't survive'." (R15)

Ultimately, the financial pressures appear to be the biggest factor involved in sweeping away a lot of the cultural resistance as job and budgets cuts and organisational restructuring took effect (R7, R8, R11) As Barton (2016:156), a former feature writer for NZME, pointed out, "redundancy is a process designed to silence". This has had further ramifications for those who managed to survive the cull or chose to see where the digital landscape may unfold as they identified the fragility of the journalism labour market as a reason for accepting the digital first strategy:

"I think people are resigned to it. As staff we are pretty powerless. We don't necessarily agree with it. We don't agree with how quickly they have undermined the newspapers. But we do see that digital as the way forward (and) .... we don't have anyone saying ' ${ }^{\star * *} k$ off, l'm not doing that'." (R9)

What was apparent in the move towards a digital-focussed environment was that neither Fairfax nor NZME really understood where it was going. It had also moved too quickly for print news media companies to implement strategies to allow them to adapt to the changing environment. It also demonstrated the belief among editorial news managers that they needed to lock in a competitive, or dominant, position in the digital market-place for news in New Zealand as they moved forward. While there was significant doubt from journalists as to the strategies pursued by their managers, the uncertainty of the journalism job market ultimately resulted in acceptance, indicating the relative lack of power they held in the hierarchy of each organisations. 


\section{Getting on the same page - tensions between print and digital}

While both Fairfax and NZME had established digital operations at the turn of the $21^{\text {st }}$ century, they had been largely ignored by print news media reporters (R1, R3, R11, R16). One respondent said the mastheads were so separated from their online operations that many of the print journalists would have had trouble naming any of their online colleagues:

"...we didn't even know who they were. We could ring them but if someone asked where does (name redacted) sit, we'd have had no idea. It was divorced. That was up until only six years ago. And it cracks me up that it was only six years ago." (R3).

One of the major reasons why there was such separation between print and online operations early on was simple, they normally sat on different floors of the editorial operation or the digital team were shoe horned into a corner 'over there' or into what one respondent termed as "a broom closet" (R12). They were also organised individually. Each newspaper had their own digital team attached to the print news operation ( $R 1, R 3, R 4, R 5, R 12, R 16)$, while at Fairfax a small national team also managed the Stuff website and solicited input from the individual mastheads' digital teams.

Some editorial news managers, despite pursuing the rhetoric of digital being the way of the future, in reality paid it lip service and ignored their digital journalists, who would offer advice on story ideas and ways to develop multimedia techniques to tell stories (R12). At the time, online sports reporters were also principally employed to produce "shovelware, that is, largely unmodified print content" (Matheson, 2004:444) from the already published newspaper onto the website. The nature of this type of newswork created a problem for the print news media organisations in that they found it difficult to hire new staff members with few young journalists at the time keen to just be 'button pushers' (R12).

This type of newswork also created further internal tension. One respondent, involved from early in the transition to digital, indicated they had been quite "excited" (R12) by the opportunities being promised by digital journalism with more 'live reporting' and 
greater use of multimedia tools to tell stories, but had become disillusioned by the way in which it had been implemented:

"(I was) ... hired because of my journalistic background but became someone who was just content loading. The only editorial decision I did get to make was whether or not as to what the top sports story of the day was. There was no time for me to write a story, or even to generate a story idea. There was no room for creativity. I also lost touch with the news. I didn't have time to listen or read anything ... the brain just turned to custard." (R12)

Singer (2004:840) argues that newsrooms create pressures on journalists through the "socialisation and control of journalists to preserve institutional mythology", like workplace norms and news values, and it was apparent that this initial ambivalence towards the online platforms and their colleagues filtered through to the sports reporters, many of whom still operated with a mentality of working primarily for the print operation. This manifested in what Deuze (2004:144) labelled as "turf wars" between the print and online platforms. Respondents saw the requirement to provide content for both digital and print platforms as an additional chore, one in which they were not receiving any extra compensation, and ultimately as only "a great moneysaving opportunity" (R3) for management. There was also significant resistance to accepting the digital-first focussed workflow (R4, R5, R8) as Daum \& Scherer (2017) also found in Canada. At NZME, there were similar feelings about providing content for the radio platforms. There was also an attitude amongst some of the older reporters that when they were required to write for the online platform that it would be not their best work, which they would hold back for the next day's newspaper:

"There was some resistance. They ... would file to the website, but gave the impression they were not going to give the best 250 words that they had. They were saving stuff for the newspaper. It was a really funny mindset." (R8)

The closure of the New Zealand Press Association (NZPA) in 2011 had a dual effect on New Zealand's print news media environment. With the loss of copy-sharing by regional newspapers and coverage of institutions like Parliament, it "erased a historic remnant of the nationally constituted public sphere" (Hope, 2012:41) and meant the public was "less able to receive a collective sense of themselves as a basis for national debate" (ibid). . It also ended the production of immediate, national wire copy that both 
companies could have used to feed their websites in the 24/7 news cycle. NZPA's closure was also arguably the point when Fairfax decided to commit fully to their digital-first path and respondents acknowledged that it changed the way they thought about who they worked for. They may have been a reporter on the Christchurch-based The Press, but they were now working for Fairfax and the Stuff website:

"When NZPA was shut down was when the push came on for more instant digital journalism from us, who were primarily (redacted) newspaper reporters. We had to become multi-skilled and the demand for instant news came from there basically." (R10)

It was obvious however, there was still a residual feeling of tension within the Fairfax newsrooms towards digital and editorial managers, with one respondent arguing the company seemed to have a desire to "kill print off" (R11), while others were convinced it was a risky economic strategy that had yet to bear any fruit:

"Our company is not investing in newspapers. We have slashed production staff. We have slashed reporters. Everything is focussed on digital because clearly the company, even though the newspapers bring in about 90 percent of the revenue, have a view that newspapers are dead and buried. They won't quantify that within a time span. Going full on into digital they're trying to achieve something that no other (media) company on the planet has achieved which is to make enough money to get into the black. You could say it's a gamble." (R9)

While both Fairfax and NZME underwent major restructuring in 2015, NZME's move to their one integrated newsroom in Auckland also broke down a lot of internal institutional barriers as they implemented three forms of convergence as outlined by Quinn (2005:30-31). They reorganised the newsrooms in a structural convergence; introduced ownership convergence, where they shared content across print and broadcast platforms and promoted each other's brands; and trained their reporters so they could provide content across platforms - for print (daily and weekend editions), online and radio $(\mathrm{R} 2, \mathrm{R} 3, \mathrm{R} 4)$ in an information-sharing convergence. One respondent acknowledged that after some initial resistance and teething issues, the internal tensions had dissipated: 
"It works quite smoothly. There is quite a lot of content sharing. The radio guys do interviews that we get material from. We'll record our interviews so they can get a (raw file) of the interview. We'll do voicers. If I'm on tour l'll send back everything." (R4)

Adapting and then transitioning to a digital environment for both NZME and Fairfax has been far from smooth. They have also adapted different strategies to deal with this challenging environment in New Zealand. Fairfax's expansion into other digital enterprises and its diminishing focus on its newspapers, however, indicates it has decided to position the company for a digital future far more aggressively than NZME, despite the fact neither is generating the returns from digital revenue they would need to replace the losses from print. The restructuring of the editorial news operations at both organisations, which included significant job cuts also allowed them to overcome internal resistance to the transition towards digital. Journalists who kept their jobs either accepted their new roles or recognised they would be looking for a new career.

\section{Newsgathering, news production \& news values}

Newsgathering practices by sports journalists in print news media became entrenched in the 1920s and did not really deviate across institutions (Lowes, 1999). Journalists spoke to people, followed tips, sourced documents, attended media conferences and then typically wrote a story based on the information they could cobble together (Lowes, 1999; Sherwood \& Nicholson, 2012; Daum \& Scherer, 2017). Respondents recognised that they followed similar news gathering practices in the $21^{\text {st }}$ century and indeed, the actual process of newsgathering appears remarkably similar across both Fairfax and NZME (R2, R4, R5, R6, R9, R13, R15). The digital environment, however, has changed the rhythms of their news gathering and forced them to undertake new tasks in the distribution of their news. The change in the distribution platforms (print to online) has also changed story formats, news values, and introduced new forms of content presentation.

\section{Becoming a utility player - multiskilling print sports journalists}

Like many of their international counterparts with the transition to digital, Fairfax and NZME have moved "from the era of single-media to multi-media reporting" (Saltzis \& Dickinson, 2007:217). Both companies invested in digital technology that would enable 
their reporters to not only report but also shoot video and take pictures as their websites incorporated more multimedia elements for their readers (R2, R3, R4, R5, R10, R14). Laptops and smartphones became an essential component of the sports reporters' toolkit, as did the ability to use them:

"Any editor, manager, director of news is going to be more attracted to a reporter who can interview, write, load their own story, picture edit. That's a boon for any editor in the modern environment." (R3)

Respondents said both companies had also provided training opportunities for reporters to learn how to capture video and pictures to accompany their text stories. Fairfax respondents, however, thought their training opportunities, which were essentially instructional videos, were "minimal" (R9). While respondents agreed that becoming comfortable with digital technology was a skillset seen as vital in the evolving journalism marketplace, the overburdening of journalists to undertake multiple tasks at the same time created issues around the quality of content, sentiments echoed by international counterparts (Cohen, 2015; Daum \& Scherer, 2017):

"You are essentially a one-man band and from a positive point of view you're picking up new skills. ... But when you're in an interview situation and trying to talk to someone, you've got your hands full. It is a juggling act and it is invariably produced poorly." (R7)

Respondents also recognised how much more time it would take to edit a video (R9, R14), while it also took away from what they considered to be their core role of interviewing people and writing stories. One respondent, however, said Fairfax had quietly abandoned the expectation that journalists provide video and photos as well as text stories: "It has never really been a goer. They have tried it, but no-one mentions it now, so no-one does it" (R9).

NZME, in contrast, have encouraged their reporters to provide content for print, digital platforms and radio, with respondents also expected to be interviewed for their own video production team to provide short 'talking heads' news items. There has also been a growing expectation that sports journalists learn how to cut packages for radio and even re-package content for rolling news bulletins ( $R 2, R 3, R 4)$. While being multi- 
skilled was considered "essential" (R2, R4) and a "benefit" (R4) in the digital environment, it has created an issue over what audience a journalist might be writing for, and Reinardy (2011:34) argues it is "a no-size-fits-all audience":

"Nowadays if you send a sports journalist for an assignment they are writing everything for every publication and RadioSport will probably ring you for a daily wrap. That's where the real challenges came from. Who were you writing for? Who were you filing for?' (R8)

As Saltzis \& Dickinson (2007) point out, much of the drive for multi-skilling journalists is to enable their company to cut labour costs and improve the efficiency of the production process. This was also evident in New Zealand. As mentioned earlier, production staff (sub-editors) jobs were among those that were cut heavily by both companies in the past decade. This was also no doubt as to why editorial Content Management Systems (CMS) were purchased (R1, R14, R16) to centralise and manage workflow (R16) and allow journalists to self-publish their own stories on the digital platforms, particularly at Fairfax. As part of the Right First Time programme, journalists were expected to not only write their stories but also select photographs, write captions, load hyperlinks and if possible, embed video and social media, in effect creating "job enlargement" (Cohen, 2018:11). For Fairfax sports journalists, this was not restricted to routine daily stories, but also while they were covering live events:

"You're writing the story, sourcing the photos, cropping them, captioning, writing the headlines, adding links to all the other stories. You're doing all this at an All Blacks test or a Black Caps one day international and its coming down to the last over, it's a pretty tough job." (R10)

Daum \& Scherer (2017:8) argue that this overburdening of sports journalists has "led to the erosion of human labour power ... and the ability of sports journalists to produce quality sports content”. Respondents complained that this overburdening resulted in a reduction in quality of their stories and journalism. In a print-focussed environment the sub-editors were employed to not only edit and rewrite stories, but also fact check and correct grammar and spelling mistakes and provide a 'second set of eyes' of journalistic scrutiny to determine whether the story met basic editorial standards of balance and fairness. This layer of staff, who acted as 'a safety net' is now gone and 
most respondents agreed that filing direct to the digital platforms, diminished the economic value and integrity of the news brand:

"It's very rarely a quality end-product so why would you expect people to pay for that? The thing is they have knocked off the layer of staff (sub-editors) who would have found those mistakes. Their answer is that they had to cut costs. But they also lost a lot of (experience and) knowledge, which was a safety net. So, you look stupid. The reporter looks stupid, if they've got a conscience and professional standards." (R7)

Despite this drive to multi-skill sports reporters and there being a recognition that being digitally savvy and able to utilise and exploit social media was becoming increasingly important in the digital journalism marketplace (Ketter, McGuire \& Murray, 2014), it was apparent that the all-singing, all-dancing backpack journalist does not exist in the Fairfax sports department. While NZME require their sports reporters to be comfortable in providing content for their print, online and broadcast distribution channels, they have not yet implemented a fully multi-platform working newsroom.

\section{Time's up on the clock}

The rhythm of a daily, or weekly, newspaper was set by its print deadlines (Lowes, 1999). While rolling television news channels like CNN, the BBC and SKY TV in Britain, and in the sports market ESPN, created a 24/7 news cycle more than 30 years ago the adoption of digital distribution platforms has brought that to print news media organisations as well. The deadline is 'now' and pressure to provide content is neverending, with the news cycle truly 24/7. This new urgency has created what may respondents described as a time crunch with the day not only speeding up but extending and the workload increasing dramatically:

"There is always a deadline. With print once you'd met your print deadlines you had another 24 hours. Of if you worked for a Sunday paper another week before your copy is due. There's always a demand for words, even in the middle of the night." (R5)

"It's 24/7 pressure now. There is no down-time for reporters, news directors, editors. ... It's so hard to switch off. Even when I go home I'm on my phone, on Slack (an online messaging platform), on websites, checking emails. There is 
always something going on. That immediacy requires (it). It has increased workloads, but resourcing has decreased significantly." (R14)

This time crunch has led to what respondents again considered to be undermining the quality of their journalism. There was no longer time to check, or double check stories because they had to be published immediately. The ability to discuss stories with their colleagues or editors to cover new angles or find different voices or even just to make sure the story is covered properly had diminished drastically (R14). These new time pressures have led to a 'once-over-lightly' approach to journalism (R15). Whereas, previously, stories underwent significant rewrites and checking, in the digital age these processes no longer exist. Content is posted instantaneously which results in "stories appearing as piecemeal bits of evidence, accusations or speculation, to be sorted out in the public as the day goes on" (Singer, 2003:151).

There is also increasing pressure to produce more stories per day, keep turning the website over and practice "warp speed" (Singer, 2003:151) 'churnalism'. The practice is well embedded within New Zealand sports journalism, with several respondents also referring to the constant turnover of stories as 'churn', while one likened news writing to now being "robotic" (R13). Another described it as working on a factory assembly line:

"It's a fast-moving consumer good on a conveyer belt. You don't have the time to do things. There's always something needing to be done. They talk about the tyranny of the urgent and everything needs to be done yesterday and that floods through (to what we do)." (R2)

The reasons for churn were explained to them in financial terms (R5, R14, R15). Print news media companies needed to turn the websites over to keep readers coming back throughout the day to generate clicks and then to also keep them engaged, allowing editorial management to generate usage data that would be favourable to advertisers (R5, R7, R12). Respondents said the lifespan on the digital pages at Fairfax, before they were archived, was normally about three hours, which created a morale issue and again highlighted the lack of intra-institutional power journalists had:

"The thing about digital is that in the old days your story sat on the paper until the next day's paper came out. The digital attitude here is that you refresh it as 
much as possible, particularly in sports. The digital lifespan for a story can only be two to three hours. If you think too much about that it can be quite soul destroying." (R5)

The change in the distribution of news from newspapers to a website or "beast" (R15) that needs to be fed an increasing amount of content under a constantly rolling deadline and turned over several times throughout the day has led to the incorporation of a news value at print news media companies that was previously only prevalent in news agencies and the broadcast media, urgency. While exclusivity, breaking news first or dominating the news agenda for several hours in the print news environment (Harcup \& O'Neil, 2017), has always been an important news value and one in which is an important fulfillment of journalism's Fourth Estate role (Singer, 2003), urgency differs slightly due to the increased focus on time in the digital environment. Respondents all argued that being first with a news story, especially in newspapers, was always still the goal ( $R 2, R 3, R 4, R 7, R 9, R 10, R 11, R 14, R 15)$, but being fast was increasingly important, particularly if a competitor - not just in the New Zealand market but globally - had a story that might be of relevance or interest for readers. Respondents all argued that 'matching' competitors was an imperative news directive. Sometimes, this is done without crediting the original publisher of the story and, as English (2011) found in his study of British and Australian newspapers, has led to some less scrupulous competitors claiming their pickup as an 'exclusive'.

The danger for respondents of increasingly matching competitors was that it amounted to an intensification of pack journalism and of following the leader, which can lead to a greater homogeneity of news content. Respondents recognised that print news media companies' ability to differentiate themselves from their competitors was what allowed them to stay relevant in the New Zealand marketplace, but if they kept "chasing each other's tails" (R3), then that would undoubtedly lead to a lessening of their brand value. Respondents also recognised that it could lessen the ability of the individual companies to try and influence the news agenda, or even just set their own news agenda (R2).

\section{Controlling the tempo of the game}

The news media develop "journalistic practices to buffer themselves from volatility" Sparrow (2006:147). News, after all is rarely planned and "thrives on unexpected 
events" so "creating a work routine ... simply ensures that covering them is possible" (Sherwood \& Nicholson, 2012:945). The need to control and manage the work routine of their staff has never been more important for editorial managers in print news media companies in the digital environment. The time crunch and need for urgency to match competitors has led to increased control from editorial managers over journalists' workflow and content (R4). Reporters are expected to account for much of their day to the point they needed to justify being able to meet a contact for a potential story (R15). This increased control of their time indicates a reduction in the autonomy of journalists to set their own workflow. This was especially evident with the adoption of urgency as a news value:

"Your time is constantly monitored. If something breaks (in my round) they will be frantic in there asking 'where is (name redacted)? We need to do a matcher, or we need to do an opinion piece'. So, it can be a bit harder to manage your own time." (R4)

While there has always been pressure on sports journalists to file stories every day "even if it's the most banal story imaginable" (Lowes: 1999:43) there was never a quota of stories to fill. Respondents said when they worked principally for their print mastheads they typically wrote one to two 'decent, something that required original reporting and research and involved speaking to sources, stories a day. In the digital environment the expectation is that "four to five" stories (R5) are required each day, while if they produced only two or three then the feedback from management was that the reporter "hadn't contributed" (R13). In the current environment, if they produced one story a day then a reporter would find themselves "out the door by the end of the week" (R14).

The need for urgency and production of continuous content has seen the introduction of two new digitally-focussed reporting shifts at Fairfax. The new morning shift starts at 0600 , while the afternoon shift ends at 2200 . These shifts could be done remotely by anyone in the country and were designated by editorial management as 'national news shifts. Journalists, however, labelled them 'clicktubate' shifts (R7). Reporters assigned to the shifts were expected to trawl through websites of competing news media companies or sports organisations both domestically and overseas and 'pickup' 
stories of interest for a New Zealand audience - particularly of New Zealand athletes who may be playing in overseas leagues or competitions:

"Our vision is quite global. We're not just here to cover New Zealand sport, we're here to cover stories that New Zealanders might be interested in." (R5).

These shifts were also required to scour social media to provide short stories where they could attach photos and videos, hypertext links to other stories and embed social media like tweets and Instagram posts into the story page. Respondents, however, argued the shifts were not seen as 'real journalism', again highlighting both the dominant newsroom cultural values (Deuze, 2003; Schudson, 2011) and the tension between the digital and print focus of current newsrooms (Singer, 2003; Saltzis \& Dickinson, 2007; Cohen 2015):

"If you're sitting on the desk surfing websites like the Daily Mail or ESPN to find a quirky video that can then be uploaded, processed and have a story written around it with hopefully a couple of embedded tweets, by the time you've done that, there's half an hour gone. You just don't have the time to concentrate on the core responsibilities of what the job used to entail." (R7)

One major outcome of these time and urgency pressures, coupled with the reduction in travel budgets, has been the expectation that reporters cover live sporting events overseas off television, no matter what time of the day they occur (R7, R9, R10, R13). Respondents said it was routine for reporters to be rostered on for shifts that start in the middle of the night, with the goal undoubtedly to ensure that readers would go to the website when they wake up in the morning because they know the content will already be there and not seek out competing news organisations.

Urgency as a news value has also seen the need to always be available to file if something breaks, meaning that reporters are increasingly becoming desk bound and rarely getting out of the office to attend routine media opportunities like training sessions and news conferences or meet sources for interviews or just chasing up a news tip. This influences the quality and quantity of information available to a sports journalist and does not allow them to "develop a full picture" (R5). It also does not allow them to build social capital and relationships with news sources. As Garrison and Sabljak (1993:37) state "a reporter is only as good as the source", while Wojciechowski 
(1990:55) argues that going to routine practice sessions could lead to an "occasional scoop and it shows the players and coaches you're serious about covering the team". Plaschke (2000) even argues that the best sports reporters are the people who are "best at hanging out", which aids in the accumulation of this social capital. Respondents, however, all pointed to the pressure they felt from editorial news managers to stay in the office:

"Staff resources means you have to ask how to best utilize your days in a skeleton newsroom. Do you spend half the day working the phones or going out to meet someone, when in the same time you can just sit at your desk and go through all the websites and social media and find things to write about? That could be considered (by managers) as a better use of your time." (R12)

\section{Adapting to the referee - changing news content}

Lowes (1999) argued that the commercial imperatives of newspapers and the standardisation of work practices concentrated news coverage into a small group of professional men's sports with the focus on events and profiles of athletes. Space was also an important factor in determining what got covered, there was a finite amount of news hole to fill, so coverage was prioritised into sports that would provide a stable flow of news and attract a predominantly male readership (Lowes, 1999). While there is now an increasing focus in some countries on covering women's sports, there has traditionally been little coverage of women in sports (French, 2013; Schmidt, 2016; Franks \& O'Neill, 2016) or what are considered 'minority' sports (Lowes, 1999; Boyle, 2006).

The digital environment, however, provides unlimited potential for content because there are no space limitations and as outlined earlier, print news media organisations turn their websites over constantly. Respondents, however, all said this was not the case in New Zealand, with the diversity of coverage "shrunk right down to the size of a walnut" (R9), while there was a concentration "on the big four of rugby, league, netball and cricket" (R2). One respondent was blunt in their assessment:

"The idea that the Internet was going to increase the cover of minority sports? Forget it. Fairfax aren't interested in sports like that. Neither is the Herald. 
Unless there are drugs scandals, or someone dies, or there is something sensational about it." (R7)

Time was again considered a major factor in the reasons why minority sports were not covered with one respondent stating simply: "I don't care how many times someone from a squash club emails me, I don't have time to do that story" (R7). Various budgetary and staff cutbacks has also resulted in editorial news managers and reporters making decisions on what they could cover, rather than what was available to be covered, which also highlighted an emerging trend that could have long-term ramifications for New Zealand sports journalism:

"We're not constrained by space online but its human resource. We don't cover minor sports anywhere nearly as well as we should. I think we're going to rely more on sports organisations providing content. I think that's a reality now. It's not a good one." (R3)

Respondents also identified that there was now an opportunity cost consideration when it came to whether they should write a story about a minority sport, or even seek more diversity in a story:

"If your time is being squeezed and you have a hockey, cycling rowing, golf, domestic football story that you know your bosses won't be encouraging you to do anyway then you'll be thinking 'Shit I better write this story about what Steve Hansen said about the Warriors'." (R4)

One of the more significant factors that has affected editorial news judgement has been the introduction of digital tracking tools into newsrooms. Both NZME and Fairfax have installed Chartbeat, which can measure audience numbers and how long readers stay on a page and gives print news media organisations the type of real-time data analytics of their readership that they could only dream about when they were printfocussed. The primary goal of "incorporating metrics into news production is ultimately to boost advertising revenue by increasing traffic and reader engagement through striving to publish stories guaranteed to be read and circulated. In the process, news outlets are recasting editorial policies toward that which will be clicked on, which eliminates the need for skilled journalistic labour and devalues journalistic autonomy" 
(Cohen, 2015:110). This is a manifestation of Smythe's (1977) audience commodity, where what is being sold is not the journalism but the eyeballs of the reader.

Respondents recognised that Chartbeat was driving editorial news judgement within their newsrooms and having a major determinant on what was, and what was not, covered (R2, R3, R4, R5, R6, R7, R8, R9, R14, R15). Coverage was becoming more concentrated around a small number of sports with anything to do with the All Blacks generating a significant number of clicks (R14), which meant that more resources were being devoted to coverage of these high-click events. In the print-focussed environment most newspapers sent one or possibly two reporters to cover All Blacks tests, with the expectation they file a match report and three or four sidebar stories after the game. In the digital environment, more than five reporters can be covering a single match, with a match reporter(s) at the game, a sidebar reporter, who would get the audio emailed by match reporters, one (or two) reporters running a rolling blog and a reporter assigned to do player ratings and possibly a more analytical story. Sports columnists would also likely file afterwards. None of this coverage was specific for the next day's newspapers, who would "take what they get and pick and choose from what was filed" (R14). To most respondents, the adherence by editorial news managers (R2, R3, R6, R7, R8, R15) to concentrating on what would get 'clicks', retweeted, liked' on social media, or 'clickbait', was ultimately diminishing the culture of public good journalism:

"It can be soul destroying sometimes. ... How it was described to everyone was that we have to do this stuff to pay the bills to do the proper journalism. So, you could ask 'why can't I just do proper journalism and not this clickbait shit?'” (R6)

"It manifested itself to the point ... you would look at something and say that's a good interesting story, but I know it won't get any clicks. So, do I bother doing it? Or do l just ignore it?" (R7)

One of the consequences of using Chartbeat for editorial news judgement has been the virtual elimination of regional sports news. Coverage of local club and age-grade sport has also disappeared (R3, R7, R10, R11, R15). Fairfax's decision to cut 11 sports jobs from their regional mastheads in 2017 was no doubt linked to wider job 
cuts across the company, but respondents felt that clicks were also contributory factors in the decision (R5, R7, R9, R11, R15).

The move to a national editorial operation in 2015 also contributed to the redundancies of Fairfax's regional sports journalists Fairfax respondents all indicated that stories now need to be nationally focussed and reporters needed to produce stories that resonated further than a masthead's traditional circulation area:

"When I started, we covered all the local sports (representative) teams. We still do, but much less now. There aren't daily (newspaper) stories. And we try to appeal to a wider audience. ... a profile on an up and coming athlete is good, but someone from Auckland and Invercargill has to be interested in reading it ... your brief is to appeal to a national sports audience but wider than diehard sports fans." (R10)

This adherence to metrics has also contributed to the concentration of coverage on individuals, or personalities, particularly those who had an international footprint. An example cited by respondents from both Fairfax and NZME was that despite New Zealand having a strong basketball culture, with the New Zealand Breakers in the Australian professional competition, a semi-professional domestic league and men's and women's national teams competing in Olympics and world championships, the sport got little attention. NBA player Steven Adams, however, would generate almost daily coverage and one respondent stated simply he was "huge in terms of clicks for us" (R5):

"The example that gets thrown around is that we're not going to do basketball stories, we'll do Steven Adams, but we won't do basketball stories about the Breakers. We could do five Breakers stories and they get the same number of clicks as a Steven Adams story. My concern is that we will start to cover some sports less and less and the way we cover other sports will change. It (coverage diversity) could become quite narrow." (R4)

The cult of celebrity has also led to what Gillian Ursell (2001:192) described as the dumbing down of the news agenda, where "human interest has supplanted the public interest". The drive for clicks in the digital environment has exacerbated this news agenda (Anderson, 2013) and respondents outlined two notable examples where they 
were asked to write 'celebrity-focussed' stories because editorial managers knew that the story would get clicked.

One, involving New Zealand singer Lorde, was identified as a piece of advertising masquerading as a 'legitimate' news story:

"I was asked to write a story around Lorde tweeting Steven Adams about a new Whitakers chocolate bar. Which I refused to do. I said, 'I'm not doing this'. I was encouraged to do it. I said, 'no I'm not'. I didn't do it. Someone else did. The next morning, I was told that it was the second-most read story on the sports page. My response was 'that doesn't make it right'." (R7)

The second example involved a 'news tip' from an anonymous source that the news desk asked the respondent to chase up. The reporter's frustration, however, was evident at the lack of journalistic scepticism from the news desk:

"I used to get frustrated with Sonny Bill mania. We used to get some crazy wild goose chases. I remember one specifically where someone rang me on a Friday evening (before a Super Rugby game) and said they'd been given a tip that Sonny Bill had signed with the Miami Dolphins in the NFL and that he was going to be one of the highest paid players in the NFL. So, I ran through some obvious pieces of information with them:

Reporter -- What position would he play?

Desk - I don't know

Reporter -- How much do you think the highest paid player in the NFL earns?

Desk -- I don't know.

Reporter -- Well it's Tom Brady and he earns $\$ 20$ million a year. Do you really think they're going to pay Sonny Bill Williams that much money when he has never played American football and nobody in America knows who he is?

Desk -- Oh, but we've been told this. Someone has heard this at Jonah Lomu's gym. 
"That was just so unrealistic (a request) I thought l'd make myself look like an idiot if I even asked the question. I'm sure that maybe 1 in 100 times they might come off and they could be a cracking yarn, but the hysteria around certain things that are so unrealistic, you ask why am I chasing this? You can't win." (R8)

Chartbeat, however, has also demonstrated the gap between what journalists think readers should know and what they are reading. Respondents all spoke about having stories that they considered to be journalism in the public interest being ignored by readers. Some were in-depth investigative pieces (R15), others were stories about poor governance at sporting organisations like the issues with New Zealand Football in 2018 (R14), while others involved considerable effort by the reporter and collaboration with multi-media colleagues to package the story in a way that would attract readers (R3). They were basically ignored by readers in comparison to "quirky" international stories that had no actual link to New Zealand sport (R15) and editorial managers would argue that such 'public good' stories may have been wasted time and money:

"I can look at something and say, well that's a bloody good piece of sports journalism. It's taken three weeks. The end product is really good. It's all really meaty and something you would think people need to know. But no-one reads them. It can be quite dispiriting. But the flip side is that (Sunday Times rugby columnist) Stephen Jones writes a column about the All Blacks, you spend 15 minutes writing it up and it's the most read story of the day." (R14)

Another outcome of chasing clicks has been the increase in 'new' forms of journalism tailored for digital platforms. Respondents all said that rolling blogs, pioneered by The Guardian for the soccer World Cup in France in 1998 (McEnnis, 2016), were now essential for 'live' news events and matches. The rolling blogs typically involve reporters watching the events off television and providing rolling play by play action and short analysis. McEnnis (2016: 971) argues, the rolling blog "encourages lengthy or repeated visits and is cheap to resource". While there was resistance to rolling blogs as "not being journalism", editorial managers "had said that it is journalism in 2018" and they were designed "to reach as wide an audience as possible" (R14). 
Rolling blogs, and inviting comments on stories, also provide for an element of interactivity between journalists and readers. While newsrooms were more sensitive to what their audiences are reading and thinking (Usher, 2013), the practice of interactivity with readers created issues, particularly on the New Zealand sports pages. Respondents who had moderated rolling blogs mentioned levels of abuse amongst fans was high and the feedback was often partisan and negative (R7, R9, R13), something McEnnis (2016) also found. Several respondents questioned the value of this type of engagement and also suggested that because metrics were now influencing editorial news judgement there was a danger in allowing readers who were "more than likely unable to tie their own shoelaces" (R7, follow-up conversation) that much power over the news agenda:

"It (feedback) attracts imbeciles' 99 percent of the time. It's attracting comments from people who should really be doing something else with their time. They're typing meaningless drivel, whether it's just to gain attention or feel as if they're important. ... If one percent of the comments were insightful and added any sort of value to the story or whatever it was l'd be surprised. It was basically talkback for people with keyboards. ... Unfortunately, that's the 'in thing' now. We have to have these idiots think they're wanted and valued." (R7)

"If you let most New Zealanders have their own opinion, most of them are wrong." (R11)

These comments only serve to highlight the dominant newsroom culture that journalists are 'insider experts' and they still felt it was important to maintain their gatekeeper role and "the need for internal controls on professional practice" (Singer, 2003:152). A similar attitude towards bloggers has also developed amongst mainstream print news media journalists who recognise that blogs have become competitors for sports news. Sport journalists, however, believe that blogs are not subject to the same journalistic practices such as fairness and balance and do not adhere to the professional standards of journalism even if they have adopted the same "professional values, norms and practices" (McEnnis, 2017:550). Respondents, however, all said that metrics were showing that commentary or opinion pieces were becoming increasingly important to the digital platforms (R1, R3, R7, R9), while speculative, open-ended news stories were also proving popular. One respondent 
suggested that these 'new' news forms may not be that different from what many people would be considered blogs:

"We unquestionably place more emphasis on opinion pieces. They get clicks, particularly if they have a strident headline.... the amount of opinion pieces might be a long way from the sensibilities of (traditional journalism) but that has been a huge change. We run a hell of a lot more speculative, open ended pieces. There used to be a mantra in journalism that you don't ask a question that you can't answer but now we'll sometimes devote entire stories to a single question that can't be answered. 'Is Dan Carter in terminal decline?' We just run open-questioned articles that would have never happened (previously)." (R3).

While the routines of newsgathering have essentially remained the same within Fairfax and NZME sports departments, the digital environment has affected the operation of newsrooms and newswork. Journalists have become increasingly desk bound due to the news value of urgency and reducing their agency and autonomy over their newswork. Opportunity cost calculations are also made by editorial news managers as to what resources should be committed and what type of stories written. Tools like Chartbeat have also further intensified the audience commodity, which only serves to reinforce the digital-first model adopted by Fairfax as they transition to a digital marketplace that also happens to provide news.

\section{The contested space}

The backdrop of increasing conflict between sports and print news media organisations frames the final section of this discussion. It will focus on what I have termed the contested space between the two institutions, the continuing battle to shape and control the news agenda, which has only intensified in the last two decade and the recent development by sports organisations to use digital distribution platforms to compete directly with New Zealand's print news media organisations. The most recent focus of conflict has been around the capture and use of video particularly on the websites of Fairfax and NZME. Sky TV have excluded digital competition emerging in New Zealand by bundling the broadcast rights into their content agreements, allowing them the control over the broadcasting of events on digital platforms (Scherer 
\& Sam, 2012). Threats by broadcasters to reduce the value of the contracts (Hutchins \& Rowe, 2012) has undoubtedly also played a part in the heightened tensions between sports and print news media organisations.

\section{Controlling the media}

Typically, New Zealand sports organisations attempt to exert control over print news media organisations in two ways. The first is to use the carrot of accreditation (Sugden and Tomlinson, 2007:50). Accreditation entails sports organisations limiting the access to live sports events and to some extent news gathering opportunities like media conferences to journalists who have undergone a formal application process. The process, however, can involve an assessment of the journalist's value to the sports organisation by seeking such information as the media organisations readership, whether it has a website, whether the journalist has social media accounts (and even asking for the number of followers) and by determining what category (print, news agency, digital, photographic and non-rights holding radio and television) the journalist belongs to. The process allows sports organisations to determine whether the organisation has sufficient reach and brand recognition to not only ensure coverage goes as far and wide as possible but also to help legitimise the event (Grimmer, 2017). As part of this process, journalists agree to certain terms and conditions (T\&Cs), which have in recent years have become increasingly restrictive (R1, R14) and been the root cause of conflict. Most respondents indicated that if there was a dispute then these were typically handled at the institutional, or in disputes with global organising bodies like World Rugby or the International Cricket Council, the industry level (R1, R9, R14, R16).

The imposition of T\&Cs the print news media deemed too restrictive has seen a backlash within New Zealand. Both NZME and Fairfax had issues with the Rugby World Cup in 2011 and the 2015 Cricket World Cup, both of which were held in New Zealand (R1, R14). These disputes only served to highlight the structural tensions between the sports and print news media organisations in the digital environment. The print news media argued sports organisations were trying to seize total control of the news agenda and to dictate the form of editorial news content and restrict how it was distributed: 
"We were delivered rights contracts that would have limited what we could cover for an Olympics, or a World Cup or a cricket World Cup and we refused to sign those contracts. Everyone started talking to each other about what was going on. We got organised. It was a censorship argument. We don't want to be censored. You are trying to prevent coverage of your sport so we're not going to cover them." (R1)

\section{Case study: 'Boycotting' the Rio Olympics and its effects on sports news coverage}

This conflict over the commercial value of broadcasting live sporting events was highlighted by a dispute ahead of the 2016 Rio Olympics. Typically, the International Olympic Committee (IOC) designates the responsibility of accrediting journalists to each country's National Olympic Committee. In this case, however the NZOC handed media accreditation responsibilities to Sky TV, who had obtained the broadcast rights for New Zealand and attempted to impose T\&Cs the print news media refused to agree to.

In July 2016, Fairfax announced that they would not be sending any sport reporters or photographers to cover the 2016 Rio Olympic Games, which were scheduled to begin on Aug. 5, a little more than two weeks later (Fairfax Media, 2016). The decision was made after "months of negotiations" (ibid) with NZOC and Sky TV, over rights to access, use of video on websites and even criticism of Sky's commentators by the media (ibid). It was a landmark decision in the history of New Zealand sports journalism. An elite New Zealand sports team, funded by the taxpayer to the tune of more than NZ\$30 million a year (High Performance Sport New Zealand annual report, 2018), and one of whose goals as signatories to the Olympic Charter was to publicise the team and promote sports participation, was going to be boycotted by the print news media.

Both Fairfax and NZME argued the terms and conditions for accreditation restricted their rights to provide coverage, with Fairfax's Boucher critical that the T\&Cs had been seemingly written by a competing media organisation: 
"It is unacceptable that a broadcast rights holder should have been given so much power to control how its competitor media organisations get to report on an event of such national and international significance." (Fairfax Media, 2016)

NZME's Currie was equally strident, claiming the T\&Cs did not comply with the fair dealing provisions of New Zealand's Copyright Act, which set out the rules regarding the use of copyrighted material in news reporting. Currie added that no-one was trying to undermine Sky TV's exclusive broadcast rights, but they were "fighting to uphold the principle of editorial freedom and our right to bring news coverage of the Games to our readers" (NZME, 2016).

The 'boycott', however, only extended to sending editorial staff to Rio. Coverage was still produced from 'off-site' in New Zealand, with reporters watching the broadcasts provided by Sky TV - and writing event-based stories off the feeds, while conducting interviews via telephone or email or writing stories from audio files emailed by freelancers or NZME radio reporters in Brazil. According to the New Zealand Herald's Dylan Cleaver in an interview with Radio New Zealand in early 2018, their online readers did not notice any difference:

"Our numbers were spectacular during the Olympics and it was built around live blogs, quick hits, Chris Rattue analysis type columns .... The traffic to the website was amazing and we weren't giving them anything beyond what they could probably see for themselves on TV, but we might have been putting on some flair or a little bit of icing and the occasional hard-hitting column... That scares me a little bit." (Peacock, 2018)

What the dispute demonstrated was that print news media organisations could adequately cover big events without being physically present. Readers, it appears, did not notice any difference in the online coverage, or more worryingly for respondents did not care:

"During the Rio Olympics the biggest (most clicked) story was about a Japanese pole vaulter who knocked the bar off with his penis. The second biggest story was about a Japanese pole vaulter, who may not have knocked the bar off with his penis but with something else. That tells you an awful lot 
about your audience but not exactly what you want to hear from your audience." (R2)

Fairfax respondents also indicated that their coverage had not suffered by covering the Games remotely (R7, R12, R14, R15). This only served to highlight the tension between taking a stand on 'principle' while also having to deliver editorial content of the event. If the principle was to boycott the event, then both organisations should have not provided any content about the Olympics at all.Statements from Currie, who said the decision had not been about cutting costs (NZME, 2016) also rang hollow with most respondents:

"In my view they used the impasse with Sky as a way of saving money. They figured they could take it all off TV and no-one would need any in depth stories. Their (digital) numbers were sky high from Rio where they didn't have one person on the ground and they were covering it off TV." (R7)

The dispute also served to highlight the print news media's belief that sports was not only news, but international sporting events were cultural public goods that contributed to the national identity and did not 'belong' only to sports organisations (Hope, 2002). It also highlighted a three-way institutional tension between print news media organisations, sports organisations and commercial rights holders, particularly in the digital space, with SKY flexing their financial muscles more aggressively than they had in the past:

"The people who pay for the rights will have a big say in it (control over coverage). I can kind of see their point, but media should be able to cover it in a fair way with full access. They do have an obligation (to the public) that everyone should be able to see the event. ... If you're poor (and can't afford pay TV) then journalists should be able to provide information unencumbered." (R12)

One respondent also suggested that Sky's monopsony power in 2016 and seizing control over the accreditation process was a chance to lay the groundwork to stave off future threats from digital competitors, like Amazon Prime or Spark Sport, who have 
now entered the sports content marketplace and have the financial resources to compete for the rights:

"The thing that pisses me off, because it still happens, is that the NZOC and Sky agree a broadcast deal with news access terms and the (print news) media get delivered it, 'these are the rules that you need to abide by'. Sky set those terms and conditions. And the NZOC have admitted that. During that whole process they said, 'you have to sort this out with Sky directly'. Well no. You're the national body. You sort it out with Sky, we'll sort it out with you. We said that we weren't going (to Rio) because of this, this, and this, get it changed. And they just said, 'no we can't do it' and washed their hands of the whole thing and said, 'it's between you and Sky'. So, you're basically asking two competitors to agree on something. It's like two parents turning up to court to sort out custody and the judge saying, 'sort it out yourselves'. It's just staggering ... we get these rules forced upon us that have been designed by television companies to shut everyone else out." (R14)

The second way in which sports organisations have exerted control over the media has been through the adoption of public relations strategies that limit the access to players, athletes and administrators for media interviews. Compared to the rest of the Western world, New Zealand has a relatively young domestic professional sports industry, with the advent of professional rugby in 1996 seen as a major catalyst in its development (Scherer \& Sam, 2012). Respondents recognised the professionalisation of sports had made a massive impact on their access to sports teams, with many stating that within their working careers they had previously been to be able to contact players directly, simply by ringing them on the phone $(R 3, R 4, R 6, R 7, R 8, R 10, R 12$, R15) for an interview. This access has all but disappeared, with one respondent acknowledging that while they could still ring players directly, there was also the strong chance the player would decline to talk and then contact the team's media manager to tell them of the approach, with the suggestions of sanctions, like limiting access or cutting off the flow of information (R10).

At the high-performance end of sport in New Zealand, teams have also become highly restrictive of access to athletes, administrators and coaches. Typically, they may have 
only two or three 'media windows' available each week, where players or coaches are ushered into 'all-in' media conferences and made available for interview for a short period of time of normally five to eight minutes (Garrison \& Sabljak, 1993; Anderson, 1994'; Koppett; 1994; Fensch, 1995; Lowes, 1999). These windows are also moderated by media managers (R14) and are seen by sports organisations as an opportunity to set the media agenda (Sherwood \& Nicholson, 2017). It also provides a homogeneity of coverage and little diversity of voices, while players have also been trained to speak without saying anything:

"It's all group scenarios, you don't get to choose who you talk to. It's harder to get any access. It's far more clinical the whole process. Harder to get colour out of athletes." (R12)

Respondents recognised the sports industry was not homogenous and there was a hierarchy of sports (Sherwood \& Nicholson, 2017) within New Zealand. Due to its prominence as New Zealand's national sport, respondents recognised that rugby held the most power when it came to media coverage and their ability to control and adhere to a planned public relations process ( $R 2, R 3, R 7, R 9, R 12, R 13)$. Such was the level of control exerted by New Zealand Rugby (NZR) one respondent jokingly described it as "the Kremlin" (R2). That power imbalance allows NZR to typically now determine what players appear at the media conferences, with requests for one-on-one interviews, which can help print news media organisations differentiate themselves from their competitors and break the homogeneity of coverage, needing to be "justified" (R13). This practice has filtered down to the lower-levels of professional rugby, with Super Rugby team media managers now determining which players are made available in the various media windows with a diminishing regard for requests:

"Let's face it the All Blacks of 1960 would have not been easy to deal with either, but sports teams now are very, very closely guarded. I used to be able to ring players directly, or have it organised through the media guy. That doesn't happen now. You get what you're given on any particular day. The players have all been trained to say or give you nothing." (R7) 
Respondents all acknowledged that the other dominant sports in New Zealand cricket, rugby league, soccer and netball - had adopted similar tactics in terms of control of access and opportunities. Their prominence is undoubtedly because they have become so deeply embedded in the national culture that news organisations have deemed them 'newsworthy'. Respondents, however, all recognised they were also battling for attention and space with rugby, and that they were more amenable to requests from the media ( $R 2, R 4, R 8, R 10, R 13)$ because: "they don't get coverage regardless; they're all competing for exposure" (R10). Respondents, however, acknowledged that even "lower-tier" sports (R13) were adopting similar tactics by refusing to engage with sports journalists unless it was first filtered through media managers and followed the goals of carefully-constructed public relations plans to try and maximise exposure and minimize damage to the organisation's brand value or reputation.

"Sports organisations are obviously more sceptical of the media because we're always chasing the big stories. We don't do the ground work - we might not cover the squad naming of the New Zealand hockey team but have a whisper of something else that would be a good story so your contact with them is always around stories they don't want (to get out)." (R14)

The increased level of control of access to sports organisations could, however, be counter-productive in the digital environment. The same respondent recounted an example of a high-participation sport that receives low visibility in the print news media complaining it was not receiving enough coverage. This tension between the print news media and sports organisation highlighted the naïve belief that some sports bodies and administrators hold in expecting that the media's role is just to promote their sports:

"They are all difficult to deal with. They don't release information, they're not proactive, they basically see us as just writing about their sport and writing these puffy pieces about their national leagues with nothing in return. We're at complete opposite ends of the scale." (R14) 
This tension between sports organisations, who arguably see journalism as a promotional activity, and journalists who do not, leads to a second related factor as to why sports organisations implement public relations strategies and attempt to control the news media's access and the media agenda. The media's role is to challenge authority, question people who spend taxpayers' dollars and use their access and gatekeeping roles to ask questions on behalf of the public (Schudson, 2011). All the respondents stated that they took these responsibilities seriously. Their primary goal was to uphold the normative Fourth Estate principles (Salwen \& Garrison, 1998; English, 2017) and "hold truth to power" (R2), "shine the light on things that needed to have light shone on them" (R6) and to do this by reporting "without fear or favour" (R3). They also had "a responsibility to provide factually accurate information" (R9) and "to cut through all the horseshit that is talked and isn't just bought and eaten by all the halfwits" (R13):

"We need it (journalism) to curb the excesses of human nature. History has proven that over and over again. If you don't have an active and effective media, there would be a hell of a lot more corruption and society would be a lot more worse off." (R6)

Despite there being a symbiotic relationship between sports and news media organisations, there has always been a power imbalance, titled in favour of the sports organisations. In the digital age, as Hutchins and Rowe (2009) argue there is now a 'plenitude' of providers of sports information and broadcast rights holders have fought to guard those rights, including controlling the point of access to, and to a certain extent editorial content from, sporting events. Sports organisations

In conclusion, respondents identified that sports organisations have competing institutional tensions when it comes to their relationships with the media. They want to be as receptive as possible and try and generate interest in their sports and events. However, they also are extremely protective of their property rights and revenue streams and therefore attempt to control the media agenda by developing public relations strategies that restrict media access, which has only been intensified in the digital environment. Print news media organisations, facing economic pressure, however, have cut back their resources and coverage and it is apparent that sports 
considered further down the pecking order that do not 'help themselves' will not get any coverage at all in the digital environment.

\section{Competing with the print news media}

While sports organisations attempt to control access and the media agenda by accreditation and public relations tactics and strategies, they have also started to compete with the mainstream news media. Sports organisations have established their own websites or use social media platforms like Facebook and Twitter, to disseminate information directly to fans and bypass the mainstream news media. In 2015 English soccer side Swindon Town banned all media access, except that which was mandated by the Football League, and chose to use their website and social media platforms to provide content produced by an inhouse journalist to communicate directly with fans (Rawlinson, 2015a). While the policy, or experiment lasted less than a year, Sherwood and Nicholson (2017:514), found that it was a harbinger of the potential for a sports organisation to cut off outside media access all together in favour of delivering its own news.

Since the turn of the $21^{\text {st }}$ century, North American professional sports leagues all have reporters assigned to cover each of the clubs and provide content for their leagueowned websites (Mirer, Duncan and Wagner, 2018). This has also occurred in Australia, where reporters are attached to clubs for the domestic Australian Rules AFL competition and for rugby league's National Rugby League. Cricket Australia and Rugby Australia have also recently employed journalists to boost the editorial content on their websites, creating some concerns for respondents in terms of the global trend:

"The growth of something like nrl.com makes me wonder if they will become more influential. I read somewhere that nrl.com was sending someone to cover the Kiwis play their (rugby league test) series in England. No news organisation in New Zealand or Australia would even consider that." (R12)

Respondents, however, did indicate that there was yet to be a similar development in New Zealand, with few sports organisations operating as competing sports 'news organisations' (R2, R3, R4, R6, R9, R10, R12). NZR's website www.allblacks.com was 
considered the closest approximation to international examples $(R 2, R 3, R 4, R 7, R 9$, R12, R15). Respondents, however, were ultimately dismissive of the website as a legitimate competitor at present, with one stating that while they could be an issue in the future, they "were a long way from" (R3) bypassing the media as a competing news organisation, while another labelled it as "pathetic" (R9).

Respondents argued that trust was a reason why sports organisation's websites were not competitors to the mainstream print news media (R3, R9), something also outlined by (Boyle \& Hutchins, 2012). Legitimacy, something that Mirer, Duncan and Wagner (2018) also discovered in their analysis of credibility of in-house content on North American sports organisations' websites was also seen as a factor. Much of the sentiment was based on their perceptions that sites like allblacks.com were simply tools used by the public relations departments of sporting organisations and a "cheerleading device" (R9). Another respondent argued that he felt readers were keen on sticking with mainstream media as their primary sports news sources:

"I still don't see them as competitors because it comes back to what I was saying about sports reporters being seen as an authority, who can form opinions and who can break news about a sporting body. All of that, you won't get from the sports organisation, but you will from the media organisation. Diehard readers are not silly. They know that sports organisations will put out information that is favourable to them. If they go to a trusted media organisation they know they will get critical analysis." (R10)

Despite the respondents' arguments that readers are more likely to go to print news media for their sports coverage (R10, R12), there was recognition of the threat to their own commercial model. A number felt that sports organisations may not have yet quite realised their competitive advantage (R2, $R 3, R 12)$ but, when they did, it could be an issue for the print news media:

"When they go on tour they can operate a closed shop. If you don't have a Fourth Estate to temper that or keep tabs on it, you can pretty much stake your (own) territory. That's definitely on the move. I don't know if they realise what they have got." (R2) 
While respondents felt, at present, that New Zealand sports organisations website were not serious competitors for news, most labelled the competing print news media organisation (Fairfax or NZME), TVNZ, Newshub (TV3), Radio New Zealand, or specialist sports websites like cricinfo.com as their main competitors for editorial content. However, they did recognise the websites were now part of the sports organisations' public relations armouries that could be used to increase the battle over mediated content. Respondents recognised the access to players by the sports organisation's websites was unlimited (R2, R3, R7, R8, R12, R15) as their reporters and videographers could provide content that no-one else had access to:

"They're trying to create their own platforms and audiences and don't need the traditional media. I had a conversation with a (organization redacted) board member the other day and they admitted that they're trying to build their own channels and their own outlet, so they can make sure they put out what they want to people." (R15)

While the major sports organisations in New Zealand have not embraced the digital space to the same extent as sports organisations overseas, the structural pressures facing print news media companies have played a part in sports establishing their own websites and online presence. Minority sports coverage has all but disappeared, while Fairfax's shift of the editorial model from local to national news focus has also reduced the opportunity for local clubs and competitions to achieve any coverage at all. This even caused some concern at NZR, with the governing body getting "all antsy" (R14) because the amateur provincial competitions and club rugby were no longer being covered regularly. There was also institutional tension evident with the respondent asking: "what do they give us in return?" (R14). Respondents therefore acknowledged it was not a surprise that more sports were moving to the digital space to provide information about their events and athletes:

"I think the smaller sports, if you're not getting that information anywhere, do you go to, say Triathlon New Zealand to see what Andrea Hewitt is doing? You probably do, because it's your only option." (R12) 
Allied with the public relations tactics, there is a growing institutional tension over who owns the news. Sports organisations have begun to use their own media channels to 'break news' before it released to the media in the form of media statements or press releases. Even run-of-the-mill news announcements like player contract signings and team announcements for upcoming fixtures are often issued as tweets with links to the organisation's website or Facebook pages where the statement or stories have been pre-written and loaded before the news has even been distributed to the print news media via email. One respondent, however, suggested that, once print news media companies shifted to digital-first, it had forced the hand of the sports organisations to adopt a similar tactic:

"When ... we had a bit of a monopoly we'd get given information by sports organisations under embargo and it was considered 'print first'. When we went digital first we gave up that right. The sports themselves realised they could do it themselves and put it out on their own channel." (R15)

An extension of this tactic has been the embargoing of statements or announcements until a certain time of day. Print news media organisations routinely adhere to embargoes, not just in sports but in also general news, politics and business, but by releasing the statement under embargo, the sports organisation could potentially still release the information on their websites before the embargo time. While there is nothing to stop the print news media companies then using this information from the website, the underlying suggestion is that there could be repercussions in future for 'breaking the embargo'. This kind of 'punishment' is a rarity in New Zealand, but it has happened when in 2014, TVNZ were accused by NZR of breaking an embargo of an All Blacks' team announcement and were banned from doing a live cross inside the ground during the $6 \mathrm{pm}$ news on the Saturday shortly before kick-off of the test match (personal conversation with TVNZ reporter). These tensions have led to a further sense of distrust from respondents towards sports organisations, but also highlighted the continuing imbalance of power in the previously symbiotic relationship:

"There is a bit of frustration and tension there...I am probably warier of the sports organisations because we are not what we used to be to them. We used 
to be quite important in terms of getting their message out, but we're not any more. We're just not as important to them anymore." (R15)

While the international experience has demonstrated the digital environment has allowed sports organisations to move into the digital space and become 'quasi-news' organisations, there has not been the same type of penetration within New Zealand. Sports organisations still see value in disseminating information to the media for distribution. Sports journalists, however, remain sceptical of the I of the 'journalistic' value of sports organisations' websites, while international research has indicated, trust and legitimacy are also an issue for readers. Much of the journalistic scepticism of the websites of the top-tier of sports organisations appears to be that they are merely public relations tools and a further way to control access and to try set and manage the news agenda. These responses indicate that despite the criticism by media sport scholars there is still an adherence to Fourth Estate principles amongst New Zealand sports journalists. Top-level sports organisations, however, still hold considerable power over the journalistic process. Underlying tensions, which are likely to only be exacerbated if prints news media organisations feel they have encroached too far into the digital news environment still remain. And as one respondent suggested, his organisation was likely to walk away from covering that sport altogether if that happened (identifier redacted at request of respondent). 


\section{CONCLUSION}

The intertwined structural pressures of financialisation and digital convergence have disrupted New Zealand sports journalism. The analysis showed that in many respects New Zealand's experience is no different from that seen internationally. It also demonstrated there is significant complexity within the current print news media environment as the companies grapple with their transition towards a digital future. Strategic decision making is influenced by several competing forces and cannot be attributed solely to financial pressure or the influence of digital technology.

Both Fairfax and NZME have been placed under financial pressure by their corporate owners as they have attempted to transition from a print-focussed environment to a digital one. There are many similarities in how they have adapted to these structural pressures, with both companies cutting costs and staff numbers to achieve the financial targets set by their board and owners. Both have adapted technology to not only allow them to cut costs and provide return on investment, but also to change the focus of their distribution platform from print to digital. Technology did not force them to do so, it became a tool from which they could best adapt to their changing environment.

Fairfax and NZME, however, have also reacted differently which demonstrates the benefits of adopting an institutional political economy approach to analysing how digital has affected sports journalism within print news media in New Zealand. Fairfax's sports department, for instance, has been restructured into a national news-gathering operation, with journalists operating along the lines of a national bureau organisation. Coupled with this move has been an editorial strategy to 'nationalise' sports stories, a decision that respondents indicated had only served to accelerate the fall off in newspaper readership amongst the provincial daily newspapers, highlighting a neverending death spiral for them. It also served as an indicator of the reduction in the local public sphere within regional New Zealand.

NZME's sports reporters at their flagship New Zealand Herald have been organised into one news-gathering operation, eliminating barriers between the daily and weekly newspapers and digital platforms. There was also a greater emphasis on multiskilling across their print, digital and radio platforms with reporters expected to be able to 
provide content for all three distribution channels as they made job cuts across the board.

Despite the rhetoric of editorial management of their desire to multi-skill journalists, the 'all-singing, all-dancing backpack sports journalist' is yet to emerge in New Zealand. Both NZME and Fairfax's journalists are still text focussed, even if that content is platform neutral and distributed to both print and online. The planned convergence proved far too difficult to achieve, especially when faced with the reduction in headcount and increased intensity in the news cycle. The fact neither Fairfax nor NZME were able to achieve a complete transition to a fully-fledged converged news operation only serves to highlight the power of institutional work routines within the print news media.

At the institutional level, there has been an aspect of technological absolutism in the managerial responses to the changed environment. Editorial news managers at both Fairfax and NZME signalled in 2015 that they were going to adopt a 'digital-first' focus, where the distribution of news content on their digital platforms has taken precedence over print despite (albeit falling) print revenues still driving the economic fortunes of both companies. Fairfax, however, has been far more aggressive in pursuing this digital-first strategy than NZME. Indeed, respondents argued Fairfax had moved too far, too fast. They also felt there was a possibility the print and digital products could have "potentially complemented each other" (R10) and they "could have got a few more years" out of their newspapers if they had not adapted a "one- approach fits-all transformation" (R15). Fairfax's acquisition of various digital service companies has also signalled that it intends to turn itself into a digital marketplace and that journalism will be used to attract readers to this marketplace.

NZME, however, appear to be intent on protecting their newspapers from the same pace of change, possibly because a greater proportion of their revenue comes from newspapers than it does at Fairfax. The New Zealand Herald is still the largest circulation daily newspaper and The Herald on Sunday the largest weekly in the country (ABC audit, 2018). The introduction of a paywall model in late-May 2019 was an indication of their desire to try to keep their newspapers alive for as long as possible: 
"The print audience is getting older and younger people aren't buying the paper, or not as much. The press is dying. But you want to keep a quality product so you can retain that audience for as long as you can. If there are print readers for another 15 years, then that's better than 5 years." (R4)

Digital technology, however, has not been the sole cause of their responses to the changing environment. As Franklin (2008:631) points out, the history of newspapers is one of "editorial Darwinism", where print news media companies have adapted the technological innovations to shape, and react to, changes in their environment. In the late $19^{\text {th }}$ century industrial printing presses, for example, allowed print news media to develop economies of scale and print thousands of copies of the newspaper at lower cost. In the $21^{\text {st }}$ century, both companies have adapted technology to suit their needs. They implemented Content Management Systems to provide a unified editorial input platform, that fed directly into their digital platforms. This allowed both Fairfax and NZME to respond to the pressures of financialisation as they consolidated the subediting, even if staff are geographically dispersed and routinely tele-work (R16), and printing of their newspapers, which enabled both to cut staffing and production costs.

Digital communication platforms have also allowed editors to have an increasingly greater control over the management of the workflow from reporters. While mobile phones and laptop computers theoretically allow reporters to work from anywhere the pressures of the 24/7 news environment have forced journalists to become increasingly office bound. This will no doubt see reduction in the accumulation of social capital between reporters and sources, which has affected news generation and content and potentially lowered the public watchdog role of the print news media.

The transition to a digital environment has also indicated significant internal tensions within both Fairfax and NZME. Journalists believed that decisions by editorial news managers highlighted a confused strategic direction and a lack of foresight or intellectual curiosity as to how print news media organisations could position themselves for the digital environment and, more importantly, monetise it. The inability to grasp the ramifications of the rise of digital intermediaries like Google and Facebook was a source of major intra-institutional tension. There was also resistance to the digital-first absolutism rhetoric, with the decision to give the news away for free seen as reducing the economic value of the newspaper to zero. 
The shifting locus of newsroom power as Fairfax and NZME moved from a print to a digital focus has also been evident. In the early days of the digital transition, even editorial news managers were conflicted, seemingly treating the online platform as something that could be ignored. As the $21^{\text {st }}$ century developed, and the digital-first strategy evolved, greater responsibility and power moved towards the digital editorial operation, creating further tensions over the control of scarce resources and editorial newswork.

Tensions between editorial news managers and journalists also developed as both companies attempted to implement organisational restructuring. Many journalists still felt wedded to their mastheads as their companies moved increasingly towards a digital-first focus. The pressures of financialisation, however, resulted in significant job cuts across both companies, which proved an effective way to negate dissent amongst staff. Those who would not, or could not, adapt were made redundant or resigned. Those who stayed were reminded how tenuous their employment was and "got on board" (R9), albeit somewhat reluctantly. These tensions have not disappeared.

Sports has seemingly been targeted for job cuts within both companies. The reduction in staff has affected the diversity of coverage with so-called 'minority sports' now even further marginalised. The redundancies of all of Fairfax's regional sports journalists in 2017 has further exacerbated this trend so that provincial daily newspapers now have no local sports coverage. Coverage of club and age-grade sport across both companies has also all but disappeared, while even provincial level competition has been drastically reduced. These decisions have lowered both Fairfax and NZME's contribution to the local public sphere and reflection of a national sporting identity and culture.

Financial pressures have also led to editorial operational budgets being slashed, which has had a particularly severe impact upon sports journalism with travel to sports events significantly reduced. Both companies now make a rigorous opportunity cost calculation as to how best to allocate their dwindling resources, with more and more editorial content being generated 'off-site' from sports journalists following it on television. This has also seen a reliance on news subsidies, audio and video files from interviews, press releases, media conferences, being provided by the sports organisations. This could have repercussions for sports journalists' internal battle with 
colleagues and those outside the organisation to be seen to be upholding the Fourth Estate's normative responsibilities.

The cut in travel budgets has also led to the blurring of the ethical lines of the "churchstate' divide that has long existed in print news media companies. While both Fairfax and NZME have typically been upfront about deals with commercial sponsorship that have allowed sports journalists to attend sporting events overseas, respondents indicated that it sat uncomfortably with them. The practice also raised issues of credibility of the news with readers able to ask whether coverage had been 'bought' and the practice is one that could compromise their integrity and brand value.

Demand for content from digital editorial managers has increased significantly while the daily rhythms at both companies have changed drastically. Print deadlines have been moved forward due to the consolidation of printing presses and distribution of newspapers, which has affected editorial output for sports. Time has sped up and condensed. 'Now' is an increasingly important news value within New Zealand's print news media, while local news, news that affects the community where newspapers are based, has become less important and there has been a homogenisation of content across the country.

New Zealand sports journalists also believe that the quality of journalism has decreased, especially the publication of what they term 'public good' journalism. The digitally-focussed environment has also increased the workload on sports journalists at Fairfax and NZME. Staff reductions has led to journalists being required to do more in terms of the production and distribution of news content. Fewer staff means that journalists are becoming 'all-rounders' and stretched thin. The reduction in production jobs has also seen journalists at Fairfax act as their own sub-editors, forcing them to not only produce the content but also oversee its digital distribution - a significant shift in the value chain of the print news media companies.

Turning over a website, or 'churn' is also seen as important to keep readers coming back to websites throughout the day, which means that even routine stories need to be published as soon as possible. These pressures have resulted in a greater need for content from reporters, which has led to increased tensions developing with digital editors, and the belief that stories have now become akin to "fast moving consumer goods" (R2). This has ramifications for the ability of sports journalists to break news 
because they are increasingly desk bound and unable to meet sources or chase down news tips outside of the office, which further endangers their Fourth Estate responsibilities and increases the reliance on news subsidies provided by sports organisations.

The influence of digital analytics has also had significant impact upon the news values and practices of sports journalism in New Zealand at Fairfax and NZME. Readers are now able to heavily influence editorial news judgement, with journalists now asking, 'will this get clicks?' or more appropriately, 'will the digital editors think this will get clicks?' becoming more apparent in their decision whether or not to cover a story. Editorial management use similar questioning when they assess the opportunity cost of devoting resources to stories. If they know that a story is unlikely to achieve a sufficiently high enough click rate, questions will be asked as to the value of producing that story, even those that would be considered in the 'public good'.

Metrics have also seen the introduction of 'new' news forms with Fairfax and NZME designed to attract readers and keep them on the digital platforms without moving away. Rolling blogs of live event coverage "go through the roof" (R8), while opinionbased stories have also become increasingly popular. Both Fairfax and NZME sports journalists complained that at times these new formats were 'not real journalism', further increasing the scrutiny on their Fourth Estate responsibilities and internal and tensions with other institutions.

The prioritisation of clicks has also seen an intensification in the celebrification of news content with Fairfax and NZME, with sports journalism particularly susceptible to concentrating on a small number of athletes with a proven ability to generate clicks. This is a further manifestation of the ways in which news organisations have adapted digital technology to produce their news content. Celebrification, tabloidisation, news as entertainment and dumbing down (Bird, 1990; Ursell, 2001, Thussu, 2008) have all been outcomes of the drive for audience by the commercial print news media for more than 100 years. Data analytics, however, merely gives print news media a better baseline from which to now base their editorial decision making. But, as respondents indicated, the feedback they have received from the analytics and interactivity with readers does not paint a good picture about their audience and raises questions about the future of news. 
The digital environment has also led to increased external tensions at the institutional level between print news media and sports organisations. Control of the news agenda has always been a critical tension between the two industries but, in the digital age, it has intensified, with sports organisations seeking to impose tighter control over their sporting events. They also allow increasingly limited access to athletes, coaches and administrators through public relations tactics and strategies. A further competitive tension has also developed with sports organisations moving into the digital media space by establishing their own websites and using social media to communicate directly with fans.

It is important to note that these tensions were evident before the transition to a digital environment. The subsequent shift in distribution channels by the print news media and the proliferation of digital competitors, however, has seen sports organisations become increasingly aggressive as they look to protect what they consider to be their commercial rights, especially those they have sold to television broadcasters. In short, it is apparent that sports organisations, who espouse to be guardians of the game, believe that sports events are a private good that can be commoditised and sold to the highest bidder.

These long-standing tensions are why sports organisations have attempted to exert a degree of control over the media through processes like accreditation to attend and cover live sports events. These tensions have boiled over in recent years, with the 'boycott' of the Rio Olympics one that is likely to be played out again in the future. The concern for sports journalists from the 'boycott' is that readers did not appear to care about how the coverage was produced.

Sports organisations using digital platforms to control and distribute their news will also undoubtedly increase the tension in an already fractious relationship between the two institutions. What is most apparent is that the future of sports journalism in New Zealand is still clouded. How to adapt to the economic and technological pressures are still being worked out in a messy and rapidly-changing environment and internal and external tensions will still be manifest as they work through these conflicts.

"The future is different content to what we know as traditional sports journalism. It will be more socially driven, discussion driven, reader engagement driven content It's grim for minor sports. The focus will go on big events and the big 
sports because that's all the resourcing will allow for. We would like to be doing what we see as sports journalism in a traditional sense but it's not just viable. ... if you're not adapting you'll be gone. It's sink or swim." (R14) 


\section{REFERENCES}

Advertising Standards Authority Advertising turnover report. http://www.asa.co.nz/industry/asa-advertising-turnover-report/

Allen, Katie (Nov.6, 2007) News agencies threaten cricket boycott in fresh rights battle https://www.theguardian.com/sport/2007/nov/06/cricket.katieallen

Anderson, Chris W. (2013) Rebuilding the news: Metropolitan journalism in the digital age Temple University Press, Philadelphia

Anderson, Douglas, A. (1994) Contemporary sports reporting. Chicago: Nelson-Hall publishers.

Arnold, Alice (March 27, 2013) Ladies: British sports journalism is waiting for you. https://www.telegraph.co.uk/women/womens-life/9955672/Ladies-British-sportsjournalism-is-waiting-for-you.html

Babbie, Earl (2017) The basics of social research (7ed) Cengage Learning, Canada

Barton, Chris (2016) Anatomy of a redundancy: the suffocation of long form journalism in New Zealand in Johnson, Emma, Tiso, Giovanni, Illingworth, Sarah \& Bennett, Barnaby (eds) Don't dream its over: Reimagining journalism in Aotearoa New Zealand Free Range Press, Christchurch, New Zealand pp 144-164

Bell, Emily (March 7, 2016). Facebook is eating the world. Columbia Journalism Review. http://www.cjr.org/analysis/facebook and media.php

Bidwell, Hamish (Nov. 18, 2017) Kiwis halfback Shaun Johnson tells critics 'yous got your way' after World Cup exit. Fairfax Media https://www.stuff.co.nz/sport/league/99023302/kiwis-halfback-shaun disappointednot-to-put-nonbelievers-in-their-place

Bird, S. Elizabeth (1990). Storytelling on the far side: Journalism and the weekly tabloid. Critical Studies in Media Communication 7 (4) pp 377-389.

Boyd-Barrett, Oliver (2009) Theory in media research in Hansen, Anders (ed) Mass communication research methods, Ch. 1. London: Sage. 
Boyle, Raymond, Dinan, William, \& Morrow, Stephen (2002) Doing the business? Newspaper reporting of the business of football. Journalism. 3 (2) pp 161-181.

Boyle, Raymond (2006) Sports Journalism. Contexts and issues Sage Publications: London

Boyle, Raymond (2012) Reflections on Communication and sport: On digital journalism and culture. Communication \& Sport 1 (1) pp 88-99

Brennan, Bonnie (2017) Qualitative research methods for media studies (2ed) Routledge: New York.

Briggs, Asa \& Burke, Peter (2009) A social history of the media. From Gutenberg to the Internet (3ed) Polity Press: Cambridge

Buchanan, Rachel (2013) Stop Press. The last days of newspapers Scribe Publications, Melbourne

Business Day (Feb 21, 2013) Fairfax mastheads go 'compact' not tabloid https://www.smh.com.au/business/companies/fairfax-mastheads-go-compact-nottabloid-20130221-2et9r.html

Business Desk (June 27, 2014) APN to print Fairfax newspapers https://www.nzherald.co.nz/business/news/article.cfm?c id=3\&objectid=11283056

Cairncross, Frances (Feb. 12, 2009) A sustainable future for journalism Department for Digital, Media, Culture \& Sport https://www.gov.uk/government/publications/thecairncross-review-a-sustainable-future-for-journalism

Chapman, Jane (2005) Comparative Media History Polity Press: Cambridge

Chyi, Hsian Iris, Lewis, Seth, C. \& Zheng, Nan (2016) Parasite or partner? Coverage of Google News in an era of news aggregation. Journalism \& Mass Communication Quarterly 93 (4) pp 789-815

Clarke, Andrew (May 7, 2009) News Corp will charge for newspaper websites says Rupert Murdoch https://www.theguardian.com/media/2009/may/07/rupert-murdochcharging-websites 
Cohen, Nicole (2015) From Pink Slips to Pink Slime: Transforming Media Labor in a Digital Age, The Communication Review, 18 (2), pp 98-122

Cohen, Nicole (2018) At work in the digital newsroom Digital Journalism, 10 pp 1-21

Croot, James (Mar. 21, 2018) Stuff Pix: New pay-per-movie streaming service launches into New Zealand market https://www.stuff.co.nz/auckland/whatson/entertainment/102438002/Stuff-Pix-New-pay-per-view-movie-streaming-servicelaunches-into-NZ-market

Dart, Jon (2014) New media, professional sports and political economy Journal of Sport \& Social Issues 38 (6) pp 528-547

Davies, Anne (Nov. 27, 2018) Fairfax Media and Nine given court approval to merge on 7 December https://www.theguardian.com/media/2018/nov/27/fairfax-media-andnine-given-court-approval-to-merge-on-7-december

Davis, Aeron (2000) Public relations, news production and changing patterns of source access in the British national media Media Culture Society 22 (39-59)

Daum, Evan \& Scherer, Jay (2017) Changing work routines and labour practices of sports journalists in the digital era. A case study of Postmedia. Media Culture \& Society pp 1-16

Deuze, Mark (2005) Professional identity and ideology of journalists reconsidered Journalism 6 (4) pp 442-464.

Drinnan, John (Sept 7, 2012) Final farewell to broadsheet Going to compact size, reporters to to tighten their writing. https://www.nzherald.co.nz/business/news/article.cfm?c id=3\&objectid=10832241Dri $\underline{\text { nnan, }}$

Edmunds, Susan \& Pullar-Strecker Tom (Feb. 21, 2018) Stuff to sell or close 28 community and rural papers https://www.stuff.co.nz/business/101632830/Stuff-toclose-some-community-and-rural-newspapers

Ellis, Gavin (Sept. 4, 2018), Radio New Zealand interview 
English, Peter (2011) Online vs. print: a comparative analysis of web first sports coverage in Australia \& the United Kingdom Media International Australia 140 (August) pp. 147-156

English, Peter (2012) Caught by the web: The case of Guardian News \& Medias sports desk Journal of Sports Media, 7 (1), pp. 133-148

English, Peter (2015) Indian sports journalisms early online steps into web-first publishing, Media Asia, 42 (1-2), pp 83-94

English, Peter (2017) Cheerleaders or Critics? Digital Journalism, 5 (5) pp 532-548

Espiner, Guyon (July 2, 2016) In the hot seat. NZ Listener (pp23-26)

Fairfax correspondent (July, 21, 2016) Don't criticise our commentators, Sky TV demanded in its Olympic coverage rules https://www.stuff.co.nz/business/82340521/concerns-sky-tv-curtailing-news-freedomsees-fairfax-media-withdraw-rio-team

Fairfax correspondent (Nov. 1, 2017) Stuff now owns 100 pct of Neighbourly https://www.stuff.co.nz/business/98467116/media-company-now-owns-100pc-ofneighbourly

Fairfax correspondent (Dec. 13, 2017) Fairfax Media, nib launch health insurance partnership Done https://www.stuff.co.nz/business/industries/99807252/fairfaxmedia-nib-launch-health-insurance-partnership-done

Farhi, Paul (2008) Don't blame the journalism American Journalism Review 30 (5) (pp14-15)

Fensch, Thomas (1995) The Sports Writing Handbook (2ed) Hillsdale: New Jersey. Lawrence Erlbaum Associates.

Fitzgerald, Scott, \& Winseck, Dwayne (2016) Media Economics: Missed Opportunities, Mischaracterizations. The Political Economy of Communication 6 (1) pp 83-97

Franklin, Bob (2008) The Future of Newspapers Journalism Studies 9 (5) pp 630-641 
Franks, Suzanne \& O’Neill, Deirdre (2016) Women reporting sport: Still a man's game Journalism 17 (4) pp 474-492

Freedman, Des (2006) Dynamics of power in contemporary media policy-making Media, Culture \& Society 28 (6) pp 907-923

French, Simone (2013) Still not there: The continued invisibility of female athletes and sports in the New Zealand print media Media International Australia 148 (August) pp $39-50$

Frey, Lawrence, R, Botan, Carl, H. \& Kreps, Gary, L. (2000) Methodologies for conducting communication research Allyn \& Bacon: Boston

Galtung, Johan \& Ruge, Mari (1973) Structuring and selecting news In Stanley, C. \& Young, J. (eds) The Manufacture of news London: Constable

Garrison, Bruce \& Salwen, Mark (1989) Newspaper sports journalists: A profile of the profession. Journal of Sport and Social Issues, 13 (2). (pp57-68)

Garrison, Bruce. \& Sabljak, Mark (1993) Sports Reporting (2ed) Ames, lowa: lowa State University Press.

Garrison, Bruce \& Salwen, Mark (1994) Sports journalists assess their place in the profession. Newspaper research journal 15(2). (pp37-50)

Google Images - Underpants gnomes business plan image

https://www.google.com/search?rlz=1C1CHFX en-

GBSG586SG586\&biw=1525\&bih=888\&tbm=isch\&sa=1\&ei=Sb8RXanGGOXiz7sP C y08A0\&q=underpants+gnomes+south+park+ripped+body\&oq=underpants+gnomes+ south+park+ripped+body\&gs I=img.3 ...61133.64481..65117 ..0.0..0.189.3090.0j18... ...0....1..gws-wiz-img......0i30j0i8i30j0i24. 5AirP1XMAA\#imgrc=tBhoTfxmIAABMM:

Goldfinch, S (2000) Paradigms, economic ideas and institutions in economic policy change: the case of New Zealand Political Science 52 (1) pp 1-21

Grieco, Elizabeth (2018) Newsroom employment dropped more than one-quarter in less 10 years, greatest decline at newspapers http://www.pewresearch.org/fact- 
tank/2018/07/30/newsroom-employment-dropped-nearly-a-quarter-in-less-than-10years-with-greatest-decline-at-newspapers/

Grimmer, Christoph G. (2017) Pressure on printed press, Digital Journalism, 5 (5), pp 607-635,

Halloran, James (2009) Mass communication research: asking the right questions (Ch.

9) in Hansen, Anders (ed) Mass communication research methods. London, SAGE. (pp 209-228)

Harcup, Tony \& O'Neill, Deirdre (2017) What is News? Journalism Studies, 18 (12), pp 1470-1488

Hardy, Jonathan (2014) Critical political economy of the media: An introduction Routledge: Abingdon

Herman, Edward S. \& Chomsky, Noam (1994) Manufacturing consent. The political economy of the mass media Random House, New York

High Performance Sport New Zealand (2018) Annual report 2018 https://hpsnz.org.nz/about-us/news-media/high-performance-reconfirms-coreinvestment-for-2018/

Hirst, Martin, Hope, Wayne, \& Thompson, Peter (2017) Australia and New Zealand Ch. 21 (pp 351-367) in Birkinbine, Benjamin, Gomez, Rodrigo, \& Wasko, Janet (eds) Global Media Giants, Routledge, New York, New York.

Holt, Amanda (2010) Using the telephone for narrative interviewing: a research note Qualitative Research 10 (1) pp 113-121

Hope, Wayne (2002) Whose All Blacks? Media, Culture \& Society 24 (2) pp 235-253 Hope, Wayne (2012) New thoughts on the public sphere in Aotearoa New Zealand Ch. 1 (pp 27-48) in Hirst, Martin, Phelan Sean \& Rupar Verica (eds) Scooped. The Politics and Power or Journalism, in Aotearoa New Zealand AUT Media, Auckland.

Hutchins Brett \& Rowe David (2009) From broader scarcity to digital plenitude. The changing dynamics of the media sport content economy. Routledge 
Hutchins, Brett \& Rowe David (2010) Reconfiguring Media Sport for the Online World: An Inquiry Into Sports News and Digital Media, International Journal of Communication 4, pp 696-718

Hutchins, Bret \& Rowe, David (2012) Sport beyond television: The Internet, digital media and the rise of networked media sport Routledge: New York

Hutchins, Brett \& Raymond Boyle, (2017) A Community of Practice, Digital Journalism, 5 (5), pp 496-512

Irvine, Annie, Drew, Paul and Sainsbury, Roy (2012) Am I not answering your questions properly? Clarification, adequacy and responsiveness in semi-structured telephone and face-to-face interviews Qualitative Research 13 (1) pp 87-106

Koppett, Leonard (1994) Sports Illusion. Sports reality. A reporter's views of sports, journalism and society. Chicago, Illinois: Chicago University Press.

Lee, Angela M., Lewis, Seth C. \& Powers, Matthew (2014) Audience clicks and news placement: A study of time-lagged influence in online journalism, Communication Research 2014, 41 (4) pp 505-530

Lowes, Mark (1999) Inside the sports pages. Work practices, professional ideologies and the manufacture of sports news. University of Toronto Press, Toronto.

Lowrey, Wilson (2011) Institutionalism, news organisations and innovation, Journalism Studies, 12 (1), pp 64-79.

Manhire, Toby (April 26, 2019) The NZ Herald is about to put up a paywall and the stakes are scarily high The Spinoff https://thespinoff.co.nz/media/26-04-2019/the-nzherald-is-about-to-put-up-a-paywall-and-the-stakes-are-scarily-high/

Matheson, Donald (2004) Weblogs and the epistemology of the news: some trends in online journalism new media \& society 6 (4) pp 443-468.

McBeth. Paul (April 3, 2019) Trade Me shareholders back $\$ 2.56$ billion takeover Business Desk http://www.scoop.co.nz/stories/BU1904/S00122/trade-meshareholders-back-256-billion-takeoveroffer.htm?utm source=The+Bulletin\&utm campaign=8c9a58901b- 
EMAIL CAMPAIGN 20180301 COPY 01\&utm medium=email\&utm term=0 55 2336e15a-8c9a58901b-533756713

McChesney, R.W. (1989) "Media Made Sport: A History of Sports Coverage in the United States" in Wenner, L. (ed) Media, Sports \& Society. (pp49-70) Newbury Park, California: Sage Publications.

McChesney, R. (2008) The political economy of the media. Enduring issues, emerging dilemmas New York: Monthly Review Press

McCollough, J. Brady (Oct. 9, 2018) Sports journalists battle for relevancy. Nieman Foundation for Journalism at Harvard https://niemanreports.org/articles/sportsjournalists-battle-for-relevancy/ (accessed Nov. 1, 2018)

Meade, Amanda (Dec. 6, 2017) Commonwealth Games urged to relax media curbs as Gold Coast boycott looms https://www.theguardian.com/sport/2017/dec/07/commonwealth-games-urged-torelax-media-curbs-as-gold-coast-boycott-looms

McGregor, J (2002) Restating news values: Contemporary criteria for selecting the news. Conference paper presented at 2002 ANZAC conference, Queensland, Australia.

Meade, Amanda (April 4, 2018a) The Commonwealth Games you won't see: 'impossible' kules media away https://www.theguardian.com/sport/2018/apr/04/how-australian-mediascommonwealth-games-dream-became-a-nightmare

Meade, Amanda (July 26, 2018b) Nine Network to take over Fairfax in estimated $\$ 4 b$ deal https://www.theguardian.com/media/2018/jul/26/fairfax-and-nine-network-agreeto-merge-in-estimated-4bn-deal

Meade, Amanda (Dec. 3, 2018c) Almost 150 jobs to go as Fairfax and Nine merger restructure revealed https://www.theguardian.com/media/2018/dec/03/almost-150jobs-to-go-as-fairfax-and-nine-merger-restructure-revealed 
Mirer, Michael, Duncan, Megan \& Wagner, Michael (2018) Taking it from the media. Assessments of bias and credibility in team-operate sports media Newspaper Research Journal 39(4) 481-495

Moritz, Brian P. (2014) Rooting for the story: Institutional sports journalism in the digital age. PhD dissertation, Syracuse University

Mosco, V. (2009) The political economy of communication (2ed) London: Sage

Murdock, Graham \& Golding, Peter (2005) Culture, communications and political economy in Curran, James \& Gurevitch, Michael (eds) Mass media and society Ch. 4 (pp 60-83) Hodder Arnold, London

Murphy, Tim (May 10, 2016) Click here for HeraldStuff.co.nz - on messy media divorces and a newspaper marriage of convenience https://thespinoff.co.nz/featured/10-05-2016/click-here-for-heraldstuff-co-nz-onmessy-media-divorces-and-a-newspaper-marriage-of-convenience/

Murphy, Tim (May 8, 2018) Media firms touch, pause, engage https://www.newsroom.co.nz/2018/05/08/107718/media-firms-touch-pause-engage

Murphy, Tim (April 30, 2019) Hark the Herald paywall https://www.newsroom.co.nz/2019/04/30/559293/hark-the-herald-paywall

Myllylahti, Merja (2015) New Zealand Media Ownership Report 2015 https://www.aut.ac.nz/ data/assets/pdf file/0017/107054/JMAD-2015-Report.pdf

Myllylahti, Merja (2016) New Zealand Media Ownership Report 2016 https://www.aut.ac.nz/ data/assets/pdf file/0020/107057/JMAD-Report-2016.pdf

Myllylahti, Merja (2017) New Zealand Media Ownership Report 2017 https://www.aut.ac.nz/study/study-options/communication-

studies/research/journalism,-media-and-democracy-research-centre/projects/newzealand-media-ownership-report

Myllylahti, Merja (April 30, 2019) How the decision to paywall NZ's largest newspaper will affect other media. The Conversation. http://theconversation.com/how-thedecision-to-paywall-nzs-largest-newspaper-will-affect-other-media-116152 
Neilsen, Rasmus Klaus \& Ganter, Sarah Anne (2018) Dealing with digital intermediaries: a case study of the relations between publishers and platforms new media and society 20 (4) pp 1600-1617

Nel, Francis (2010) Laid off. What do journalists do next? https://www.journalism.co.uk/uploads/laidoffreport.pdf

New Zealand Audit Bureau of Circulation (2018) Press Audit results 2017 http://newspaper.abc.org.nz//audit.html?org=npa\&publicationid=\%25\&mode=embarg o\&npa admin=1\&publicationtype=19\&memberid=\%25\&type=\%25

New Zealand Commerce Commission (May 3, 2017) Commission declines Fairfax/NZME merger https://comcom.govt.nz/case-register/case-registerentries/nzme-limited/media-releases/commission-declines-nzmefairfax-merger

Nicholson, Matthew, Zion, Lawrence \& Lowden, David (2011) A profile of Australian sports journalists revisited. Media International Australia 140 (pp84-96)

NZME correspondent (Sept. 15, 2015) NZME creates world class integrated newsroom

https://www.nzherald.co.nz/business/news/article.cfm?c id=3\&objectid=11514001

NZME correspondent (July 21, 2016) NZ Herald withdraws reporting team from Rio https://www.nzherald.co.nz/sport/news/article.cfm?c id=4\&objectid=11678777

O'Neill, Deirdre \& Franks, Suzanne (2016) A sporting chance for women? Gender imbalance on the sports desks of UK national newspapers Media Report to Women; Winter 2016; 44, 1 p12

Packham, Colin (2017) Australian media wins relaxed ownership laws, but online rivals' threat to stay https://www.reuters.com/article/us-australia-media/australianmedia-wins-relaxed-ownership-laws-but-online-rivals-threat-to-stayidUSKCN1BP100

Peacock, Colin, (July 24, 2016a) Big names in NZ media boycott the Olympics http://www.radionz.co.nz/national/programmes/mediawatch/audio/201809266/rioreporting-reversal 
Peacock, Colin (Feb. 16, 2016b) 70 more Fairfax jobs to go https://www.radionz.co.nz/news/national/296687/70-more-fairfax-media-jobs-to-go

Peacock, Colin (Feb. 11, 2018) Is sports journalism on the ropes? Radio New Zealand Mediawatch programme

https://www.radionz.co.nz/national/programmes/mediawatch/audio/2018630086/issports-journalism-on-the-ropes

Plaschke, B. (Jan/Feb 2000) "The reporter: That's twice you get me. I'm gonna hit you, right now. Right now!" Columbia Journalism Review (online edition http://www.cjr.org).

Plumb, Simon (2015) Aussie media groups to boycott World Cup URL (accessed Oct. 7, 2015) http://www.stuff.co.nz/sport/rugby/rugby-world-cup/5500028/Aussie-mediagroups-to-boycott-World-Cup

Pullar-Strecker, Tom (Aug. 9, 2016) Stuff to enter the fibre broadband market with Stuff Fibre https://www.stuff.co.nz/business/industries/82907984/fairfax-to-enter-thebroadband-market-with-stuff-fibre

Pullar-Strecker, Tom (Jan. 15, 2019) Stuff set for quick sale by new owners https://www.stuff.co.nz/business/109931109/stuff-set-for-quick-sale-by-new-owner$\underline{\text { nine }}$

Pullar-Strecker, Tom (Feb. 6, 2019) Stuff faces possible break-up as NZME readies its wall. https://www.stuff.co.nz/business/110367152/stuff-faces-possible-breakup-asnzme-readies-its-wall

Ralston, Bill (March 5, 2016) Hold the homepage NZ Listener (pp 22-27)

Rawlinson, Kevin (July 14, 2015a) Swindon Town FC bans journalists from press conferences https://www.theguardian.com/media/2015/jul/14/swindon-town-fc-bans$\underline{\text { media-outlets-from-press-conferences }}$

Read, Ellen (May 28, 2015a) Fairfax plans further editorial restructure https://www.stuff.co.nz/business/industries/68938640/fairfax-plans-further-editorialrestructure 
Read, Ellen (June 17, 2015b) Fairfax NZ confirms newsroom restructure URL (accessed Oct. 7, 2015) http://www.stuff.co.nz/business/69469570/fairfax-nzconfirms-newsroom-restructure

Read, Ellen (Oct. 31, 2017a) Fairfax plans to take papers compact https://www.stuff.co.nz/business/98398310/fairfax-plans-to-take-papers-compact

Read, Ellen (March 28, 2017b) Fairfax's Marlborough Express reduces publication https://www.stuff.co.nz/business/90913306/fairfaxs-marlborough-express-paperreduces-publication

Reinardy, Scott (2011) Newspaper journalism in crisis. Burnout on the rise, eroding young journalists career commitment Journalism 12 (1) pp 33-50

Robinson, Sue (2011). Journalism as Process: The Organizational Implications of Participatory Online News. Journalism and Communication Monographs, 13 (3), pp 137- 210.

Ross, Amy. A (2017) If nobody gives a shit is it really news? Digital Journalism, 5 (1), pp 82-99.

Rosenberg, Bill (2008) News media ownership in New Zealand http://canterbury.cyberplace.org.nz/community/CAFCA/publications/Miscellaneous/m ediaown.pdf

Rowe, David. (1999) "Working in Media Sport: The discipline of sports journalism" in Sports, Culture \& the Media. Buckingham, England: Open University Press: Ch 3 (pp36-63)

Rowe, David (2005) Fourth estate or fan club? Sports journalism engages the popular in Allan, S. (ed) Journalism: Critical Issues, Open University Press: Maidenhead (Ch.9 pp 125-137)

Rowe, David (2007) Sports journalism: Still the 'toy department' of the news media? Journalism 8 (4) pp385-405

Rowe, David (2016) Sports Journalism and the FIFA Scandal: Personalization, Cooptation, and Investigation Communication \& Sport 10 (1) pp 1-19 
Ryfe, David M. (2012) Can Journalism Survive? An inside look at American newsrooms Polity Press, Cambridge

Saltzis, Konstantinos \& Dickinson, Roger (2007) Inside the changing newsroom: journalists' responses to media convergence. New Information Perspectives 60 (3), pp. 216-228

Salwen, Michael \& Garrison, Bruce (1998) Finding their place in journalism: newspaper sports journalists' professional problems, Journal of Sport \& Social Issues 22 (1) pp 88-102

Scherer, Jay \& Sam, Michael P. (2012) Public broadcasting, sport and cultural citizenship: Sky's the limit in New Zealand? Media, Culture \& Society 34(1) pp 101111

Schmidt, Hans (2016) Women's sports coverage remains largely marginalised Newspaper Research Journal 37 \&3) pp 275-298

Shaw, Aimee (June 9, 2016) NZME to sell Wairarapa Times Age https://www.nzherald.co.nz/business/news/article.cfm?c id=3\&objectid=11653497

Sherwood, Merryn \& Nicholson, Matthew (2012) Web 2.0 platforms and the work of newspaper sports journalists. Journalism 14 (7) pp 942-959

Sherwood, Merryn, Nicholson, Matthew \& Marjoribanks, Timothy (2017) Controlling the Message and the Medium? Digital Journalism, 5 (5) pp 513-531

Simons, Margaret (April 15, 2017) Journalism faces a crisis worldwide - we might be entering a new dark age.

https://www.theguardian.com/media/2017/apr/15/journalism-faces-a-crisisworldwide-we-might-be-entering-a-new-dark-age

Singer, Jane (2003) Who are these guys? The online challenge to the notion of journalistic professionalism, Journalism, 4 (2) pp 139-163

Singer, Jane (2004a) Strange bedfellows? The diffusion of convergence in four news organisations. Journalism Studies, 5: (1), pp 3-18 
Singer, Jane (2004b) More than ink-stained wretches. JMC Quarterly 81 (4) pp 838856

Sparrow, Bartholomew, H. (2006) A research agenda for an institutional media Political Communication 23 (2) pp 145-157

Spits, Scott (Feb. 26, 2010) News agencies threaten IPL boycott https://www.smh.com.au/sport/cricket/news-agencies-threaten-ipl-boycott-20100226p6qa.html

Strom, Marcus (July 26, 2018) MEAA rejects Nine's takeover of Fairfax https://www.meaa.org/news/meaa-rejects-nines-takeover-of-fairfax/

Sturges, Judith E., \& Hanrahan, Kathleen, J. (2004) Comparing telephone and face to face qualitative interviewing: a research note. Qualitative Research 4 (1) pp 107-118 Sugden, John., \& Tomlinson, Alan (2007) Stories from Planet Football and Sportsworld. Journalism Practice 1 (1) pp 44-61

Sweney, Mark (Aug. 4, 2011) Premier League press coverage under threat https://www.theguardian.com/media/2011/aug/04/premier-league-press-coveragethreat

Trier-Bieniek Adrianne (2012) Framing the telephone interview as a participantcentred tool for qualitative research: a methodological discussion Qualitative Research 12 (6) pp 630-644

Thussu, Daya (2008) News as Entertainment Sage: London

Thompson, Peter (May 3, 2017) NZME-Fairfax merger decision leaves a regulatory challenge https://www.stuff.co.nz/business/industries/92184167/peter-thompsonnzmefairfax-merger-decision-leaves-a-regulatory-challenge

Tucker, Jim (2014) Pressing on. Reinvention of the daily news https://jimtuckermedia.files.wordpress.com/2014/11/pressing-on-july-21-revisedfinal.pdf

Ursell, Gillian (2001) Dumbing down or shaping up? New technologies, new media, new journalism. Journalism 2 (2) (pp 175-196) 
Wasko, Janet (2009) The Political Economy of communication in Hansen, Anders (ed) Mass communication research methods, Ch. 21. London: Sage.

Williams, Alex T (Feb, 29, 2016) How digital subscriptions took over the newspaper industry. American Press Institute https://www.americanpressinstitute.org/publications/reports/digital-subscription-takeoverl

Winseck, Dwayne (2010) Financialisation and the 'crisis of the media'. The rise and fall of (some) media conglomerates in Canada. Canadian Journal of Communication 35 (3) pp 1-365-393

Winseck, Dwayne (2011) The political economies of media \& the transformation of the global media industries in Winseck, D. \& Dal-yong, J. The political economies of media \& the transformation of the global media industries London: Bloomsbury Academic

Winseck, Dwayne (2016) Reconstructing the Political Economy of Communication for the Digital Media Age, The Political Economy of Communication 4(2), pp73-114

Winter, Chloe (Oct. 9, 2017) Stuff buys 49 percent stake in energy firm energyclub https://www.stuff.co.nz/business/97661154/stuff-buys-49-per-cent-stake-inelectricity-firm-energyclubnz

Wojciechowski, G. (1990). Pond Scum \& Vultures. America's sportswriters talk about their glamorous profession. New York: Macmillan Publishing. 


\section{Appendices}




\section{Interview guide/questions}

General biographical info (not for individual publication - just need it for contextual reasons)Age?

Experience?

Education?

Current role?

How long with company? Current role?

\section{Economic decisions}

What was the rationale behind the move to digital?

Did management quantify it? How did they describe it to the staff?

How did you feel? What did your colleagues think (if you discussed it)?

How did/has it impacted the sports desk?

Has the composition of the sports desk changed?

What about resources?

Has it affected the budget/staffing? In what ways? What do you think about that?

What is/was News Rewired? (for FFX reporters only)

Who are your major competitors in the digital environment?

Do you have any concerns about the future of sports journalism in your organization?

Can you outline them?

\section{Convergence}

How did your organisation implement convergence?

What do you understand it to be? 
How do you classify/describe yourself?

What sort of resources did your organisation commit to convergence?

What kind of technological innovation has there been?

Have you been given any training?

What do you see as multiskilling?

How is your newsroom/sports desk now structured?

What was the rationale for this?

Was there resistance or antagonism to the idea of convergence? Or support? In what ways?

Do you and your younger colleagues have different ideas on convergence? (and content?)

\section{Content}

What do you think journalism's role is?

What about sports journalism's role?

What is news to you?

Have news values changed?

What changes have been implemented to meet the digital first strategy?

What is the primary driver when it comes to publication - timeliness or exclusivity?

How is your online content measured?

Does this influence editorial decision making?

What audiences are you now writing for?

What sports/stories are covered? Why? 
Has the digital focus allowed for greater diversity/plurality?

Is there scope for richer and deeper reporting? In what ways is this demonstrated?

Are you encouraged to write differently?

Is there a 'style' you need to adhere to for digital audiences?

Has there been a blurring of the church-state divide in sports content?

Is there a difference in 'quality' between online content and print platforms?

\section{Newswork}

Can you describe your typical day?

Has it changed in the digital environment? If so, in what ways?

Has your role changed? If so, in what ways?

Do you have time?

How has production changed?

Do you write 'fresh' copy for the newspapers?

Is this even possible? (time constraints)

How many stories are you expected to write a day?

How have print deadlines changed?

Are you platform neutral?

Churn v quality - is this an issue?

Is journalism still a solitary endeavour or now more collaborative? In what ways?

Do you have more autonomy in the digital environment?

Do you use social media platforms? In what ways? 
Has digital changed source relations?

\section{The contested space}

Have your relationships with sports organisations changed in the digital environment?

Do you see them as competitors?

Do they see your organisation as a competitor?

Has your organisation been in dispute with sports organisations over anything? (not just Rio). If so, what? And why?

Do sports organisations use the carrot and stick? If so, how is this manifested?

Do sports organisations give preferential treatment to certain media organisations? Or reporters?

And finally, what do you think is the future for sports journalism in New Zealand? 


\section{Click off: How digital has disrupted New Zealand sports journalism}

\section{INFORMATION SHEET FOR PARTICIPANTS}

Thank you for your interest in this project. Please read this information before deciding whether to take part. If you decide to participate, thank you. If you decide not to take part, thank you for considering my request.

My name is Greg Stutchbury and I am a part-time Masters of Arts (MA) student in the English, Film, Theatre \& Media Studies department at Victoria University of Wellington (VUW). This research project is work towards my thesis.

I am also an employee of international news agency Thomson Reuters, working as a sports/general news reporter based in the Wellington bureau and you may know me personally in a professional capacity. For the purposes of this study, however, I am working SOLELY as a researcher. Our discussions as they pertain to this study will be confidential and used ONLY for academic reasons (eg: MA thesis).

The project is under the supervision of Dr. Peter Thompson, a senior lecturer in the Department of English, Film, Theatre \& Media Studies at VUW and been approved by the Victoria University of Wellington Human Ethics Committee (Ref no: 24930)

What is the aim of the project?

This project will examine how the move to a digital publishing environment in the New Zealand news media has affected sports journalism.

I have identified two key areas that I feel are important in this study. The first is to ascertain how the work of sports journalists has changed in the past 10 years due to the digital disruption within the news industry.

This could include, but not be limited to:

- work practices

- decisions on news coverage and how they are made

- what drives the digital first focus that the major media companies in New Zealand have identified as their future 
- how that has affected sports journalists.

- what role do you feel you have within the digital environment?

- how have you reacted to these changes?

- what issues do sports journalists face both internally and externally in the age of convergence.

- how has this changed in the last 20 years?

The second area is what I have labelled the contested space that now exists between media and sports organisations, who are using digital platforms as part of their public relations strategy.

Areas of interest include:

- does this restrict and control content?

- how have the PR strategies of sports organisations changed in the digital environment? Has it changed how you gather news?

- Are there restrictions on your reporting?

- Are you in competition with sports organisations as news providers?

- Has the digital environment changed the Fourth Estate responsibilities of sports journalism?

\section{How can you help?}

- If you agree to take part I will interview you at a quiet location of your choosing, away from your place of business, or via telephone

- I will ask you questions about how the digital publishing environment has affected sports journalism in New Zealand.

- The interview should take take no more longer than 60 minutes.

- I will audio record the interview with your permission and transcribe it later.

- You can choose to not answer any question or stop the interview at any time, without giving a reason.

- You can withdraw from the study by contacting me at any time up to 21 days after the interview. If you withdraw, the information you provided will be destroyed or returned to you.

\section{What will happen to the information you give?}

This research is confidential. This means that the researcher named below will be aware of your identity but the research data will be combined and your identity will not be revealed in any reports, presentations, or public documentation, UNLESS you expressly agree to do so. However, you should be aware that in small projects your identity might be obvious to others in your community. 
As with any interviews, topics could veer into other areas of which you have knowledge that are pertinent to the study. If these areas are commercially sensitive then please do not hesitate to tell me at the time so we can discuss how, or if, the information can be used. Similarly, within any information you feel should be off the record please do not hesitate to tell me at the time.

The audio recording of the interview will be transcribed only by the researcher.

Only I will have access to the notes or original transcript of the interview, however the material will be used in the thesis and read by the supervisor and the examiners.

The interview transcripts, summaries and any recordings will be kept securely on a password protected computer and destroyed three years after the research ends.

What will the project produce?

The information from my research will be used in my Masters dissertation.

If you accept this invitation, what are your rights as a research participant?

You are not obliged to participate in this project. If you do decide to participate, you have the right to:

- choose not to answer any question;

- ask for the recorder to be turned off at any time during the interview;

- withdraw from the study within 21 days of initial interview;

- ask any questions about the study at any time;

- receive a copy of your interview recording;

- receive a copy of your interview transcript;

- read over and comment on a written summary of your interview;

- receive a copy of the final thesis by emailing the researcher to request a copy. 


\section{If you have any questions or problems, who can you contact?}

If you have any questions, either now or in the future, please feel free to contact:

Student:

Supervisor:

Greg Stutchbury

Peter Thompson

stutchgreg@myvuw.ac.nz

Senior Lecturer

+64 8027977 (wk)

English, Film, Theatre, Media Studies

peter.thompson@vuw.ac.nz

+6444636827.

\section{Human Ethics Committee information}

If you have any concerns about the ethical conduct of the research you may contact the Victoria University HEC Convenor: Associate Professor Susan Corbett.

Email susan.corbett@vuw.ac.nz or telephone +64-4-463 5480.

Thank you again for agreeing to participate in this project and I am now willing to answer any, and all, questions you may now have.

Greg Stutchbury 


\section{Click off: How digital has disrupted New Zealand sports journalism}

\section{CONSENT TO INTERVIEW}

This consent form will be held for three years.

Researcher: Greg Stutchbury, School of English, Film, Theatre \& Media Studies, Victoria University of Wellington.

- I have read the Information Sheet and the project has been explained to me. My questions have been answered to my satisfaction. I understand that I can ask further questions at any time.

- I agree to take part in an audio recorded interview.

I understand that:

- That the results will be used for a Masters dissertation.

- That I may withdraw myself (and any information I have provided) from this project at any time during or within 21 days of participation without having to give reasons

- Any information I provide will be kept confidential to the researcher and the supervisor

- That any audio recordings and transcripts of such recordings will be stored on a password-protected computer, which only the researcher will have access to.

- That the audio recording of interviews and all data, including this consent form, will be destroyed three years after the conclusion of the research.

- The published results will not use my name, and that no opinions will be attributed to me in any way that will identify me or my instituteion UNLESS I expressly agree to do so (below): 
- I consent to information or opinions which I have given being attributed to me in any reports on this research:

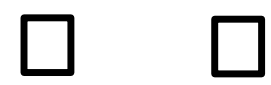

- I consent to the name of my instition being disclosed in any reports of this research:

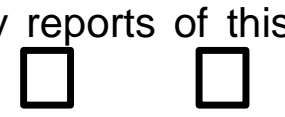

- I would like a copy of the recording of my interview:

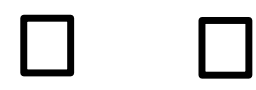

- I would like a copy of the transcript of my interview:

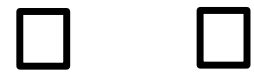

- I would like a summary of my interview:

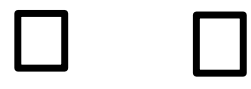

- I would like to receive a copy of the final report and have added my email address below.

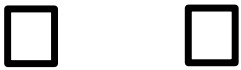

Name of participant:

Signature:

Date:

Contact details: 